\title{
An approach for transparent and electrically conducting coatings: a transparent plastic varnish with nanoparticulate magnetic additives
}

G. Beck $^{\text {a) }}$, S. Barcikowski ${ }^{\text {b) }}$, V.S.K. Chakravadhanula ${ }^{\text {c) }}$, M. Comesaña-Hermo ${ }^{\text {d) }}$, M. Deng ${ }^{\text {e) }}$, M. Farle ${ }^{\text {d) }}$, M. Hilgendorff $^{\text {f) }}$, J. Jakobi ${ }^{\text {b) }}$, J. Janek ${ }^{\text {g) }}$, L. Kienle ${ }^{\text {e) }}$, B. Mogwitz ${ }^{\text {g) }}$, T. Schubert $^{\text {h) }}$, and F. Stiemke ${ }^{\text {h) }}$

a) Chair of Resource Strategy, Institute of Physics, University Augsburg, Germany,

corresponding author:

postal address: Chair of Resource Strategy, Institute of Physics, University Augsburg, Universitaetsstrasse 1a, 86159 Augsburg, Germany,

email: gesa.beck@physik.uni-augsburg.de,

phone: 00498215983570

b) University Duisburg-Essen, Chair of Technical Chemistry I and Center for Nanointegration Duisburg-Essen (CENIDE), Universitätsstr. 7, 45141 Essen, Germany.

c) Helmholtz Institute UIm (HIU), Karlsruhe Institute of Technology (KIT), Helmholtzstraße 11, 89081 Ulm, Germany

d) Experimental Physics, University Duisburg-Essen, Campus Duisburg, Lotharstr. 1, 47048 Duisburg, Germany

e) Chair for Synthesis and Real Structure, Christian Albrecht University Kiel, Kaiserstrasse 2, 24143 Kiel, Germany

f) Experimental Physics, Freie University Berlin, Arnimallee 14, 14195 Berlin, Germany

g) Institute of Physical Chemistry, Justus-Liebig-University Giessen, Heinrich-Buff-Ring 17, 35392 Gießen, Germany

h) IOLITEC Ionic Liquids Technologies GmbH, Salzstraße 184, 74076 Heilbronn, Germany 
Abstract

For the purpose of preparing TCCs (=transparent and electrical conducting coatings), metallic and ferromagnetic nano-additives were dispersed into a transparent varnish and the obtained dispersions were coated on transparent plastic substrates. During hardening of the dispersion the magnetic nano-additives were aligned by a magnetic field. The resulting coatings have electrical pathways along lines of nano-additive chains and are highly transparent in the areas between the lines. Therefore, the electrical conductivity is anisotropic, and it depends on the alignment of the nano-additives (i.e. on the distance between the nano-additives within the chains and the length of the lines) as well as on the thickness of an oxide and/or solvent shell around the nanoadditives. The transparency depends also on the alignment and here especially on the thickness and the distance between the formed lines. The quality of the alignment in turn, depends on the magnetic properties and on the size of the particles. We used commercial plastic varnishes, which form electrically isolating $\left(\geq 10^{-12}\right.$ $\mathrm{S} / \mathrm{m}$ ) and transparent (about $90 \%$ transparency) coatings, and the following magnetic additives: Co-, $\mathrm{Fe}_{-}, \mathrm{CoPt}_{3}$, $\mathrm{CoPt}_{3} @ \mathrm{Au}$ - and Fe@Au-nanoparticles as well as CoNi-nanowires. Coatings with Fe@Au-nanoparticles show the best results in terms of the electrical conductivity $\left(10^{-5} \mathrm{~S} / \mathrm{m}-10^{-6} \mathrm{~S} / \mathrm{m}\right)$ at transparencies above $70 \%$. Furthermore, in addition to the magnetic nano-additives, transparent additives $\left(\mathrm{Al}_{2} \mathrm{O}_{3}\right.$-particles $)$ and nonmagnetic, but better conducting additives (carbon-nanotubes) were added to the varnish to increase the transparency and the electrical conductivity, respectively.

Keywords: transparent conductive coatings; magnetic nanoparticles; magnetic nanowires; transparent varnish; carbon nanotubes 


\section{Introduction}

The demand of transparent and electrically conductive coatings (TCCS) is large due to their enormous range of applications in numerous industrial fields ranging from microelectronics, or medicine to aerospace technology, among others. Admittedly, any application depends strongly on the actual value of the transparency and electrical conductivity of these coatings. The electrical conductivity can be subdivided into the insulating $\left(\leq 10^{-11} \mathrm{~S} / \mathrm{m}\right)$, antistatic $\left(10^{-11}\right.$ $\left.\mathrm{S} / \mathrm{m}-10^{-7} \mathrm{~S} / \mathrm{m}\right)$, discharging $\left(10^{-7} \mathrm{~S} / \mathrm{m}-10^{-3} \mathrm{~S} / \mathrm{m}\right)$, semiconducting $\left(10^{-3} \mathrm{~S} / \mathrm{m}-10^{1} \mathrm{~S} / \mathrm{m}\right)$ and metallic range $\left(\geq 10^{1} \mathrm{~S} / \mathrm{m}\right)$. This subdivision is not sharp and differing limits are found in the literature [1]. Antistatic and transparent coatings are for example used on transparent cover plates for machinery, where the antistatic behaviour minimises contamination by dust. Here the required transparency is not very high. Transparent coatings with discharging capacity are used for electromagnetic shielding of mobile phone displays, whereas better conductive coatings are used for touch screens and transparent electrodes in solar cells, applications for which also the required transparency is high.

In cases where the requirements for conductivity and transparency are high, indium-tinoxide-(=ITO)-coatings are mainly used, although these coatings have some disadvantages. The main disadvantage of ITO-coatings is the shortage of tin and especially indium [2]. In 2009 it had been predicted that the industry will run out of indium in the next 10 to 20 years, but in the newer literature - due to newly explored indium ores, indium extracting from byproducts, from residues, slag and tailings and due to reclaiming of ITO targets - it is forecasted that the reserves could last for almost 90 years [2-5]. Nevertheless, indium is rated to be critical and since a new application of indium in absorber layers of solar panels increases the indium demand additionally, the indium market will probably develop more narrow [6]. In addition, ITO coatings have small chemical and mechanical resistivity and their 
fabrication via PVD (physical vapour deposition) techniques is technically not easy, especially in the case of big and complicated-shaped parts. Therefore, many research activities are focused on finding an alternative or a supplement to ITO coatings [7].

One approach to reduce the demand of ITO is the use of coatings formed by other thin film transparent semiconductors e.g. fluorine-doped tin oxide, antimony-doped tin oxide, aluminium-doped zinc oxide or niobium-doped titanium oxide [8-10]. Nevertheless, the conductivities and/or the transparencies are generally lower than those for ITO coatings and especially antimony-doped tin oxide is not a reasonable alternative for ITO, since antimony is rated as even more critical than indium [6]. Another approach is the use of ICPs (intrinsic conducting polymers) for the preparation of TCCS, but ICPs are not stable and ICP-based coatings show poor transparencies [11,12]. An interesting approach to overcome this problem is the use of a non-conducting polymer-foil in which electrical conductivity is induced via the formation of carbon clusters by an excimer-laser [13].

Other TCCs are formed by cross-linking or drying a solvent (e.g. a transparent plastic varnish) with conducting additives. Conducting additives can be metallic nanoparticles, metallic nanowires or carbon nanotubes (CNTs). To obtain good electrical conductivity the conducting particles have to form pathways through the isolating matrix of the coating. This is the case, when an alignment of the particles can be adjusted with enough particles in contact with each other. The corresponding particle concentration (and the specific alignment) is called the percolation limit (fig. 1a). Since most of the conducting particles are black due to light absorption by free electrons the transparency of such a coating is low $[14,15]$. The use of nanowires as additives has the advantage that an electrically connected network of nanowires can be formed at lower concentration than in the case of isotropic nanoparticles (fig. 1b). Therefore, good results have been reported for silver nanowires $[16,17]$ and CNTs [18-20] as additives. Moreover, nearly transparent ITO- or ICP-nanoparticles were also used 
as additives in a plastic varnish to enhance the electrical conductivity without diminishing the transparency significantly. Hereby, coatings with a sufficient conductivity for antistatic behaviour have been prepared [21]. Higher conductivities cannot be reached with such systems and the ITO varnish also has the disadvantage that it still requires the use of indium. Networks of CNTs films as well as graphene films (e.g. prepared by chemical vapour deposition) attract much interest recently and may help to develop transparent conductive coatings $[22,23]$. A possible alternative is also the formation of self-assembled or printed silver arrays in a coating $[24,25]$.

Beside the aforementioned approaches, combinations of them have also been developed, e.g. using antimony-doped tin oxide with CNTs additives [26]. It should finally be noted that there are also activities to develop recycling strategies for ITO coatings [27].

In spite of all these research activities, the main limitation for the use of such materials remains that most of the coatings with higher conductivity show reduced transparency and vice versa. In the work described here another approach was tested, i.e. the use of magnetic nanomaterials as conducting additives within a transparent plastic varnish. The magnetic nano-additives have the advantage that they can be aligned by an external magnetic field during the coating process of the varnish [28]. Thereby the conducting additives form lines of electrically connected chains of particles within the coating, while large spaces between the lines present high transparency (fig. 1c).

Therefore, good electrical conductivity might be achieved at concentrations below the percolation limit and correspondingly high transparency of the coatings might be obtained. Additionally, the resulting coatings will show anisotropic electric conductivity and could consequently be used for other applications like directional sensors, where transparency is important. These transparent and conductive coatings might also have the advantages of all coatings prepared with a plastic varnish: they can easily be prepared (e.g. spraying, printing 
or flooding) and the components are inexpensive and not resource-critical, at least as long as the nano-additives do not complicate the coating process and do not increase the price and the criticality considerable.

Therefore, in the work presented here, we prepared coatings on the basis of a transparent plastic varnish and different magnetic nano-additives. We used different concentrations of the particular additive and measured the electrical conductivity and transparency of the coatings. Moreover, coatings with additional transparent particles $\left(\mathrm{Al}_{2} \mathrm{O}_{3}\right)$ or with additional conducting particles (carbon nanotubes) were prepared. To understand the reasons for the obtained electrical conductivity and transparency, the microstructures of all coatings (mainly the alignment of the nanoparticles and the composition of them) were also studied. Furthermore, the magnetic properties of the magnetic nano-additives within the coatings were measured.

\section{Materials and Methods}

\subsection{Materials}

Coatings that can replace ITO-based coatings should be inexpensive, the components should not be resource-critical and easily available. Therefore we used commercial varnishes, commercial dispersing agents and nano-additives that are already prepared in large volumes or for which the chemical synthesis can easily be up-scaled.

\subsubsection{Varnishes}

The requirements on the varnish are that it has to form a transparent coating and that the nanoparticles form a stable dispersion. In addition, there must be one step during the 
coating process of this varnish, which can be modified in such manner that the magnetic nano-additives can form a stable alignment within an external magnetic field here.

Two commercial varnishes were used. The first one was a thermosetting polysiloxane varnish (PHC587 from Momentive Performance Materials, Germany). The binder material is a silica ester and a mixture of methanol, butanol and isopropanol (2:3:5) was used as solvent. It cross-links at a temperature of $130{ }^{\circ} \mathrm{C}$ (30 min. heating) and forms scratch-, temperature-, UV- and chemical-resistant coatings. The magnetic field was applied during this cross-linking process to achieve alignment of the nanoparticles.

Alternatively, the acrylic resin varnish (ABRASIL FAP-30-MP1 from T_O_P Oberflaechen, Germany) with a mixture of 1-Methoxy-2-propanol, 2-Methoxy-1-propanol and 2Methylpropan-1-ol as solvent was used. It cross-links by UV-radiation after drying at room temperature for 30 up to 60 minutes. The magnetic field was applied during this drying process to achieve stable alignments of the nanoparticles. After the cross-linking scratch-, temperature-, UV- and chemical-resistant coatings were formed.

The disadvantages of both varnishes are a high content of water (a few Vol\%), which can support the oxidation of oxidation-sensitive nanoparticles, and that they form coatings with very low electrical conductivity $\left(\geq 10^{-12} \mathrm{~S} / \mathrm{m}\right)$.

\subsubsection{Magnetic Nano-Additives}

The magnetic nano-additives should have a high electrical conductivity, they should form stable dispersions within the varnish and they have to be ferromagnetic and relatively stable against oxidation. Accordingly, commercial Co-nanoparticles with a mean diameter of $28 \mathrm{~nm}$ and Fe-nanoparticles with a mean diameter of $25 \mathrm{~nm}$ (both from IOLITEC, Germany) were used. We also worked with passivated Fe-nanoparticles $(\varnothing=35 \mathrm{~nm}$, oxide shell: $4 \mathrm{~nm})$, synthesized from the gas-phase by thermal decomposition of $\mathrm{Fe}(\mathrm{CO})_{5}$ in a hot wall reactor 
and a subsequent passivation process $[29,30]$. We marked these as $\mathrm{Fe}(\mathrm{p})$ within the figures. The commercial Fe-nanoparticles react in air explosively with oxygen, whereas the passivated Fe-nanoparticles are stable under the same conditions.

Additionally, we used chemically synthesized and also passivated CoNi-nanowires $[\varnothing \approx(5-8)$ $\mathrm{nm}$, length $=(30-50) \mathrm{nm}$, oxide shell $\approx 2 \mathrm{~nm}][31,32]$.

Also, nanoparticles stabilised against oxidation by precious metals were used. These were chemically synthesised $\mathrm{CoPt}_{3}-$ [33] and $\mathrm{CoPt}_{3} @ A u-n a n o p a r t i c l e s$ (which were prepared similar to FePt@Au-nanoparticles [34]) and Fe@Au-nanoparticles formed by a laser ablation process within a solvent [35-37].

\subsubsection{Further Additives}

In additional experiments, transparent non-conducting $\mathrm{Al}_{2} \mathrm{O}_{3}$ particles (marked as "transp. additive" within the figures, particle sizes approximately $\leq 1 \mu \mathrm{m}$ ) were added in addition to the magnetic nanoparticles to increase the transparency of the formed coatings. Their concentration within the dispersions was $10 \mathrm{~g} / \mathrm{L}$.

Furthermore, high-conductive additives like carbon nanotubes (CNTs) were used additionally to the magnetic nanoparticles to increase the conductivity of the coatings. We used multiwall CNTs [MWCNT with a diameter $<10 \mathrm{~nm}$ and a length of $(5-15) \mu \mathrm{m}$, from IOLITEC, Germany]. The concentration of this CNTs additive was $1 \mathrm{~g} / \mathrm{L}$.

\subsubsection{Dispersing agents}

As dispersing agents the following compounds were used: sodium-dodecylsulfate, oleic acid, lauric acid and Dysperbyk 107. In addition, different ionic liquids of the company IOLITEC were used. IOLITEC performed the dispersion experiments. The ionic liquids (IL) consist of imidazolium, pyrrolidinium, phosphonium and ammonium-based cations and standard 
anions from lolitec's portfolio (trademark symboles: IOLIDispers ${ }^{\circledR} 0349-04$, IOLIDispers ${ }^{\circledR}$ 034910, IOLIDispers ${ }^{\circledR} 0349-18$ and IOLIDispers $\left.{ }^{\circledR} 0349-20\right)$. These cations were differently substituted with C2-C18 or longer alkyl side chains and/or contained additional functional groups.

\subsubsection{Substrates}

For the coatings prepared with the polysiloxane varnish polycarbonate and for the coatings prepared with acrylic resin varnish, acrylic glass (polymethylmethacrylat, PMMA) was used as substrate. For most of the experiments the substrates had dimensions of $2.5 \mathrm{~cm} \times 2.5 \mathrm{~cm} \times$ $3 \mathrm{~mm}$. For up-scaling experiments $10 \mathrm{~cm} \times 10 \mathrm{~cm} \times 3 \mathrm{~mm}$ pieces were utilized.

\subsection{Preparation Methods}

\subsubsection{Preparation of Dispersions}

Firstly, the particular plastic varnish was pipetted within a glass envelope and the particular dispersing agent was weighed into the varnish. This mixture was flushed with Argon for 10 minutes to remove the oxygen. The magnetic nano-additives were then added to the mixture within a glove box (with nitrogen atmosphere). We prepared dispersions with nano-additive concentrations between $0.5 \mathrm{~g} / \mathrm{L}$ and $60 \mathrm{~g} / \mathrm{L}$ (always with similar concentrations of the dispersion agent). In some cases we also added a transparent additive (10 g/L) or CNTs (1 $\mathrm{g} / \mathrm{L})$ at this point.

To enable homogeneous dispersion, most of the mixtures were then physically dispersed in an ultra-sonic bath (SONOREX RK-100, Bandelin Electronic GmbH, Germany) for half an hour. Directly before the coating process the dispersion was also treated by an ultra-sonic tip (Branson Ultrasonic, USA) for 30 seconds. Other physical dispersion experiments were done 
with a commercial micro wave (AFK, Germany) and a rotation shaking bath (Unimax 1010, Heidolph Instruments, Germany).

\subsubsection{Preparation of Coatings}

The coating process used here is similar to the flow coating process. The dispersions were "flooded" onto the substrate by an Eppendorf pipette. The volume used depended on the target thickness of the coating. Most of the coatings were prepared with acrylic resin varnish dispersions onto PMMA substrates with an area of $2.5 \mathrm{~cm} \times 2.5 \mathrm{~cm}$ and a thickness of about $(10 \pm 2) \mu \mathrm{m}$. Therefore, an aliquot of the dispersion of $100 \mu \mathrm{L}$ was used. However, coatings with thicknesses in a wide range between $4 \mu \mathrm{m}$ and $200 \mu \mathrm{m}$ were also prepared. The exact thickness of the coating depends not only on the volume used, but also on the solid content of the dispersion. In addition, the thickness was not completely homogenous within one coating, but varied in the range of a few $\mu \mathrm{m}$. In pre-experiments the coating thicknesses were determined by a touch profilometer (Mahr Perthometer, Germany) at different points of the coatings and the results of these pre-experiments are the basis for the indicated thickness values.

After flooding, the wet coating was placed between the pole shoes of an electromagnet (Bruker, Germany) and the magnetic field was set to 0.8 Tesla.

In the case of dispersions with polysiloxane varnish an IR lamp was used to cure the samples at about $130{ }^{\circ} \mathrm{C}$ for 30 minutes within the magnetic field applied. In the case of dispersions with the acrylic resin varnish the coatings were only dried within the magnetic field for 40 minutes at room temperature and afterwards cross-linked by UV (ultra-violet) radiation within an UV dryer (Beltron GmbH, Germany). 


\subsection{Characterisation Methods}

\subsubsection{Optical Appearance and Transparency of the Coatings}

The optical appearance of the coatings and the length of the formed nano-additive lines were investigated and documented with an optical microscope. The transparency was measured by the spectrophotometer CM-5 (Konica Minolta, Germany) with the illuminant D 65 , at $10^{\circ}$, in the wavelength range between 360 and $740 \mathrm{~nm}$. To compare the transparency of different samples we always used the value at $660 \mathrm{~nm}$.

\subsubsection{SEM (scanning electron microscopy) investigations}

The alignment of the nano-additives within the coatings was investigated by a highresolution scanning field emission electron microscope (Gemini Supra 55 VP, Zeiss GmbH, Germany). In order to do this, the surface of the coatings had to be removed by an ion beam (BAL-TEC, Res 101, Germany), since no nano-additives were found directly on the surface.

\subsubsection{TEM (transmission electron microscopy) investigations}

The morphology of the nanoparticles and nanowires as well as their alignment within the coatings were investigated by transmission electron microscopy with a Tecnai F30 STwin electron microscope (300 kV, field-emission gun, spherical aberration coefficient $C_{S}=1.2 \mathrm{~mm}$. STEM (scanning transmission electron microscopy) Z-contrast images were recorded using a HAADF (high-angle annular dark field) detector and an aberration corrected Titan80-300 electron microscope operated at $300 \mathrm{kV}$. STEM images were acquired using a HAADF detector. EDX (energy dispersive X-ray spectroscopy) and EELS (electron energy loss spectroscopy) analysis was performed in STEM mode using an EDAX (Si/Li detector) EDX detector and a post-column Gatan Imaging Filter, GIF-Tridiem. The elemental distribution and 
the chemical composition of the nanoparticles, nanowires, core-shell structures was studied by elemental mapping using the EDX and/or EELS spectroscopic analysis.

\subsubsection{Electrical measurements}

The electrical conductivity of the coatings was anisotropic because of the specific alignment of the nano-additives forming chains of conducting particles. Therefore the conductivity in the direction of the lines was much higher than those perpendicular to them. The specific volume conductivity of the coatings was determined in the direction of the lines by a twopoint method using a Keithley 6430 Sub-Femtoamp SourceMeter (Keithley, Germany). Voltages up to $210 \mathrm{~V}$ could be set using this device In order to process contacts that allow measurements perpendicular to the surface, two $60^{\circ}$ trenches using a CNC engraving cutter were milled. Thereafter, the trenches were covered with a $100 \mathrm{~nm}$ thick gold film by using a standard vacuum thermal deposition system (tectra $\mathrm{GmbH}$ ). To verify our conductivity measurements, a second method was used in which a custom tool, consisting of two isolated parallel metal (electrodes) blades, was pressed into the film. All measurements were performed within a glove box, otherwise, in the case of coatings with high resistances, adsorbed water would adulterate the measurements.

Moreover, the surface conductivity was measured by using an annular electrode with a precision resistance system set (PRS-801, Prostat; USA).

\subsubsection{XRD (X-ray diffraction) measurements}

The composition, possible oxidation and the crystallite sizes of the nano -particles and -wires under air and within the coatings were determined by 2theta-scans (D8 Discover diffractometer, Bruker axs, Germany). Cu- $\mathrm{K}_{\alpha}$ radiation was used with $40 \mathrm{kV}$ and $40 \mathrm{~mA}$ as operational conditions and a one-dimensional LynxEye-Detector (Bruker axs) for the analysis. 


\subsubsection{Magnetic hysteresis measurements}

The magnetic properties ( $\mathrm{M}$ vs. $\mathrm{B}$ ) of the magnetic nano-additives in air and within the coatings were measured by a vibrating sample magnetometer (Oxford, England) at room temperature. The diamagnetic contribution of the sample holder was measured separately and subtracted from each measurement. To reduce magnetic interactions between the nanoparticles, coatings with small concentrations (up to maximum $5 \mathrm{~g} / \mathrm{L}$ ) were prepared and the particles were not aligned within a magnetic field for these measurements.

\section{Results and Discussion}

\subsection{Quality of the Dispersions}

All dispersions with the nano-additives appeared black to the naked eye, due to the absorption of the black nano-additives. However, the dispersions looked clear, because light scattering was minimal, as to be expected for nanoparticle dispersions [38]. The transparency was found to be below $20 \%$ and nearly constant in the visible range (approximately $380 \mathrm{~nm}-750 \mathrm{~nm}$ ). Up to concentrations of about $50 \mathrm{~g} / \mathrm{L}$ or $60 \mathrm{~g} / \mathrm{L}$ the dispersions could be pipetted and coated easily. At higher concentrations, a complete dispersing of the nano-additives was not possible anymore. Dispersions with concentrations higher than $2 \mathrm{~g} / \mathrm{L}$ formed a precipitate after about 30 minutes. The proportion of the precipitate depends on the particular nano-additive, the dispersing agent and the additive concentration.

The most stable dispersions (even for weeks) were formed with sodium-dodecylsulphate and Dyserbyk 107 as dispersing agents. Figure 2 demonstrates this for CoNi-acrylic resin varnishdispersions. Unfortunately, sodium-dodecylsulphate has two disadvantages. Besides being 
very toxic it apparently reacted with the varnish, leading to the formation of very brittle coatings. In the case of Co-nanoparticles, stable dispersions could also be prepared using oleic acid as stabilizer, but the electrical conductivity of these coatings is smaller (around $1 \cdot 10^{-8} \mathrm{~S} / \mathrm{m}$ ) compared to similar coatings with Dysperbyk 107 (around $3 \cdot 10^{-8} \mathrm{~S} / \mathrm{m}$ ). In view of this, most of the investigations presented in this work include only Dysperbyk 107 as dispersing agent. Besides, the ionic liquids used form very stable dispersions and also increase the electrical conductivity compared to coatings with Dysperbyk 107 (see results for coatings with CoNi-nanowires in figure 8, marked as "CoNi-IL"). In addition, for the case of $\mathrm{CoPt}_{3}, \mathrm{CoPt}_{3} @ \mathrm{Au}$ and Fe@Au nanoparticles, stable dispersions were formed even without an additional dispersing agent.

In most cases an ultrasonic treatment was used for the physical dispersion of the nanoadditives, but in the case of the CoNi-nanowires, the elongated structures were destroyed using this procedure, as shown in figure 3. Moreover, in the case of CNTs as an additional additive, agglomerates of these tubes were formed due to the ultrasonic treatment, where the sizes of the agglomerates increase with ultra-sonication time. Therefore, other physical dispersing methods were tested for these cases. One was the use of a standard household microwave at 200 Watt, but the varnish-dispersions coagulate after a few seconds. Another approach consisted in the use of a laboratory shaker for several days, but the dispersion effect of this method was minimal. Consequently, with CoNi-nanowires as well as with CNTs we did not get dispersions of good quality.

\subsection{Quality of the Coatings}

Firstly, coatings were prepared with the polysiloxane varnish, but the alignment of the nanoadditives within these coatings were bad, especially using the very small nanoparticles (i.e. 
$\mathrm{CoPt}_{3}$ with sizes of about $9 \mathrm{~nm}$ ). Here the nano-additives had to be aligned in the magnetic field during the cross-linking process at $130{ }^{\circ} \mathrm{C}$. We assume that at this high temperature the magnetisation of the particles is too low and the Brownian forces are too strong, impeding the alignment of the nano-additives [39]. Therefore, the UV-hardening system acrylic resin varnish was chosen for further coatings, since here the nano-additives aligned during the drying process step at room temperature. For each nano-additive acrylic resin-based coatings in the concentration range between $1 \mathrm{~g} / \mathrm{L}$ and $60 \mathrm{~g} / \mathrm{L}$ were prepared.

In the following the results of the transparency measurements and the resistance measurements for these acrylic resin-based coatings are described and discussed on the basis of the characteristics of the specific coatings with different nano-additives.

\subsubsection{Transparency of the Coatings}

The transparency of the coatings strongly increased due to the alignment of the nanoadditives within a magnetic field, as demonstrated in figure 4. Even without an external magnetic field the magnetic nanoparticles form aggregates due to the interacting of their magnetic moments (fig. 4b), but in the presence of the magnetic field the particles form chains (fig. 4c), as also found by Townsend et al. and theoretically described by de Gennes and Pincus $[40,41]$. Thereby, the transparency depends on the strength of the applied magnetic field. Good transparencies were reached at a magnetic field of $\geq 0.8$ Tesla. Consequently, all further coatings were prepared at 0.8 Tesla.

The transparency depends also on the concentration of the additive (fig. 5) and on the particular additive (fig. 6). In figure 5a the transparency of acrylic resin-based coatings with different concentrations of Fe@Au-nanoparticles as a function of the wavelength is shown. We found for all prepared coatings with nano-additive a similar behaviour with a nearly 
constant transparency value in the visible wavelength range (about $380 \mathrm{~nm}$ and $750 \mathrm{~nm}$ ). Naturally, a strong dependence of the transparency on the concentration of the nanoadditive was observed (this concentration dependence is visible to the naked eye in figure 5b). Figure 6a shows the transparency (at $660 \mathrm{~nm}$ ) as a function of the concentration of the nano-additive for most of the prepared coatings. The coatings with Co- and Fe@Aunanoparticles showed very high transparencies, while those with CoPt ${ }_{3} @ A u-n a n o p a r t i c l e s$ showed only small ones. Additional transparent additives increased the transparency, e.g. a coating with $10 \mathrm{~g} / \mathrm{L}$ CoNi-nano-additive had a transparency of about $45 \%$, whereas a coating with $10 \mathrm{~g} / \mathrm{L}$ CoNi-nano-additive and the transparent additive $\left(10 \mathrm{~g} / \mathrm{L} \mathrm{Al} \mathrm{O}_{2} \mathrm{O}_{3}\right)$ had a transparency of about $80 \%$ (black diamond in fig. 6a). In contrast, additional CNTs decreased the transparency: for example, a coating with $0.5 \mathrm{~g} / \mathrm{L} \mathrm{CoPt}_{3} @ \mathrm{Au}$ had a transparency of about $70 \%$ and a coating with 0.5 g/L CoPt $\mathrm{L}_{3} @ \mathrm{Au}$ and $1 \mathrm{~g} / \mathrm{L}$ multi-walled CNTs had only one of about $45 \%$ (black star in figure 6a).

In figure $6 \mathrm{~b}$ the dependence of the transparency on the particular nano-additive is shown for some selected coatings. From these images and also in the images of figure $5 \mathrm{~b}$ it can be seen that the transparency within one coating is not completely homogeneous, most probably as a result of an inhomogeneous thickness of the coatings.

\subsubsection{Electrical Conductivity of the Coatings}

Figure 7 illustrates the results for the specific conductivity as a function of the nano-additive concentration. As to be expected the conductivity increases with increasing concentration of the magnetic and metallic nano-additive. Most of the prepared coatings have antistatic conductivities, which is 3 to 5 orders of magnitude higher than that of a pure acrylic resinbased coating. The best electrical conductivities (within the semiconducting range) were obtained when the magnetic nano-additives (e.g. CoPt $\left.{ }_{3} @ A u\right)$ were used together with CNTs. 
Nevertheless, the latter are responsible for a significant decrease in the transparency of the final composite. Good conductivities (within the discharging range) were also found for coatings with Fe@Au-nanoparticles.

However, the surface conductivity of all prepared coatings is only about 1 order of magnitude higher than that of a pure acrylic resin-based coating. The reason for this was found by SEM investigations: the nano-additives are not directly located at the surface of the coatings and therefore the surface is only formed by an acrylic resin varnish film.

\subsubsection{Transparency versus Electrical Conductivity}

A combination of high electrical conductivity with high transparency is extremely important for the use of these materials in the applications envisaged. Unfortunately, with increasing concentration of the additive the electrical conductivity increases while the transparency decreases. Figure 8 shows the transparency of prepared coatings versus their specific conductivities. Many of the coatings have good transparencies (between 70 and $85 \%$ ) and also electrical conductivities in the antistatic range (more than $10^{-9} \mathrm{~S} / \mathrm{m}$ ) as illustrated in figure 8. The coatings with Fe@Au-nanoparticles show the best values, with conductivities in the discharging range (between $10^{-7} \mathrm{~S} / \mathrm{m}$ and $10^{-5} \mathrm{~S} / \mathrm{m}$ ) and up to $78 \%$ transparency. It can also be seen that coatings with ionic liquids as dispersing agent have a better transparency and conductivity than those in which Dysperbyk 107 has been used (compare results for CoNi and CoNi-IL in figure 8).

\subsubsection{Characteristics of the Coatings}

\section{Coatings with Co-Nanoparticles}

Figures 6a, 7 and 8 show that a coating with $4 \mathrm{~g} / \mathrm{L}$ Co-nanoparticles (violet point in the figures) has a transparency of about $88 \%$ and an electrical conductivity in the antistatic 
range (between $10^{-8} \mathrm{~S} / \mathrm{m}$ and $10^{-9} \mathrm{~S} / \mathrm{m}$ ). In figure $6 \mathrm{~b}$ a photograph of the coating is shown, exemplifying the extremely high transparency of the composite. Figures $9 a$ and $9 b$ show the alignment of the nanoparticles in more detail. Accordingly, the nanoparticles (or more precisely, agglomerates of the nanoparticles) are aligned within long lines with a thickness of about $10 \mu \mathrm{m}$. Thereby, some of the lines run completely through the coating. The spaces between lines range between $50 \mu \mathrm{m}$ and $100 \mu \mathrm{m}$. In the SEM image in figure $9 \mathrm{~b}$ it can be seen that the nanoparticles are aligned in chains very close to each other and probably in direct contact. Such findings (lines running throughout the sample and very close packed particles) could account for an even better electrical conductivity than the antistatic one measured here.

However, XRD measurements (not shown) and TEM images (fig. 10) show that the Conanoparticles within the coating have an oxide shell of about $10 \mathrm{~nm}$. The size of this oxideshell was investigated under atmospheric conditions and within the coatings as a function of time (up to several weeks). These investigations show that the oxide shell remains unchanged even in air.

Magnetic measurements confirm the existence of the oxide shell, since the saturation mass magnetisation of the Co-nanoparticles within the coating is reduced by $37 \%\left[\mathrm{M}_{\mathrm{S}}\right.$ (nanoCovarnish $\left.)=(105 \pm 1) \mathrm{A} \cdot \mathrm{m}^{2} \cdot \mathrm{kg}^{-1}\right]$ if compared to that of the bulk $\left[\mathrm{M}_{\mathrm{s}}(\mathrm{Co})=166 \mathrm{~A} \cdot \mathrm{m}^{2} \cdot \mathrm{kg}^{-1}\right]$. We conclude that due to the oxide-shell the electrical conductivity is reduced. Conanoparticles free of an oxide-shell would give better conductivities in the coating, but this cannot be obtained within such coatings, as the varnish has a high concentration of water, and the coatings are permeable to oxygen. 


\section{Coatings with Fe-Nanoparticles}

Both types of Fe-nanoparticles behave similarly within the coatings as can be seen in the photographs of coatings with both types of Fe-nanoparticles in figure 6b. Figure 11 shows the alignment of passivated Fe-nanoparticles (the results for the commercial Fenanoparticles are nearly identical) in more detail. The Fe nanoparticles form very long lines of interconnected particles, which run completely through the coating. Large spacings (50 $500 \mu \mathrm{m})$ between the lines are observable. Moreover they present thicknesses between 20 $\mu \mathrm{m}$ and $50 \mu \mathrm{m}$, even at low concentrations $(1 \mathrm{~g} / \mathrm{L})]$. As a consequence, the transparency of the coatings with Fe particles is lower than that obtained with the Co particles (fig. 6a).

XRD investigations show that the commercial Fe-nanoparticles form a thicker oxide shell within the coating (about $12 \mathrm{~nm}$ thickness) compared to the originally passivated Fenanoparticles (about $6 \mathrm{~nm}$ thickness) (fig. 12).

The magnetic measurements confirm the different thicknesses of the oxide shells. The saturation mass magnetisation of the coatings with passivated Fe-nanoparticles is only reduced by $24 \%\left[\mathrm{Ms}_{\mathrm{s}}(\right.$ nanoFe $\mathrm{pass}$-varnish $\left.)=(165 \pm 2) \mathrm{A} \cdot \mathrm{m}^{2} \cdot \mathrm{kg}^{-1}\right]$, whereas the saturation magnetisation of the coatings with Fe-nanoparticles from IOLITEC is reduced by $29 \%$ $\left[\mathrm{M}_{\mathrm{S}}(\right.$ nanoFe-varnish $\left.)=(155 \pm 5) \mathrm{A} \cdot \mathrm{m}^{2} \cdot \mathrm{kg}^{-1}\right]$ compared to the bulk value $\left[\mathrm{M}_{\mathrm{S}}(\mathrm{Fe})=217\right.$ $\left.\mathrm{A} \cdot \mathrm{m}^{2} \cdot \mathrm{kg}^{-1}\right]$

According to the thinner oxide shell, coatings with passivated Fe-nanoparticles have a slightly better electrical conductivity than coatings with the commercial Fe-nanoparticles (fig. 7). Nevertheless, all coatings with Fe-nanoparticles have conductivities in the antistatic range. 


\section{Coatings with CoNi-Nanowires}

As already shown in figures $3 a$ and $3 b$ the CoNi-nanowires are destroyed within the coatings, probably due to the ultra-sonic treatment. Therefore, we tried to disperse the CoNinanowires by microwaves or with the help of a shaking bath, but without success (see chapter 3.1).

However, even though the CoNi-nanowires were broken, the pieces of these nanowires could be aligned by a magnetic field, resulting in coatings with good transparencies (figs. 6a and 6b) and even better electrical conductivities than the coatings with Fe-nanoparticles, but still within the antistatic range (fig. 7).

The aligned lines were thinner $(\leq 5 \mu \mathrm{m})$ and closer together (spacings around $10 \mu \mathrm{m})$ than the lines formed by Co- and Fe-nanoparticles. Furthermore, it was not clear, whether these lines were running completely through the coatings and whether the particles were very close together (fig. 13).

Magnetic measurements show that the saturation magnetisation of the CoNi pieces within the coatings is reduced by $38 \%\left[\mathrm{M}_{\mathrm{s}}(\right.$ nanoCoNi-varnish $\left.)=(32 \pm 1) \mathrm{A} \cdot \mathrm{m}^{2} \cdot \mathrm{kg}^{-1}\right]$ compared to asprepared nanowires $\left[\mathrm{M}_{\mathrm{s}}\left(\right.\right.$ nanoCoNi $\left.\left.\mathrm{Nas}_{\text {-prepared }}\right)=(52 \pm 1) \mathrm{A} \cdot \mathrm{m}^{2} \cdot \mathrm{kg}^{-1}\right]$. X-ray investigations exclude the formation of an oxide-shell of more than $5 \mathrm{~nm}$ (the as-prepared nanowires have already an oxide-shell of $2 \mathrm{~nm}$ ), and therefore it can be assumed that a solvent shell formed by the dispersing agent exists around the CoNi pieces, reducing their saturation magnetisation and influencing the electrical conductivity of the final coatings. This assumption is also underlined by the fact that coatings with CoNi and Dysperbyk 107 as dispersing agent have lower electrical conductivities than those formed with ionic liquids (fig. 8). 


\section{Coatings with $\mathrm{CoPt}_{3-}$ and $\mathrm{CoPt}_{3} @ \underline{@ \text { Au-Nanoparticles }}$}

The determination of the concentration of the $\mathrm{CoPt}_{3}-$ and $\mathrm{CoPt}_{3} @ \mathrm{Au}$-nanoparticles could only be done by a very inaccurate differential weighing because of an unknown loss of particles during the post-synthetic cleaning steps and an unknown weight of the surfactant shell. Therefore, the concentration values are not very precise and a comparison of the transparency and electrical conductivity values with those of other coatings is difficult. Figure 6a shows photographs of coatings with $\mathrm{CoPt}_{3}$ - and the $\mathrm{CoPt}_{3} @ \mathrm{Au}$-nanoparticles (both with concentrations of about " $4 \mathrm{~g} / \mathrm{L}$ "), and figure 14 shows the alignment of $\mathrm{CoPt}_{3} @ A u-$ nanoparticles in a coating with " $1 \mathrm{~g} / \mathrm{L}$ ". Optical micrographs and SEM images of the two different coatings with $\mathrm{CoPt}_{3}$-nanoparticles look very similar. Both types of nanoparticles form short and very thin $(\leq 1 \mu \mathrm{m})$ lines within an applied magnetic field. These lines are obviously not running completely through the coatings, and they are very close together (distances $\leq 10 \mu \mathrm{m}$ ) (fig. 14a). SEM investigations show a relatively close packing of the nanoparticles within these lines (fig. 14b) and that the nanoparticles are very small, with sizes of approximately $10 \mathrm{~nm}$.

In XRD investigations only reflections of $\mathrm{CoPt}_{3}$ (and also $\mathrm{Au}$ in the case of coatings with $\mathrm{CoPt}_{3} @$ Au-nanoparticles) could be observed, excluding the presence of a well-crystallised oxide phase. The crystal sizes of the nanoparticles, calculated from the full width at half maximum are in good agreement with results of the SEM investigations (about $10 \mathrm{~nm}$ ).

Since the concentration values are very inaccurate, the saturation magnetisations, calculated from the hysteresis curves, are also very inaccurate and not specified here. Nevertheless, the magnetic measurements allow us to assume that the saturation magnetisations of the $\mathrm{CoPt}_{3}-$ and $\mathrm{CoPt}_{3} @ A u-n a n o p a r t i c l e s$ within the coatings are below the value of the bulk $\mathrm{CoPt}_{3}$ $\left[\mathrm{Ms}_{\mathrm{s}}\left(\mathrm{CoPt}_{3}\right)=18.2 \mathrm{~A} \cdot \mathrm{m}^{2} \cdot \mathrm{kg}^{-1}\right]$ 
The transparency and the electrical conductivity of coatings with $\mathrm{CoPt}_{3}-$ and with $\mathrm{CoPt}_{3} @ \mathrm{Au}-$ nanoparticles are very different (figs. 6-8). This divergence may come from the fact that the concentration values cannot be accurately measured. Probably the concentration values of the coatings with $\mathrm{CoPt}_{3}$-nanoparticles are too low and/or the concentration values of the coatings with $\mathrm{CoPt}_{3} @ \mathrm{Au}$-nanoparticles are too high. This assumption is underpinned by the similar dependence between electrical conductivity and transparency for coatings with $\mathrm{CoPt}_{3}-$ and with $\mathrm{CoPt}_{3} @ \mathrm{Au}$-nanoparticles presented in figure 8.

Anyway, coatings with $\mathrm{CoPt}_{3^{-}}$and with $\mathrm{CoPt}_{3} @ A u$-nanoparticles have antistatic conductivities in the same range as coatings with Fe-nanoparticles and with similar transparency values. Therefore, the values of the electrical conductivity and the transparency are much worse than what could be expected due to the absence of an oxide shell. The poor electrical conductivity of these composites may come from two different sources: the alignment only in short lines and the presence of the surfactant shell (about $2 \mathrm{~nm}$ thickness), which is necessary to control particle size and colloidal stability throughout the preparation.

\section{Coatings with Fe@Au-Nanoparticles}

The coatings with Fe@Au-nanoparticles showed good transparency (70 - 80 \%) even for coatings with relatively high nanoparticle concentrations (up to $6 \mathrm{~g} / \mathrm{L}$, figs. 5-8).

The nanoparticles formed very thin $(\leq 1 \mu \mathrm{m})$ lines in the magnetic field (fig. 15a) that ran throughout the entire sample and were spaced at distances of about $10 \mu \mathrm{m}$. SEM investigations showed that the lines were formed by nanoparticles with a very wide size distribution (10 nm - $300 \mathrm{~nm})$ and that densely packed nanoparticles were obtained through the entire length of the lines (fig. 15b). TEM investigations show also the iron-core gold-shell structure of the Fe@Au-nanoparticles (fig. 16a), but gold-core and iron-shell Au@Fenanoparticles (fig. 16c) as well as nanoparticles of Au-Fe-alloys were also found in the 
coatings (fig. 16b). The fraction of Fe@Au-nanoparticles could be estimated to be about $50 \%$ of the total.

The saturation mass magnetisation $\left(16.8 \mathrm{~A} \cdot \mathrm{m}^{2} \cdot \mathrm{kg}^{-1}\right)$ determined from the hysteresis measurements, (fig. 17) of this nano-additive within the coatings was about $37 \%$ of bulk AuFe and only about $8 \%$ of metallic bcc Fe $\left(218 \mathrm{~A} \cdot \mathrm{m}^{2} \cdot \mathrm{kg}^{-1}\right.$ at $\left.295 \mathrm{~K}\right)$. The reason for this discrepancy is probably the fraction of Au@Fe- and Au-Fe-alloy-nanoparticles and a possible formation of oxide in these particles. We note that oxide shells thinner than $5 \mathrm{~nm}$ are not detectable in X-ray investigations.

Due to the high packing density, the presence of some big and therefore good conducting particles (about $300 \mathrm{~nm}$ size) and the absence of a solvent shell in the case of the Fe@Aunanoparticles, very good electrical conductivities can be expected for coatings containing this nano-additive. And indeed, the electrical conductivities of these coatings were in the discharging range and 2 to 3 orders of magnitude higher than the conductivities of the coatings with the other nano-additives (figs. 7 and 8).

\section{Coatings with CNTs and Transparent Additives}

For coatings with additional transparent particles $\left(\mathrm{Al}_{2} \mathrm{O}_{3}\right.$-particles) we found a higher transparency, but accompanied with the reduction of the electrical conductivity (figs. 6-8).

Coatings with additional conductive additives (i.e. CNTs) and magnetic nano-additives show better electrical conductivities (figs. 7-8) than the other coatings with only magnetic nanoadditives, but with much worse transparencies (figs. 6a and 8). 


\section{Conclusions}

All used magnetic nano-additives formed lines of chains of aggregates of the nano-additives within the coatings. From the comparison between the magnetic measurements and the alignment of the different magnetic-additives within the coatings we conclude: Magnetic nano-additives with high saturation magnetisation values (i.e. Co and Fe) formed thick lines $(10 \mu \mathrm{m}-50 \mu \mathrm{m})$ with large distances between these lines $(50 \mu \mathrm{m}-500 \mu \mathrm{m})$ within the coatings. Many of these lines were found to be extended completely through the coatings. In contrast, magnetic nano-additives with small saturation magnetisation values (i.e. CoNi, $\mathrm{CoPt}_{3}, \mathrm{CoPt}_{3} @ \mathrm{Au}$ and Fe@Au) formed thin lines $(\leq 5 \mu \mathrm{m})$ with small distances between the lines $(\leq 10 \mu \mathrm{m})$. In the case of $\mathrm{CoPt}_{3}-\mathrm{CoPt}_{3} @ A u$-nanoparticles, which had the smallest saturation magnetisation, the formed chains were not running completely through the coatings. The distance between the nano-additives depends on the size of the saturation magnetisation (higher values deliver a closer packing), but as well on the size distribution of the nano-additives and on the existence of a solvent shell. Our results show that nanoadditives with a wide size distribution can easily form lines with densely packed nanoparticles (i.e. Fe@Au). On the other hand, those nano-additives that present a solvent shell cannot align very close to each other (i.e. $\left.\mathrm{CoPt}_{3}, \mathrm{CoPt}_{3} @ \mathrm{Au}, \mathrm{CoNi}\right)$.

The transparency of the coatings depends on the particular alignment. Lines with thicknesses of $10 \mu \mathrm{m}$ to $50 \mu \mathrm{m}$ are visible by the naked eye, whereas thinner lines downgrade the transparency only when their distances are below approximately $10 \mu \mathrm{m}$. Also the electrical conductivity depends on the particular alignment (probably especially on the fraction of lines that expand through the entire sample), but also strongly on the existence or absence of an oxide shell. 
The optimum for transparency and electrical conductivity was found for coatings with Fe@Au-nanoparticles. Obviously, the relatively small saturation magnetisation, the wide size distribution and the absence of a solvent shell result in an ideal alignment of the nanoparticles. The absence of an oxide-shell around the Fe@Au-nanoparticles and the presence of big nanoparticles (around $300 \mathrm{~nm}$ ) also contribute to the good electrical conductivity. However, these coatings have only a fraction of approximately $50 \%$ of the Fe@Au-nanoparticles since other chemical compositions are also present. Increasing the fraction of Fe@Au-nanoparticles should result in an improvement of electrical conductivity without affecting the outstanding transparency values.

\section{Acknowledgements}

We are grateful to financial support by the BMWi (IGF/AiF project $16375 \mathrm{~N}$ ) and the EU network SyntOrbMag. G. Beck thanks also the Research Institute of Precious Metals \& Metals Chemistry (FEM, Schwaebisch Gmuend, Germany) that the main part of the investigations could be performed there and J. Keogh as well as J. Ashford for revising the manuscript. V.S.K. Chakravadhanula acknowledges the support of the Karlsruhe Nano Micro Facility (KNMF), a large scale user facility operated at KIT, and C. Kübel (KIT) and C. Mitterbauer (FEI) for their support and discussions towards fruitful TEM investigations. We also thank T. Hülser (Institute of Energy and Environmental Technology, Duisburg, Germany), M. Kirsch (Kirsch Kunststofftechnik GmbH, Ebersbach, Germany), D. Kleber (Entwicklungs- und Prüflabor Holztechnologie GmbH, Dresden, Germany), U. Leute (Institute of Applied Natural Sciences, University of Applied Science, Ulm, Germany), U. Schuermann (Christian Albrecht University Kiel, Germany) and M. Spasova (Technical Chemistry I, University Duisburg-Essen, Germany) for their knowledge transfer and continued support during the project. 


\section{References}

[1] H.-J. Mair, S. Roth (Editor), Elektrisch leitende Kunststoffe, second ed., Hanser, München 1989.

[2] U. Schwarz-Schampera, P. M. Herzig, Indium: Geology, mineralogy, and economics, Springer, Berlin, New York 2002.

[3] M. Christen, Die stofflichen Grenzen des Wachstums - Schlüsselelemente des technologischen Fortschritts werden knapp, NZZ Forschung und Technik 286 (2005) 61.

[4] G. Phipps, C. Mikolajczak, T. Guckes, Indium and Gallium: long-term supply, Renewable energy focus 9 (2008) 58-59.

[5] Tolcin, A. C., Indium, in: U.S. Geological Survey (ed.) Mineral commodity summaries (2013) 74-75.

[6] Ad-hoc Working Group on defining critical raw materials, Report on Critical raw materials for the EU, European Commission, May 2014.

[7] M. Elbahri, M.K. Hedayati, V.S.K. Chakravadhanula, M. Jamali, T. Strunskus, V. Zaporojtchenko, F. Faupel, An Omnidirectional Transparent Conducting-Metal-Based Plasmonic Nanocomposite, Advanced Materials 23 (2011) 1993-1997.

[8] N.A. Dahoudi, A. AlKahlout, S. Heusing, P. Herbeck-Engel, R. Karos, P. Oliveira, Indium doped zinc oxide nanopowders for transparent conducting coatings on glass substrates, Sol-Gel Sci. Technol.67 (2013) 556-564. 
[9] S. Li, P. Zhu, T. Zhao, R. Sun, Optical, electrical, and thermal insulation properties of antimony-doped tin oxide nanoparticles prepared by frozen gel method, J. Sol-Gel Sci. Technol. 70 (2014) 366-370.

[10] M.V. Catro, L. Rebouta, P. Alpuim, M.F. Cerqueira, M. Benelmekki, C.B. Garcia, E. Alves, N.P. Barradas, E. Xuriguera, C.J. Tavares, Optimisation of surface treatments of $\mathrm{TiO}_{2}: \mathrm{Nb}$ transparent conductive coatings by a post-hot-wire annealing in a reducing $\mathrm{H}_{2}$ atmosphere, Thin Solid Films 550 (2014) 404-412.

[11] V.G. Kulkarni, J.C. Campbell, W.R. Mathew, Transparent conductive coatings, Synthetic Metals 57 (1993) 3780-3785.

[12] J.-A. Pomposo, E. Ochoteco, C. Pozo, P.-M. Carrasco, H.-J. Grande, F.-J. Rodriguez, Conductivity enhancement in raw polypyrrole and polypyrrole nanoparticle dispersions, Polym. Adv. Technol. 17 (2006) 26-29.

[13] H.M. Phillips, T. Feurer, S.P. LeBlanc, D.L. Callahan, R. Sauerbrey, Excimer Laser Induced Permanent Electrical Conductivity and Nanostructures in Polymers, Laser Radiat. Photophys. 1856 (1993) 143-154.

[14] P.McCluskey, M. Nagvanshi, V.R.P. Verneker, P. Kondracki, D. Finello, Nanocomposite materials offer higher conductivity and flexibility, Internat. Conf. Adhesive Joining and Coating Technol. Electronics Manuf., Proceedings 1998, 282-286.

[15] H. Jiang, K.-S. Moon, J. Lu, C.P. Wong, Conductivity enhancement of nano silver-filled conductive adhesives by particle surface functionalization, J. Electronic Mater. 34 (2005) 1432-1439.

[16] T. Akter, W.S. Kim, Reversibly Stretchable Transparent Conductive Coatings of SprayDeposited Silver Nanowires, Appl. Mater. Interfaces 4 (2012) 1855-1859.

[17] Y.C. Lu, K.S. Chou, Tailoring of silver wires and their performance as transparent conductive coatings, Nanotechnology 21 (2010) 215707 (6pp). 
[18] W. Wang, K.A.S. Fernando, Y. Lin, M.J. Meziani, L.M. Veca, L. Cao, P. Zhang, M.M. Kimani, Y.-P. Sun, Metallic Single-Walled Carbon Nanotubes for Conductive Nanocomposites, J. Am. Chem. Soc. 130 (2008) 1415-1419.

[19] Z. Li, H. R. Kandel, E. Dervishi, V. Saini, Y. Xu, A.R. Biris, D. Lupu, G.J. Salamo, A.S. Biris, Comparative Study on Different Carbon Nanotube Materials in Terms of Transparent Conductive Coatings, Langmuir 24 (2008) 2655-2662.

[20] X. Hao, G. Gai, Y. Yang, Y. Zhang, C.-w. Nan, Development of the conductive polymer matrix composite with low concentration of the conductive filler, Mater. Chem. Phys. 109 (2008) 15-19.

[21] S. Hill, elements - Degussa-Science Newsletter 18 (2007) 8-11.

[22] K.A. Sierrros, D.S. Hecht, D.A. Banerjee, N.J. Morris, L. Hu, G.C. Irvin, R.S. Lee, D.R. Cairns, Durable transparent carbon nanotube films for flexible device components, Thin Solid Films 518 (2010) 6977-6983.

[23] J. Hecht, Graphene photonics are making their way to practical use, Laser Focus World 48 (2012) 62-65.

[24] M. Layani, S. Magdassi, Flexible transparent conductive coatings by combining selfassembly with sintering of silver nanoparticles performed at room temperature, J. Mater. Chem. 21 (2011) 15378-15382.

[25] M. Layani, M. Gruchko, O. Milo, I. Balberg, D. Azulay, S. Magdassi, Transparent conductive coatings by printing coffee ring arrays obtained at room temperature, ACS Nano 3 (2009) 3537-3542.

[26] M.R.S. Castro, H.K. Schmidt, Transparent conducting antimony-doped tin oxide films containing functionalized multi-walled carbon nanotubes, Phys. Stat. Sol. (a) 204 (2007) 3380-3386. 
[27] S.-S. Lee, N.-R. Lee, K.-I. Kim, S.-J. Hong, T.-W. Hong, MLCA (Material Life Cycle Assessment) for ITO recycling, Mater. Sci. Forum 724 (2012) 12-16.

[28] E. L. Bizdoaca, M. Spasova, M. Farle, M. Hilgendorff and F. Caruso Magnetically directed self-assembly of submicron spheres with a $\mathrm{Fe}_{3} \mathrm{O}_{4}$ nanoparticle shell, J. Magn. Magn. Mater. 240 (2002) 44-46.

[29] J. Knipping, H. Wiggers, B. F. Kock, T. Hülser, B. Rellinghaus, P. Roth, Synthesis and characterization of nanowires formed by self-assembled iron particles, Nanotechnology 15 (2004) 1665-1670.

[30] T. P. Huelser, H. Wiggers, P. Ifeacho, O. Dmitrieva, G. Dumpich, A Lorke, Morphology, structure and electrical properties of iron nanochains, Nanotechnology 17 (2006) 3111-3115.

[31] D. Ciuculescu, F. Dumestre, M. Comesana-Hermo, B. Chaudret, M. Spasova, M. Farle, C. Amiens, Single-Crystalline Co Nanowires: Synthesis, Thermal Stability, and Carbon Coating, Chem. Mater. 21 (2009) 3987-3995.

[32] Y. Soumare, J.-Y. Piquemal, T. Maurer, F. Ott, G. Chaboussant, A. Falqui, G. Viau, Oriented magnetic nanowires with high coercivity, Chem. Mater. 18 (2008) 56965702.

[33] N. Pazos-Pérez, Y. Gao, M. Hilgendorff, S. Irsen, J. Pérez-Juste, M. Spasova, M. Farle,| L. M. Liz-Marzán, M. Giersig, Magnetic-noble metal nanocomposites with morphology-dependent optical response, Chem. Mater. 19 (2007) 4415-4422.

[34] N. Pazos-Pérez, B. Rodríguez-González, M. Hilgendorff, M. Giersig, L. M. Liz-Marzán, J. Gold encapsulation of star-shaped FePt nanoparticles, J. Mater. Chem. 20 (2010) 6164. 
[35] J. Jakobi, S. Petersen, A. Menendez-Manjon, P. Wagener, S. Barcikowski, Magnetic alloy nanoparticles from laser ablation in cyclopentanone and their embedding into a photoresist, Langmuir 26 (2010) 6892-6897.

[36] A. Menéndez-Manjón, A. Schwenke, T. Steinke, M. Meyer, U. Giese, P. Wagener, S. Barcikowski, Ligand-free gold-silver nanoparticle alloy polymer composites generated by picosecond laser ablation in liquid monomer, S. Appl. Phys. A 110 (2013) 343-350.

[37] P. Wagener, G. Brandes, A. Schwenke, S. Barcikowski, Impact of in situ polymer coating on yparticle dispersion into solid laser-generated nanocomposites, Phys. Chem. Chem. Phys. 13 (2011) 5120-5126.

[38] P. Stoller, V. Jacobsen, H. Seelig, V. Sandoshdar, Bulletin ETH Zürich 295 (2004) 20-23.

[39] C. Kittel, Introduction to Solid State Physics, eighth edition, Wiley, 2004.

[40] J. Townsend, R. Burtovyy Y. Galabura, I. Luzinov, Flexible Chains of Ferromagnetic Nanoparticles, ACS Nano 8 (2014) 6970-6978.

[41] P.G. de Gennes, P.A. Pincus, Pair Correlations in a Ferromagnetic Colloid, Phys. Kondens. Mater. 11 (1970) 189-198.

\section{Figure Captions}

Figure 1: Sketch of the formation of electrically conducting pathways of conducting particles within an isolating matrix. a) In the case of spherical particles the percolation is reached at very high concentrations of the particles. b) In the case of elongated particles the percolation can be reached at smaller concentrations. c) In the case of spherical magnetic particles conducting pathways can be formed and directed within a magnetic field. d) In the case of elongated magnetic particles an alignment along the magnetic field to conducting pathways can be also formed, but at lower concentrations than in the case shown in 1c. 
Figure 2: Dispersions of acrylic resin varnish with CoNi-nanowires $(6 \mathrm{~g} / \mathrm{L})$ and different dispersing agents after ultrasonic treatment for 30 minutes and standing for about 4 hours.

Figure 3: TEM images of a) as-prepared CoNi-nanowires and b) destroyed CoNi-nanowires within an acrylic resin-based coating (after ultrasonic treatment).

Figure 4: Photos of dispersions with $4 \mathrm{~g} / \mathrm{L}$ Co-nanoparticles in acrylic resin varnish on a PMMA substrate (with an area of $2.5 \mathrm{~cm} \times 2.5 \mathrm{~cm}$ ) a) directly after coating and after drying for 40 minutes at room temperature b) without a magnetic field and c) within a magnetic field. Very thick coatings of $80 \mu \mathrm{m}$ were prepared for a good clearness.

Figure 5: a) Transparency of acrylic resin-based coatings with different concentrations of Fe@Au-nanoparticles. b) Photographs of the corresponding coatings.

Figure 6: a) Transparency (at $660 \mathrm{~nm}$ ) of acrylic resin-based coatings with different nanoadditives as a function of their concentration. (The lines are only indicating the trend of the curve. They do not represent a line fit.) b) Photographs of corresponding coatings with nanoadditive concentrations of about $4 \mathrm{~g} / \mathrm{L}$.

Figure 7: Electrical conductivity of acrylic resin-based coatings with different nano-additives as a function of their concentration. (The lines are only indicating the trend of the curve. They do not represent a line fit.) 
Figure 8: Electrical conductivity of acrylic resin-based coatings with different nano-additives versus the transparency. (The lines are only indicating the trend of the curve. They do not represent a line fit.)

Figure 9: a) Light optical microscope image and b) SEM image of an acrylic resin-based coating with $4 \mathrm{~g} / \mathrm{L}$ Co-nanoparticles.

Figure 10: TEM investigations of the oxygen shell of Co-nanoparticles in air.

Figure 11: a) Optical microscope image and b) SEM image of an acrylic resin-based coating with $5 \mathrm{~g} / \mathrm{L}$ passivated Fe-nanoparticles.

Figure 12: XRD theta-2theta-scans of acrylic resin-based coatings with Fe-nanoparticles (red curve) and passivated Fe-nanoparticles (black curve). Reflections of cubic iron and magnetite are marked. From the line width the crystal sizes of these phases were calculated by the fundamental parameter method.

Figure 13: a) Optical microscope image and b) SEM image of an acrylic resin-based coating with $4 \mathrm{~g} / \mathrm{L}$ CoNi-nanoparticles.

Figure 14: a) Light optical microscope and b) SEM and image of an acrylic resin-based coating

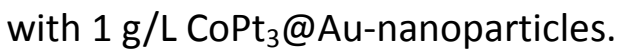

Figure 15: a) Optical microscope and b) SEM image of an acrylic resin-based coating with 2 g/L Fe@Au-nanoparticles. 
Figure 16: STEM images and EDX element scans and maps, respectively, of a) an iron-core gold-shell, b) a gold-iron-alloy- and c) a gold-core and iron-shell laser-generated nanoparticle.

Figure 17: Magnetic hysteresis measurement at room temperature of Fe@Au-nanoparticles within an acrylic resin-based coating. 
Click here to download high resolution image

a)

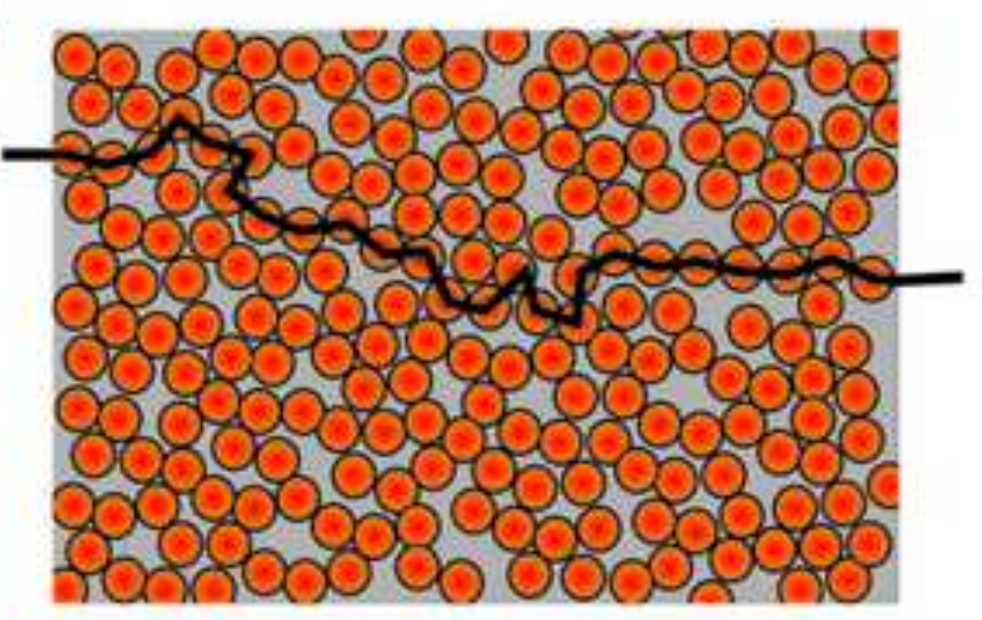

c)

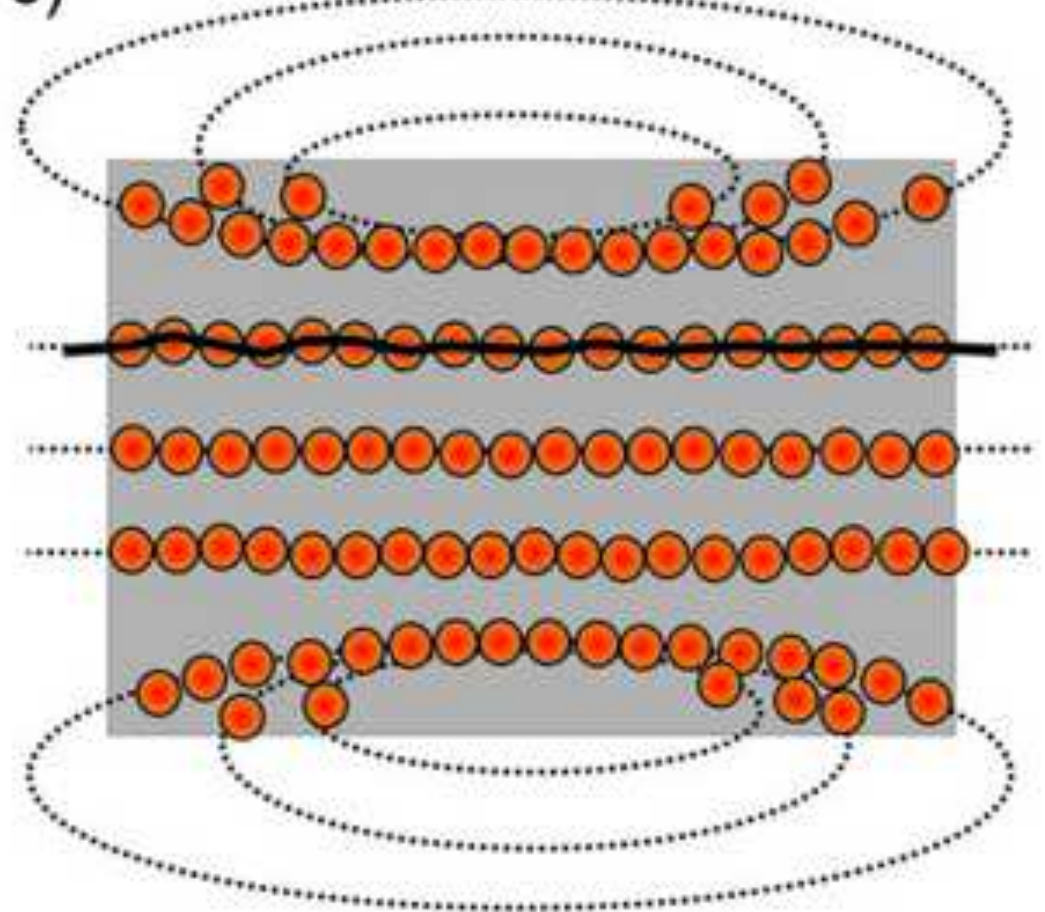

b)

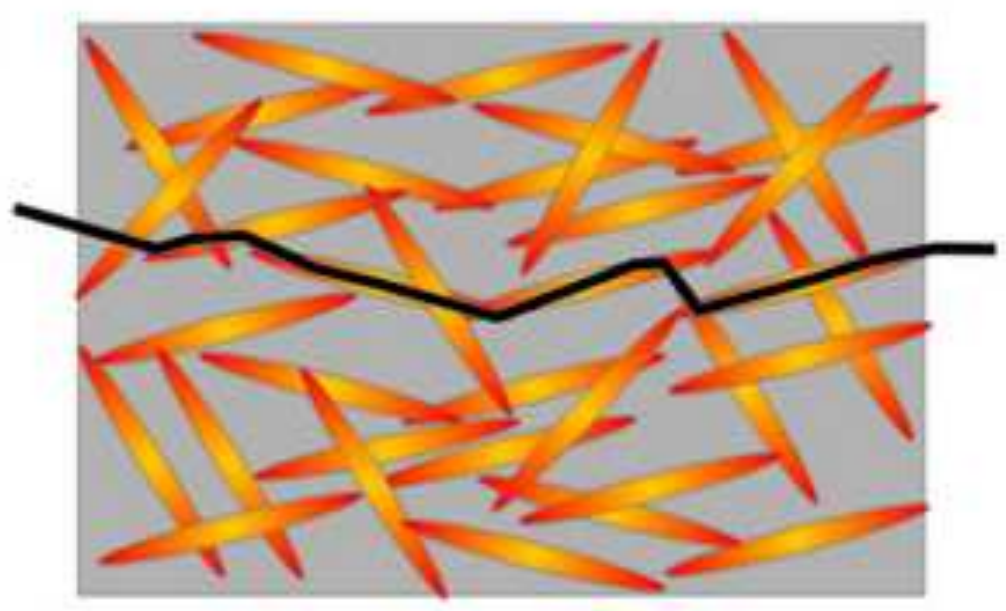

d)

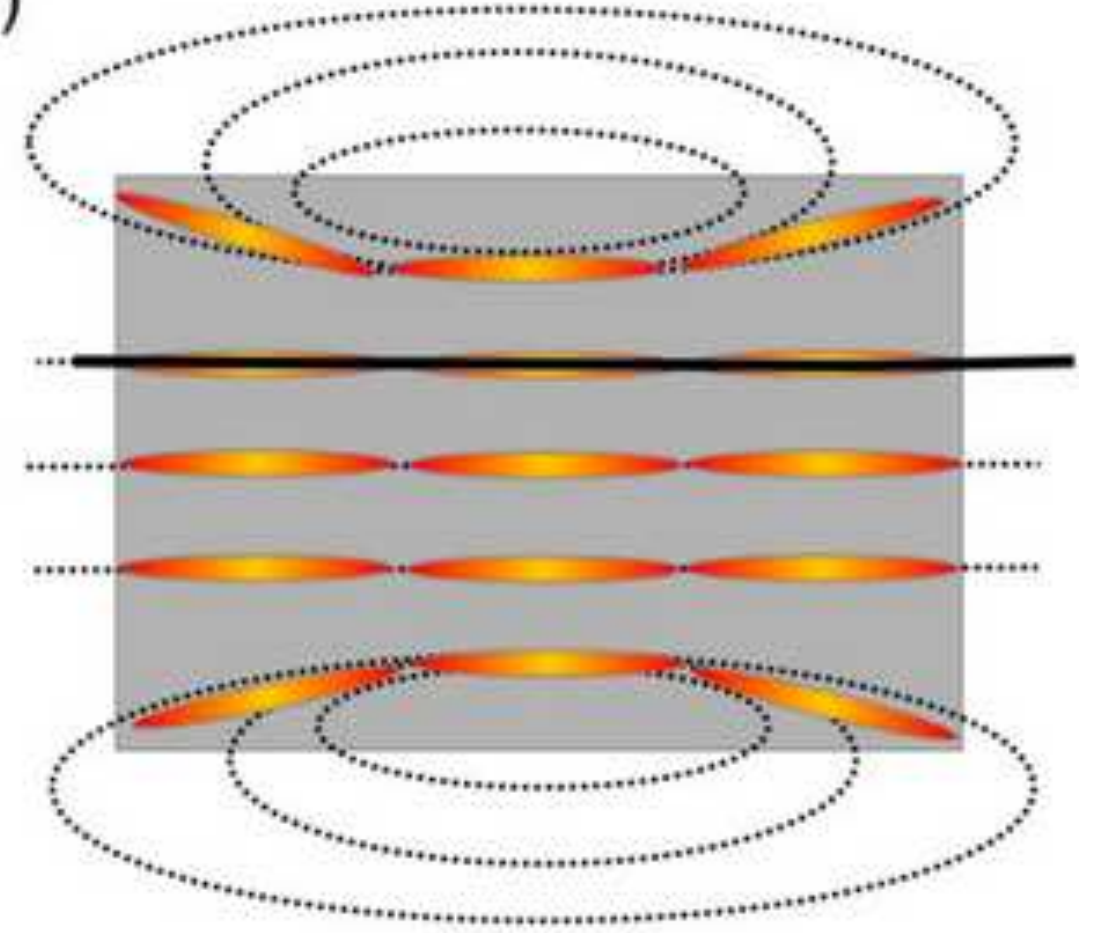


Click here to download high resolution image
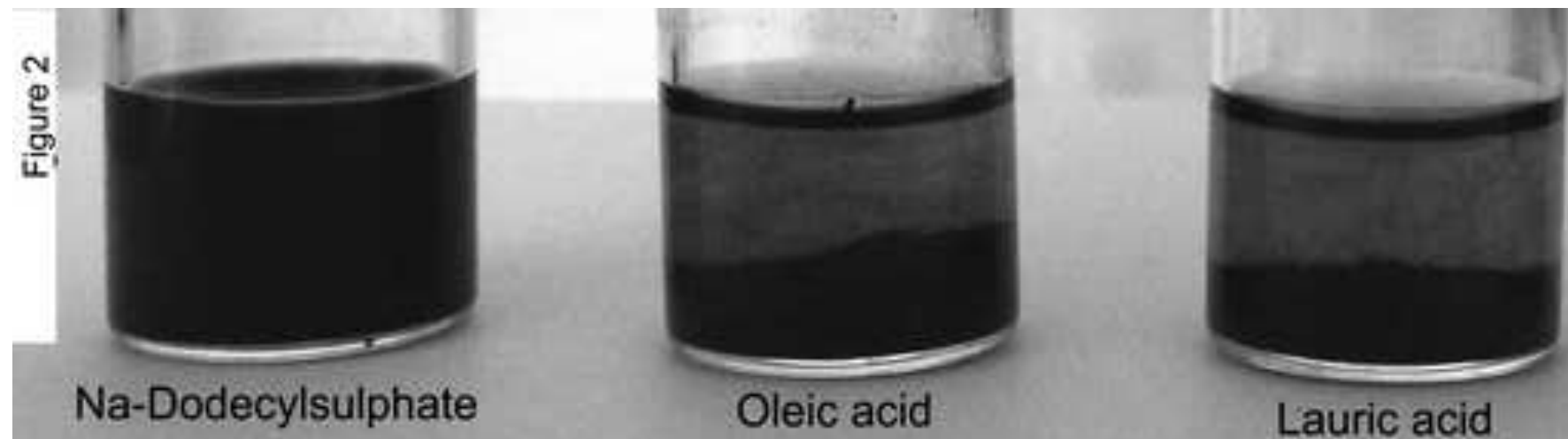

Lauric acid

Dysperbyk 107

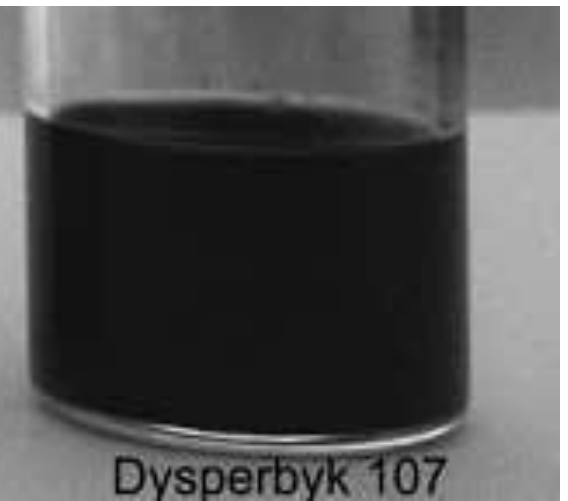


Figure3a-colour
Click here to download high resolution image

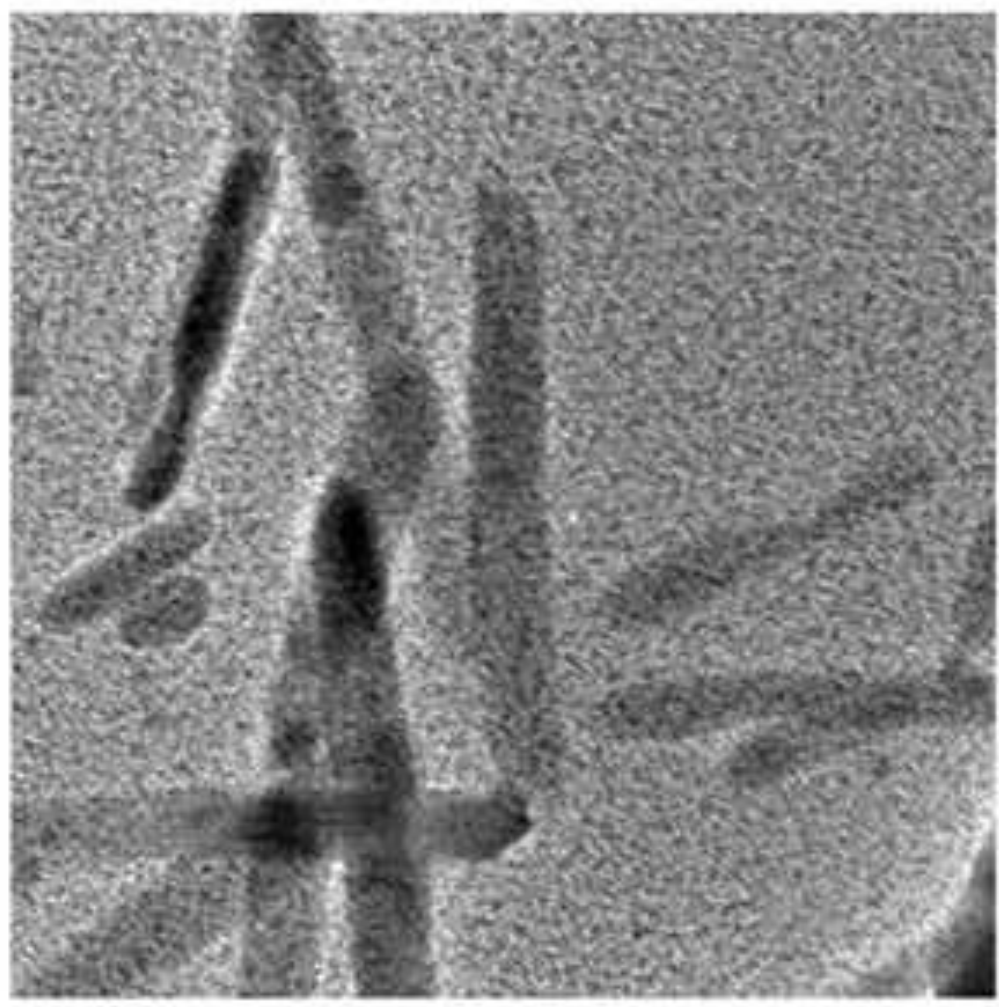

$-10 \mathrm{~nm}$

STEM

\section{C-K}

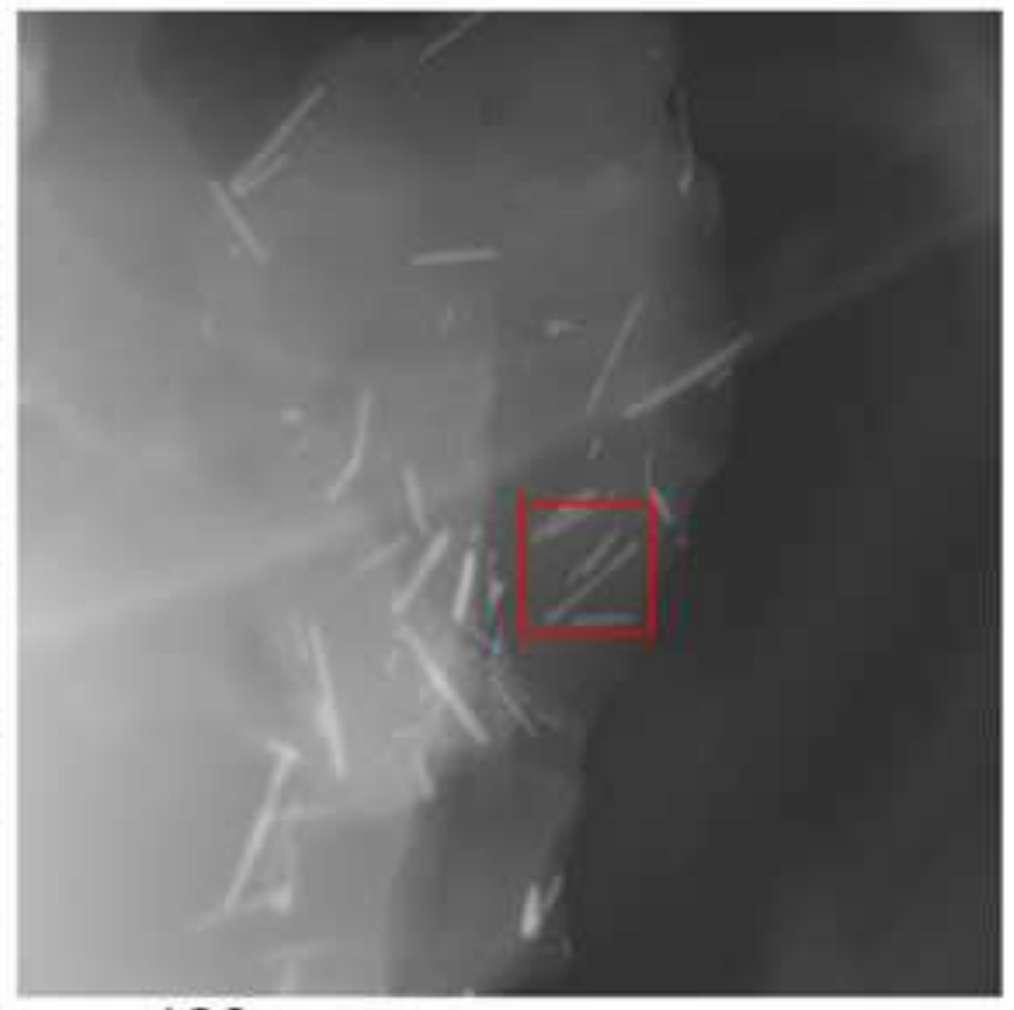

$-100 \mathrm{~nm}$

Co-K

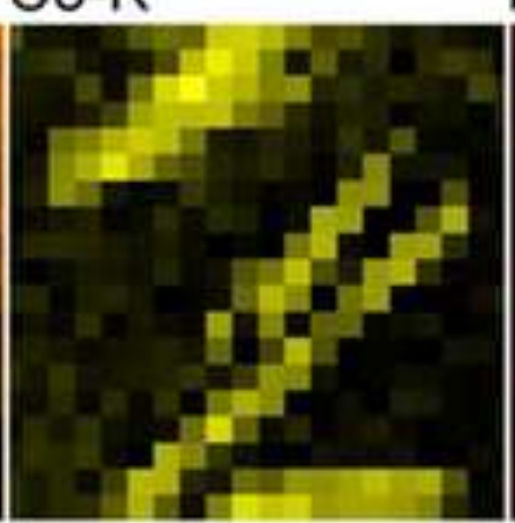

$50 \mathrm{~nm}$

$\mathrm{Ni}-\mathrm{L}$

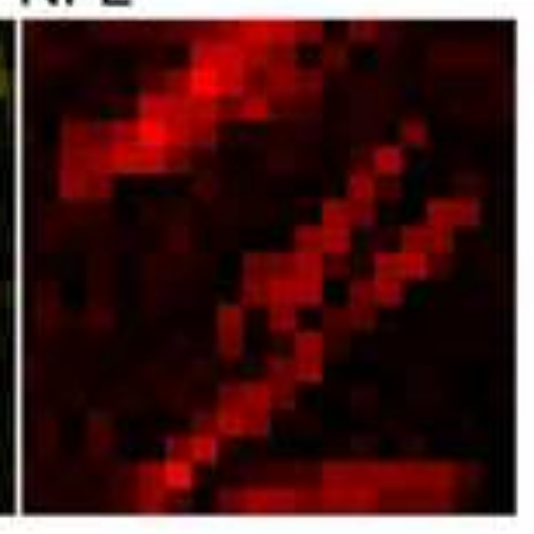

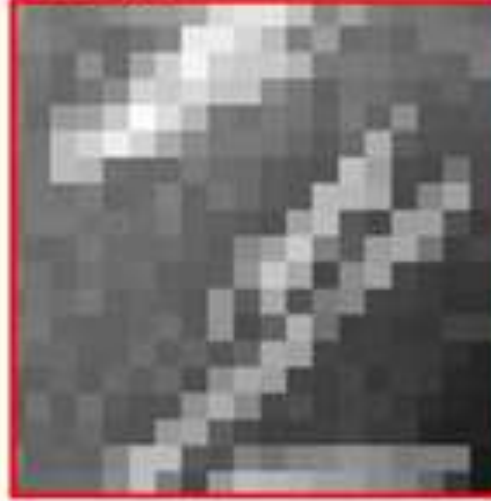

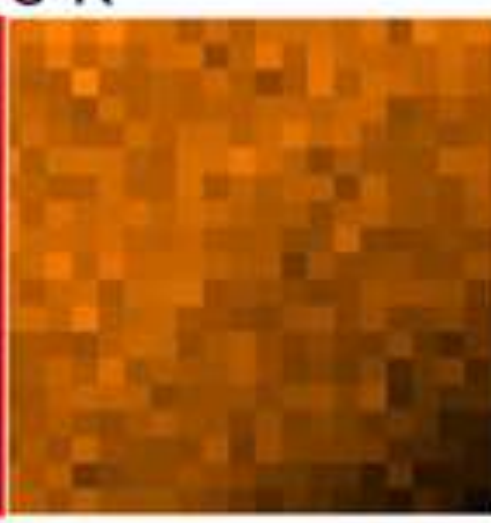

Figure $3 a$ 
Click here to download high resolution image

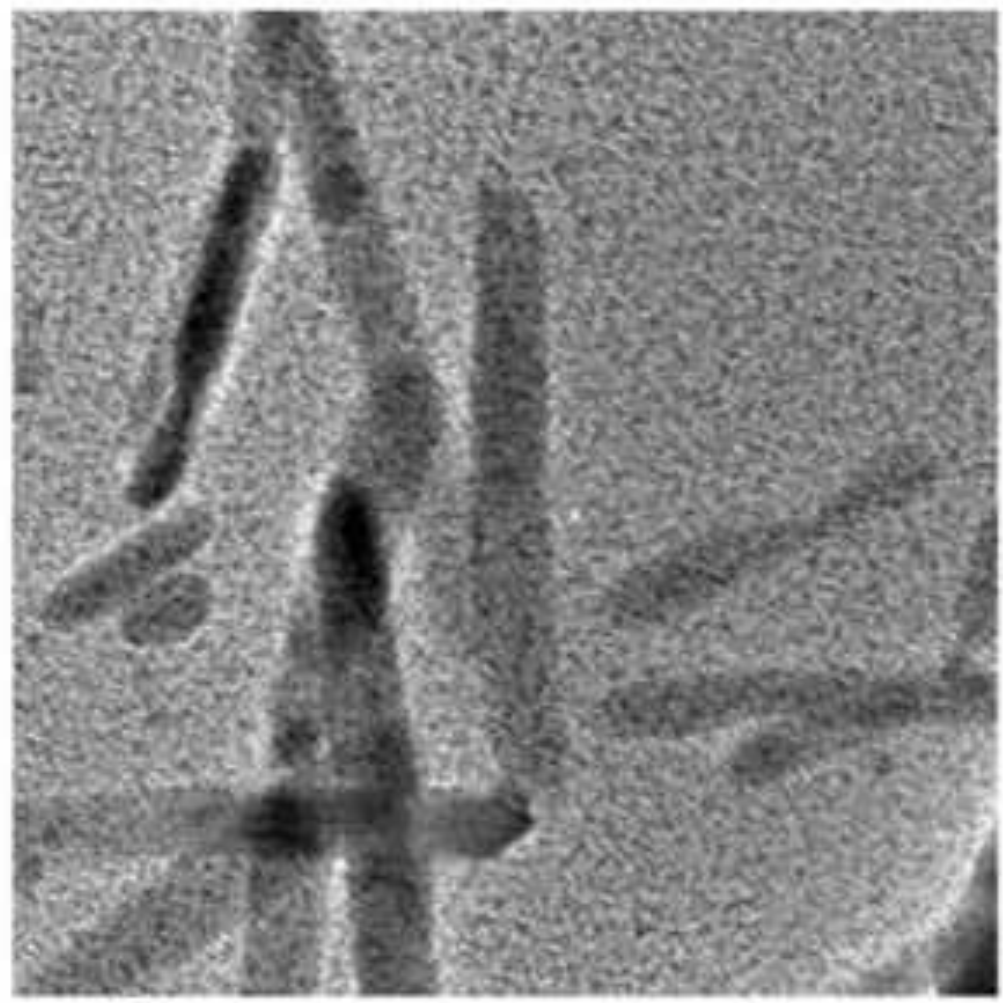

$-10 \mathrm{~nm}$

STEM
C-K

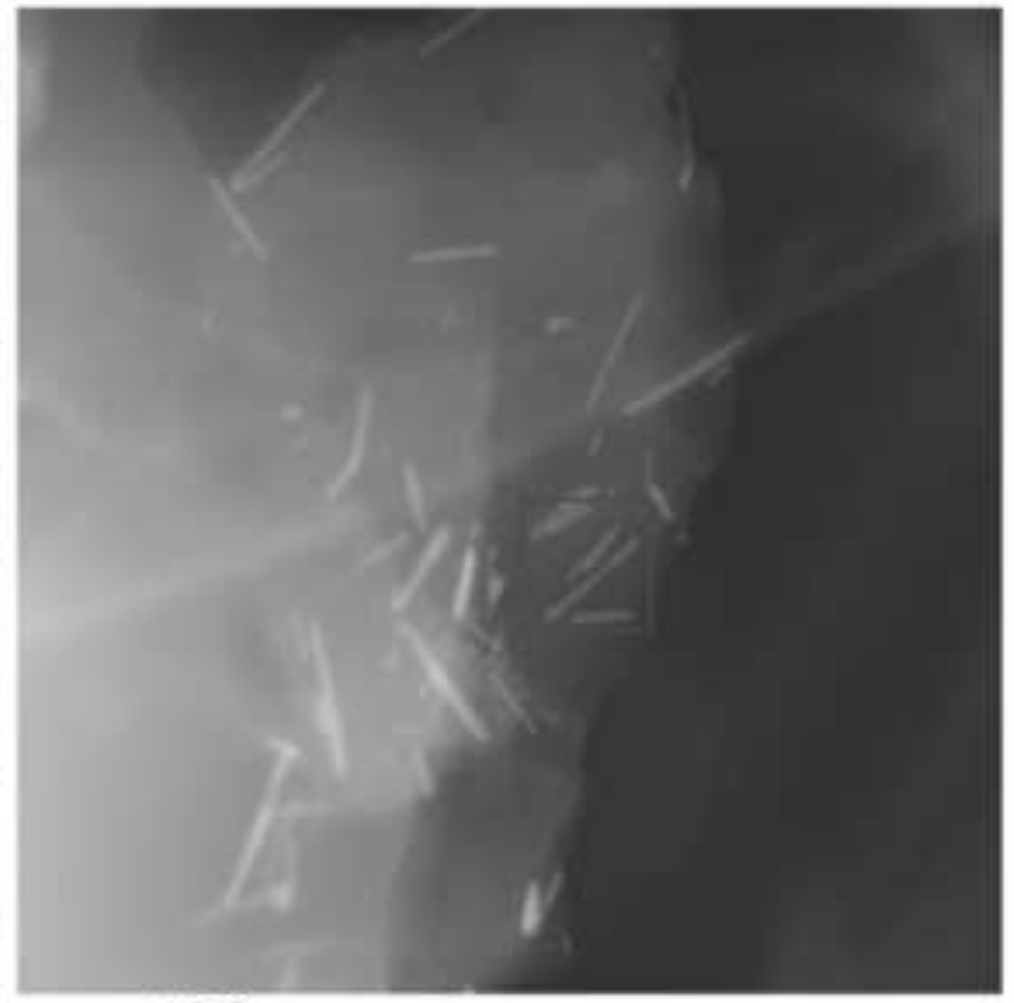

$-100 \mathrm{~nm}$

Co-K

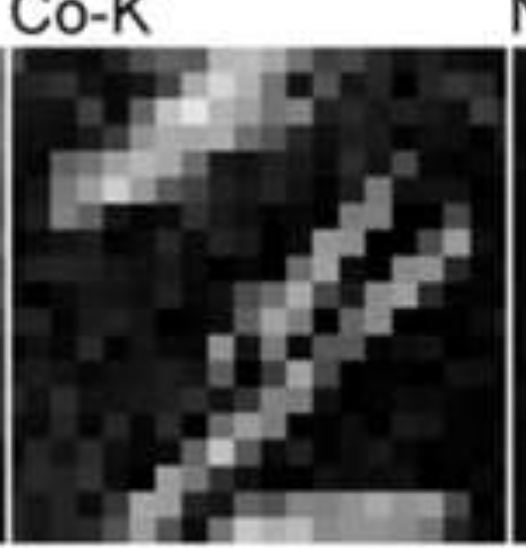

$50 \mathrm{~nm}$
$\mathrm{Ni}-\mathrm{L}$

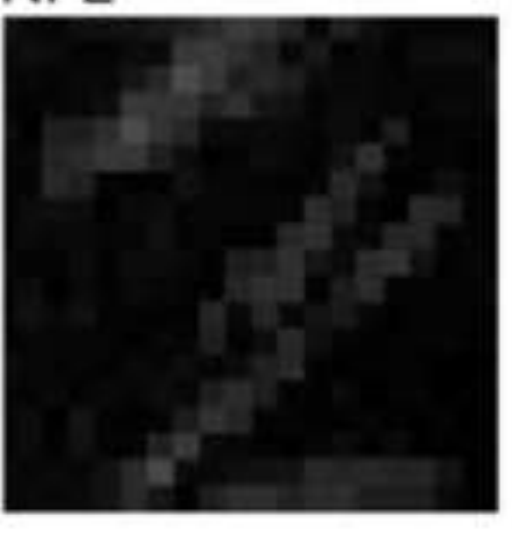

Figure $3 a$ 


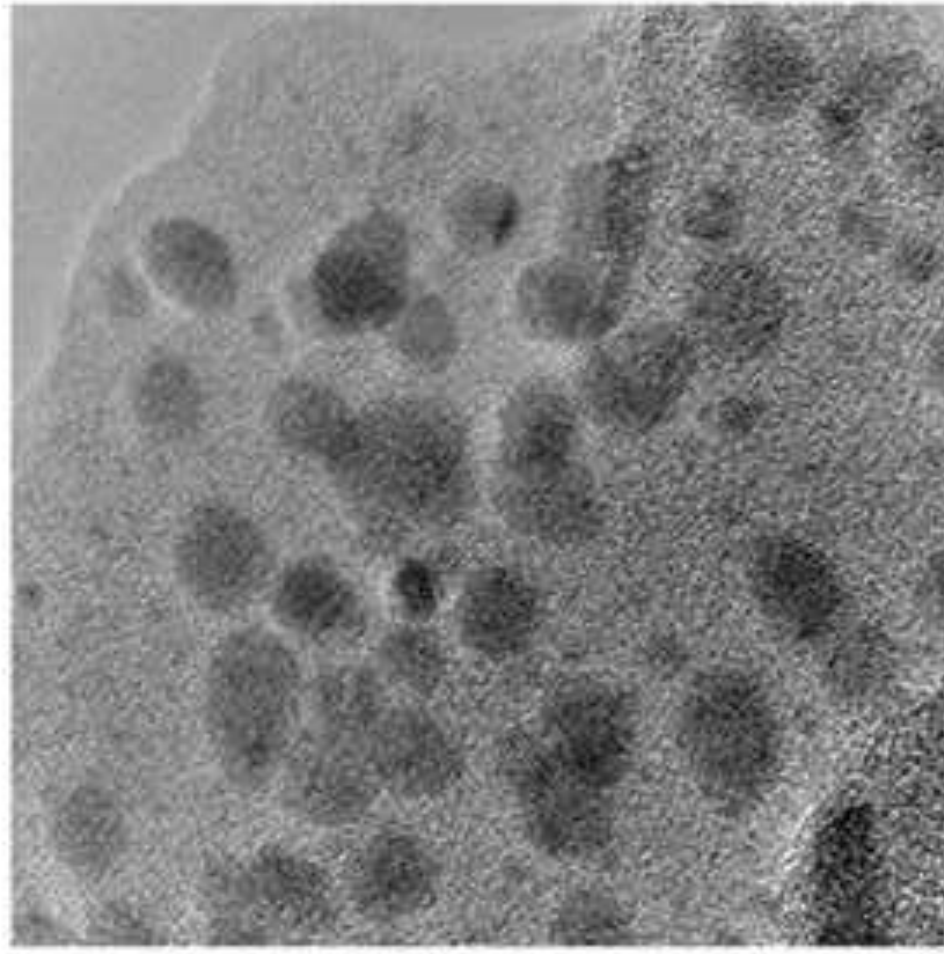

\section{$-10 \mathrm{~nm}$}

STEM

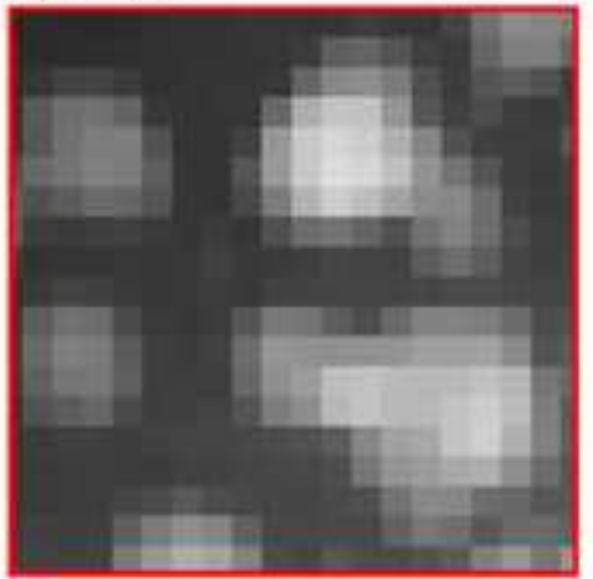

Co-K

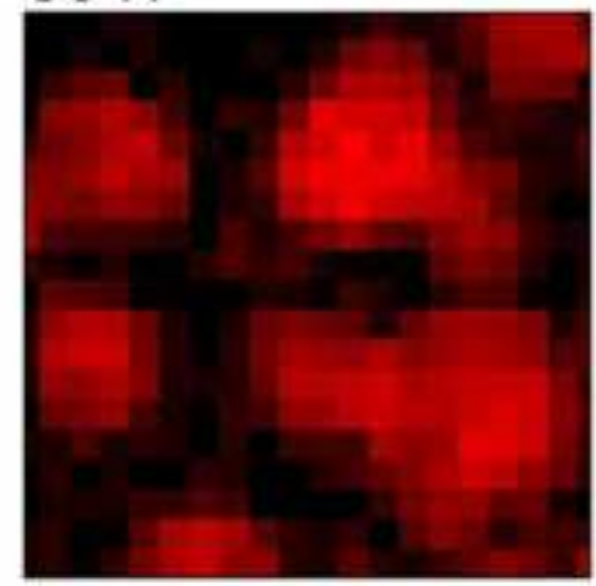

$10 \mathrm{~nm}$

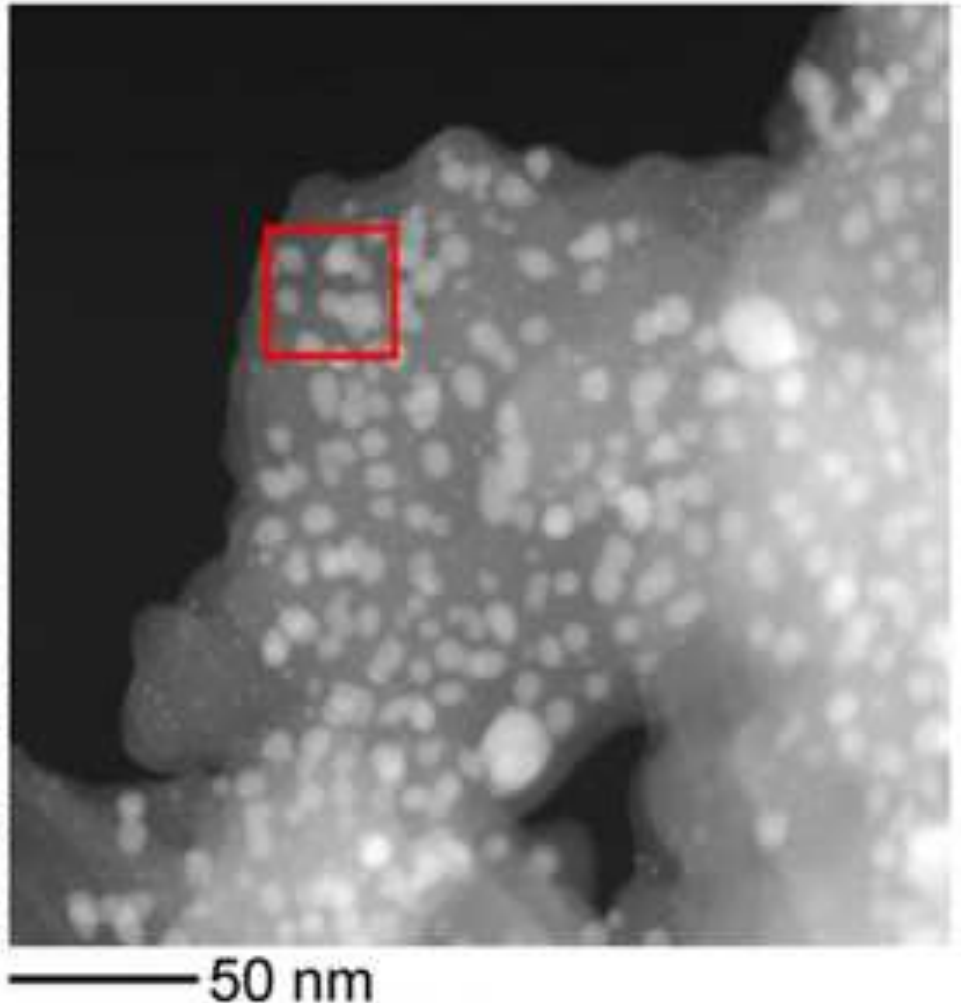

$\mathrm{Ni}-\mathrm{K}$

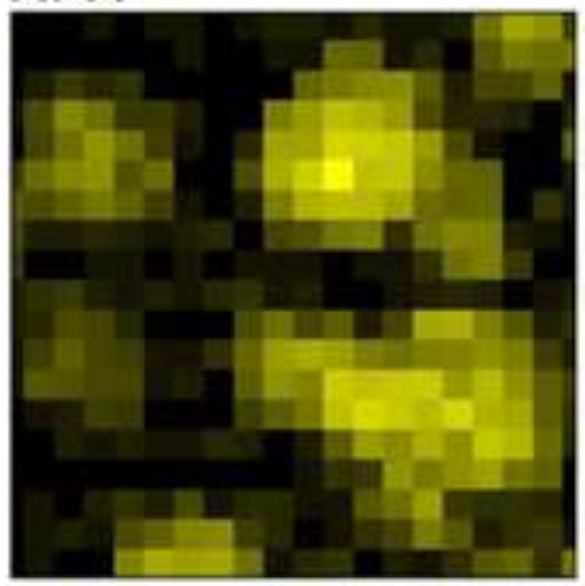

Figure $3 b$ 


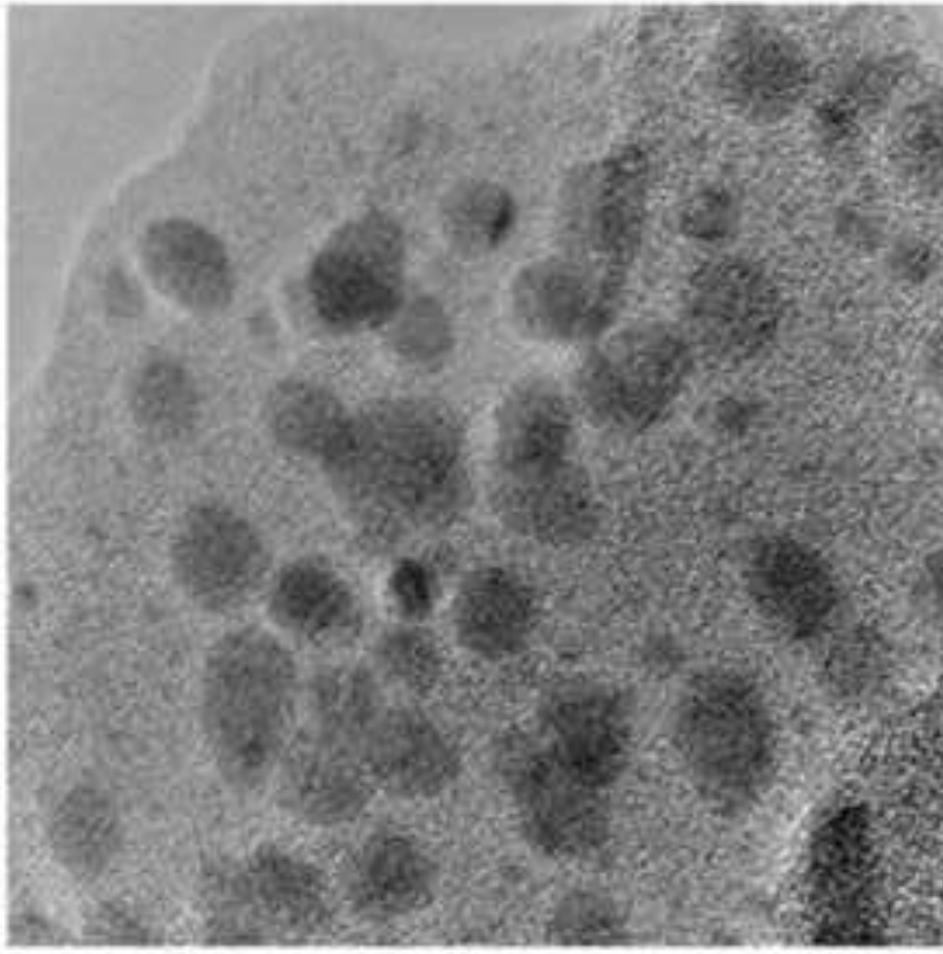
$-10 \mathrm{~nm}$

\section{STEM}

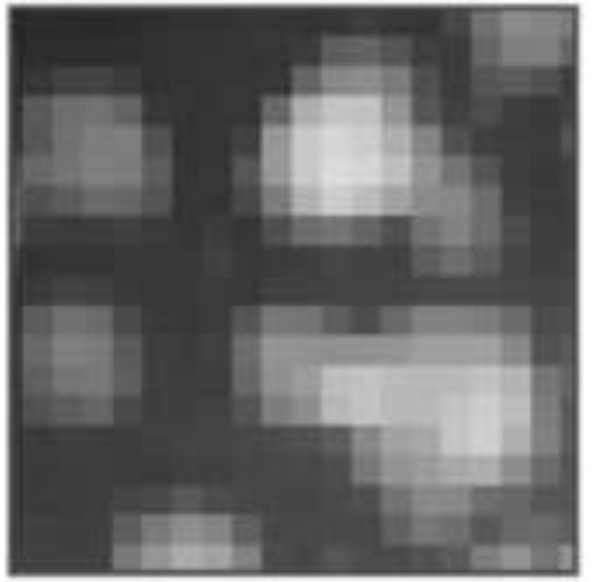

Co-K

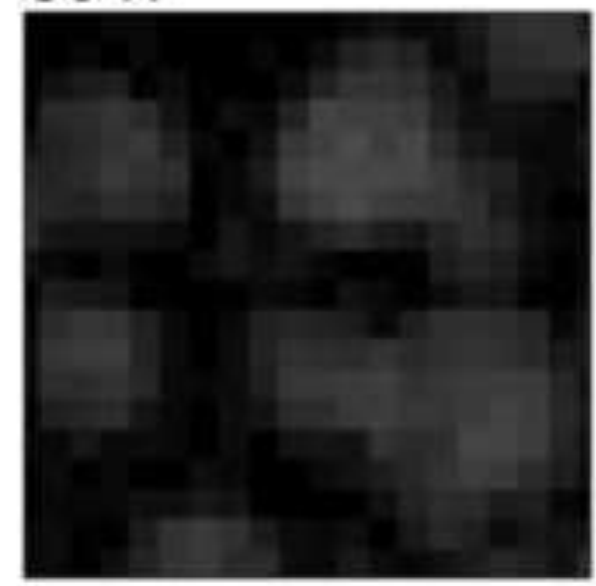

$10 \mathrm{~nm}$

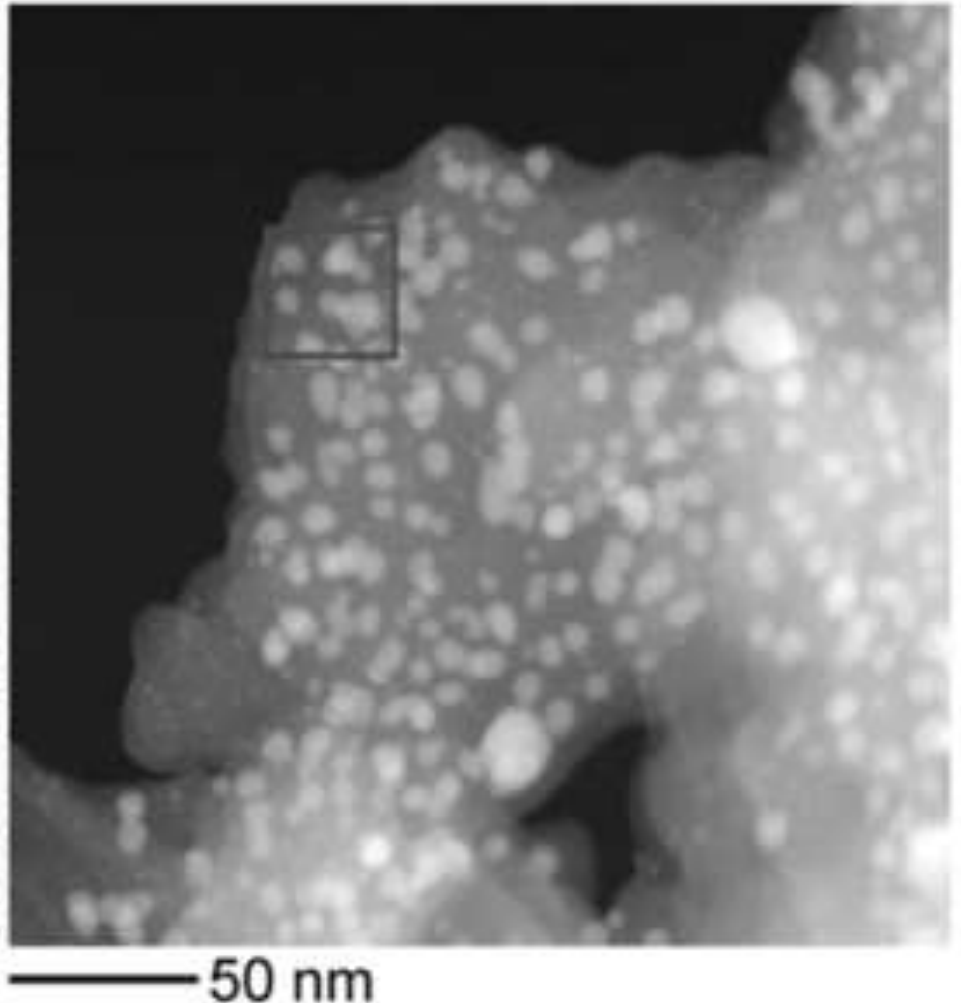

$\mathrm{Ni}-\mathrm{K}$

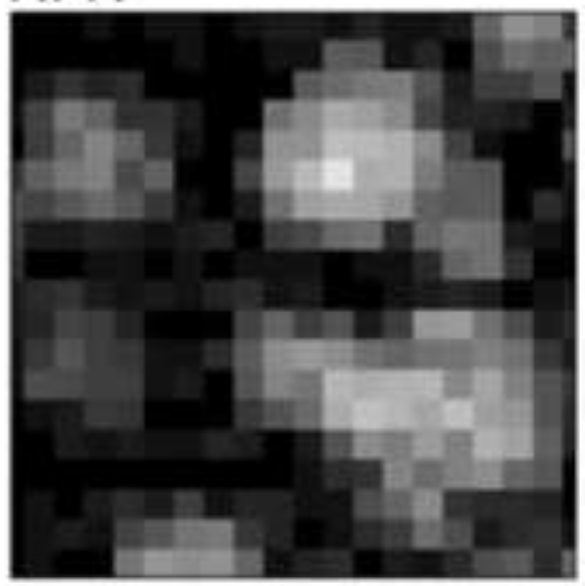

Figure $3 b$ 
Figure 4
Click here to download high resolution image
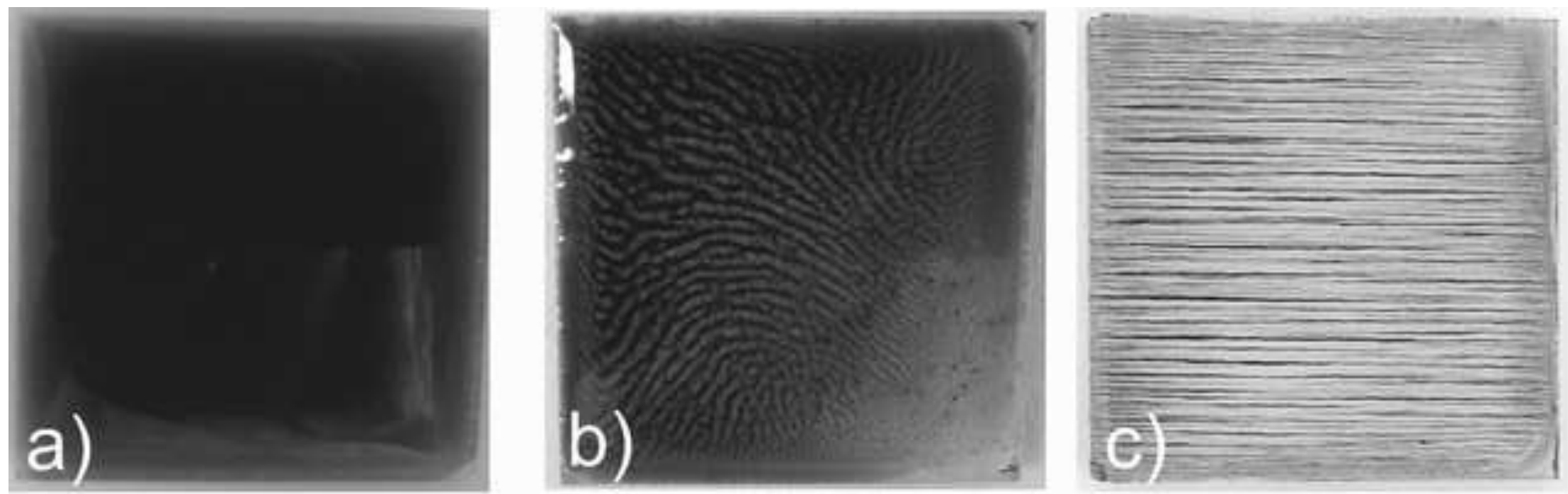

Figure 4 


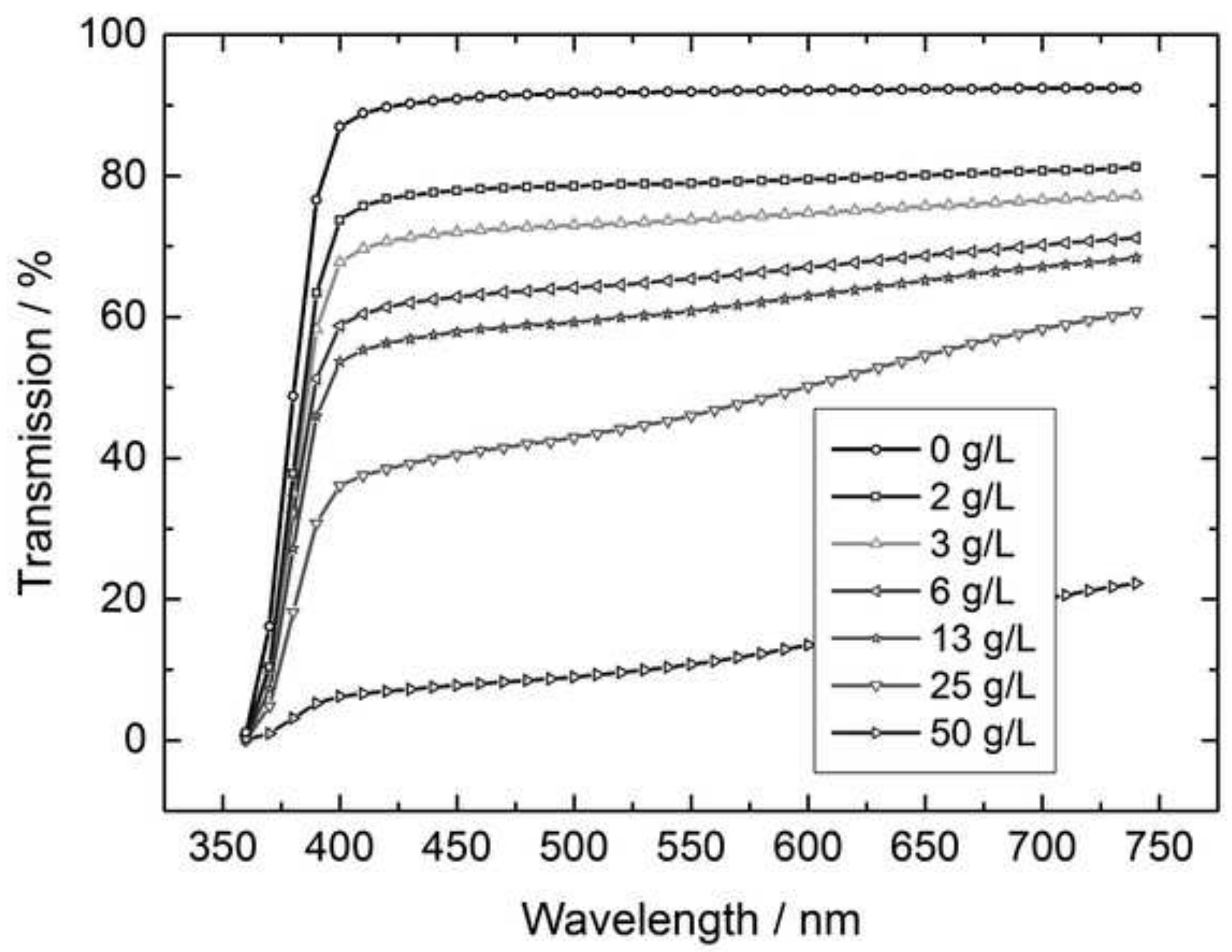




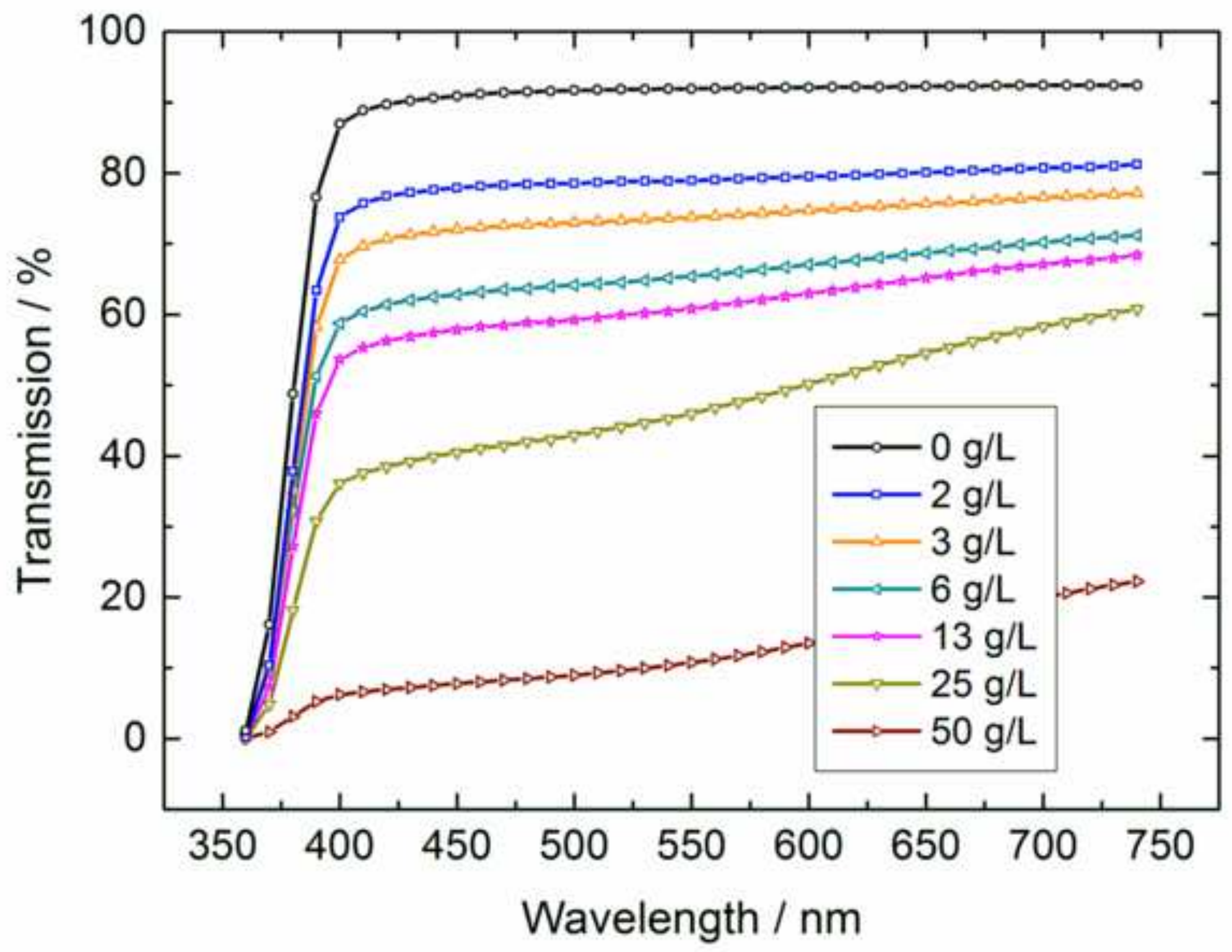




\section{$50 \mathrm{~g} / \mathrm{L}$}

\section{$25 \mathrm{~g} / \mathrm{L}$}

$13 \mathrm{~g} / \mathrm{L}$

$3 \mathrm{~g} / \mathrm{L}$

\section{$2 \mathrm{~g} / \mathrm{L}$}

Figure $5 b$ 


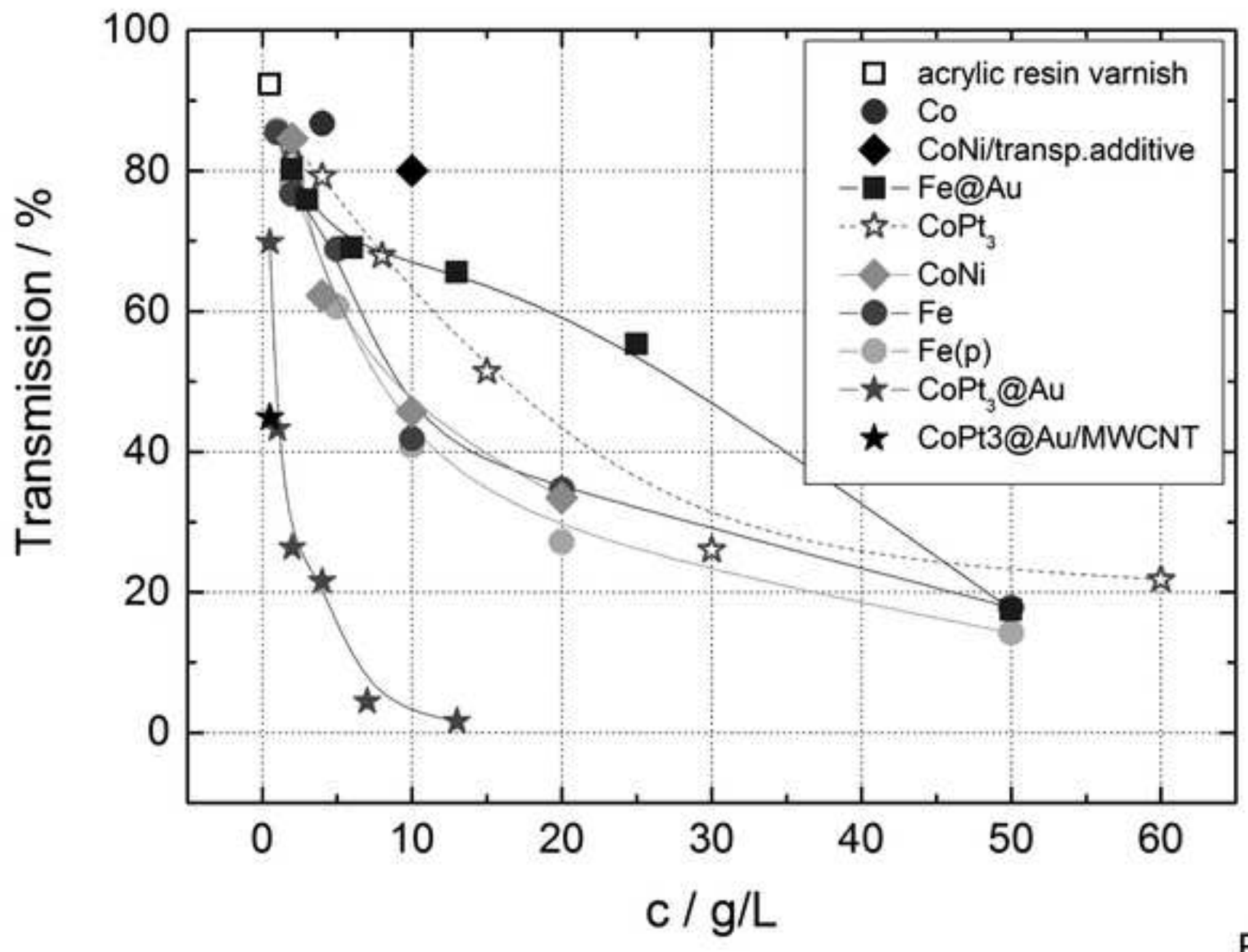

Figure 6a 


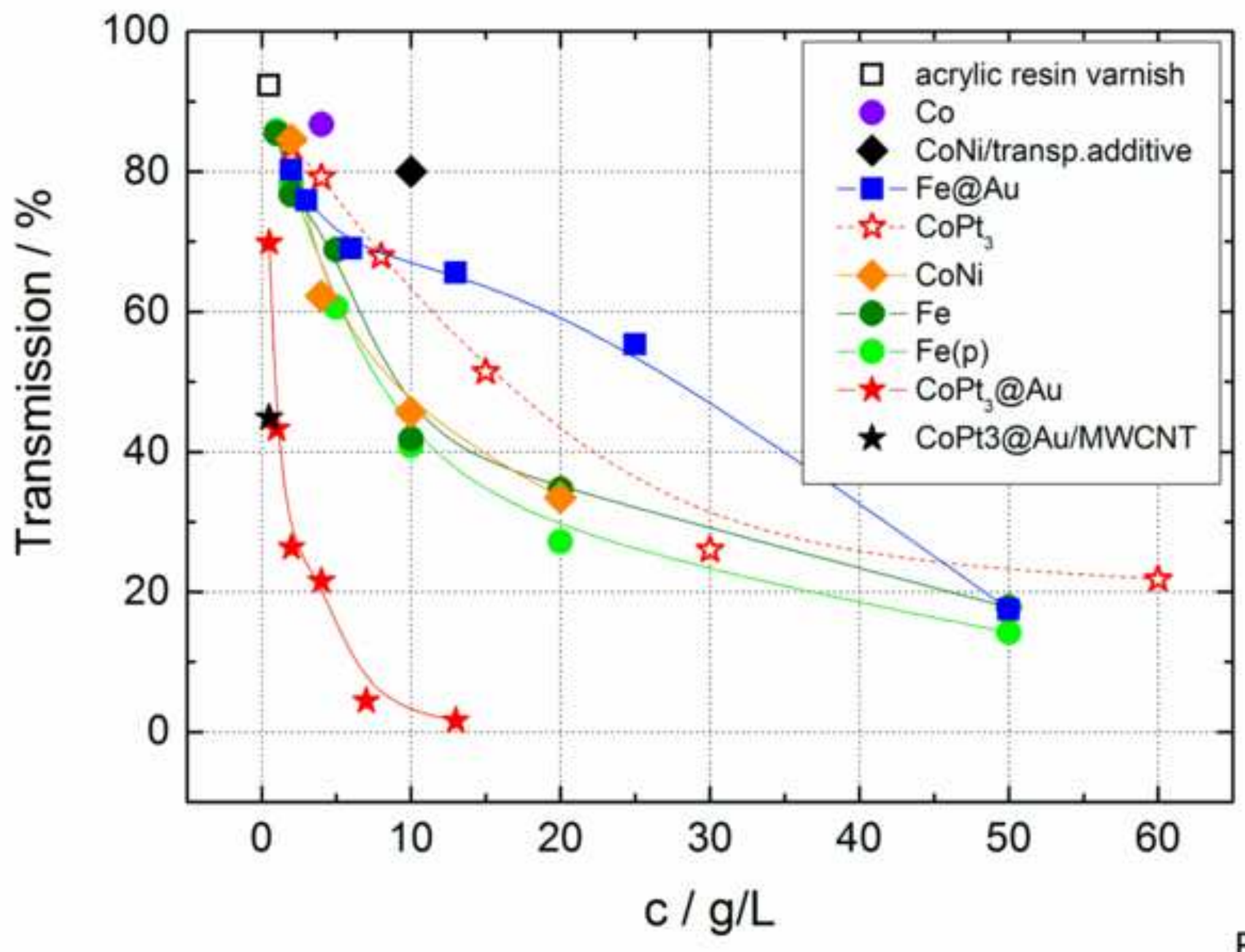

Figure $6 a$ 

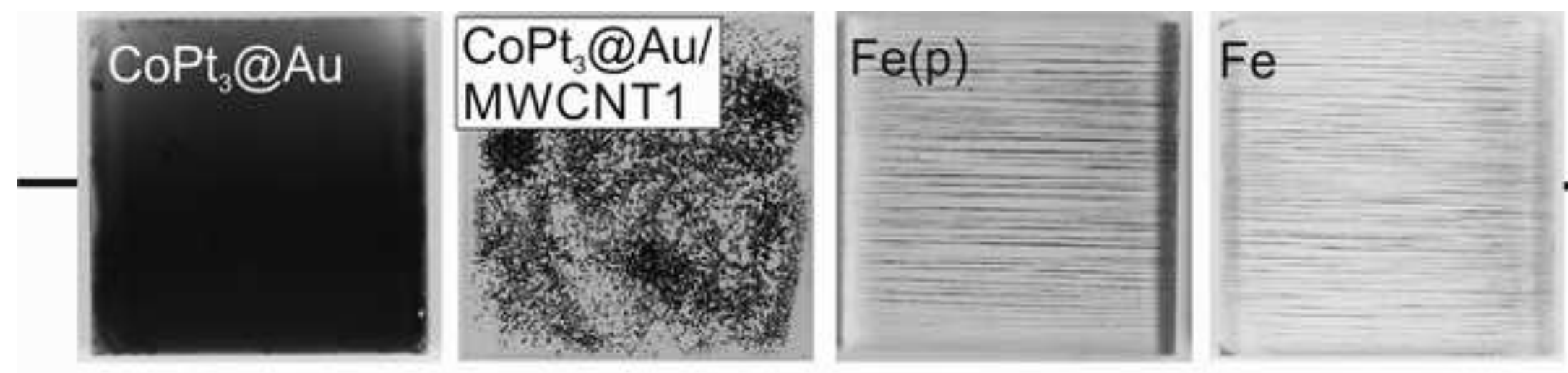

\section{Transmission}
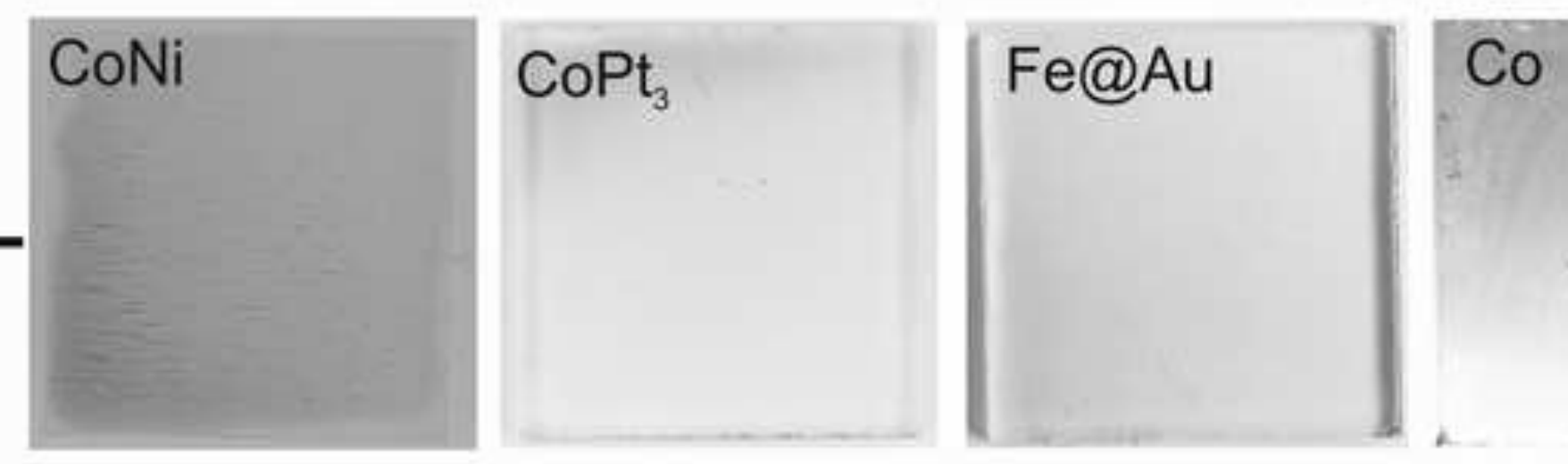

Figure $6 b$ 


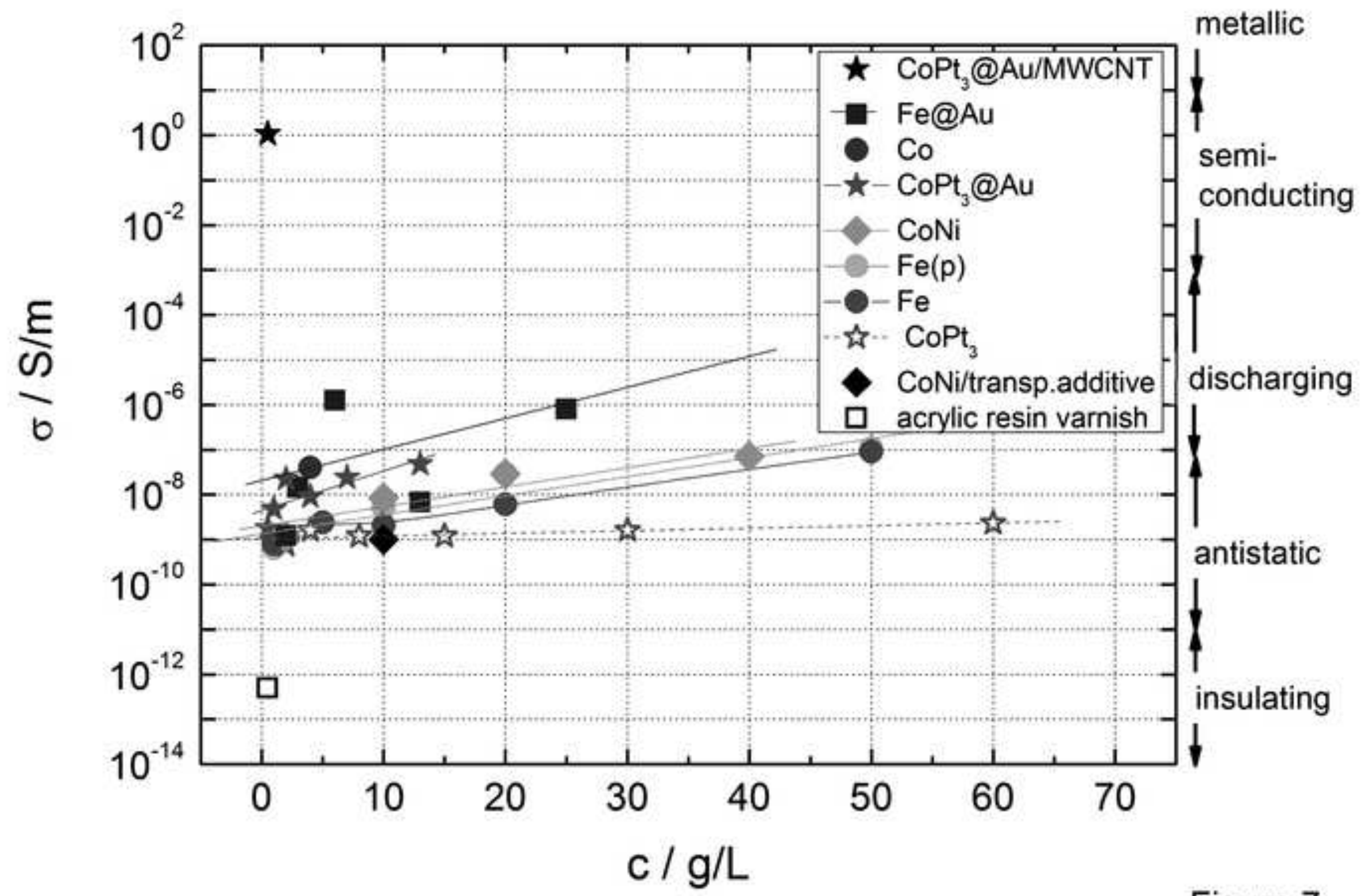

Figure 7 


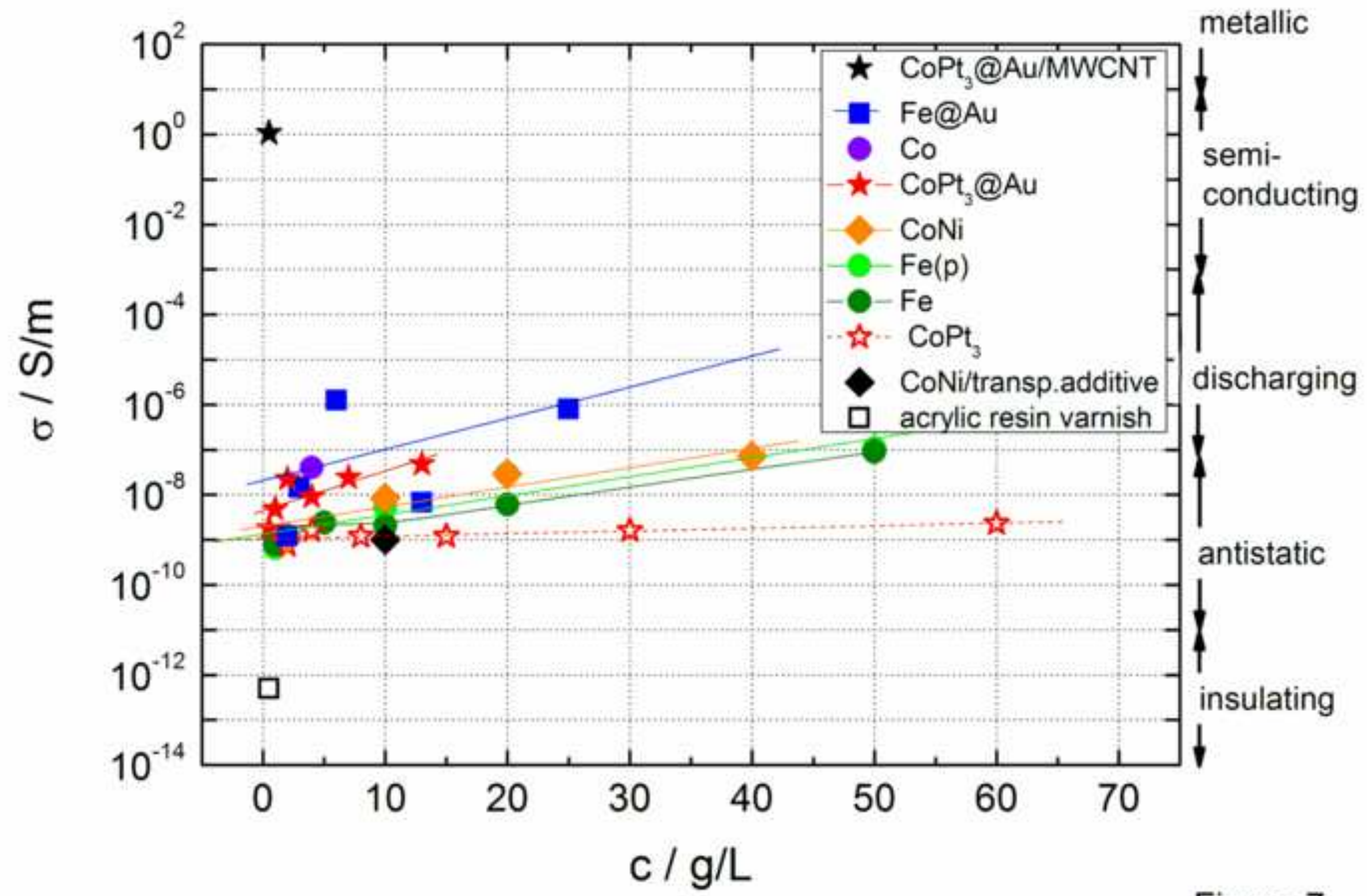

Figure 7 


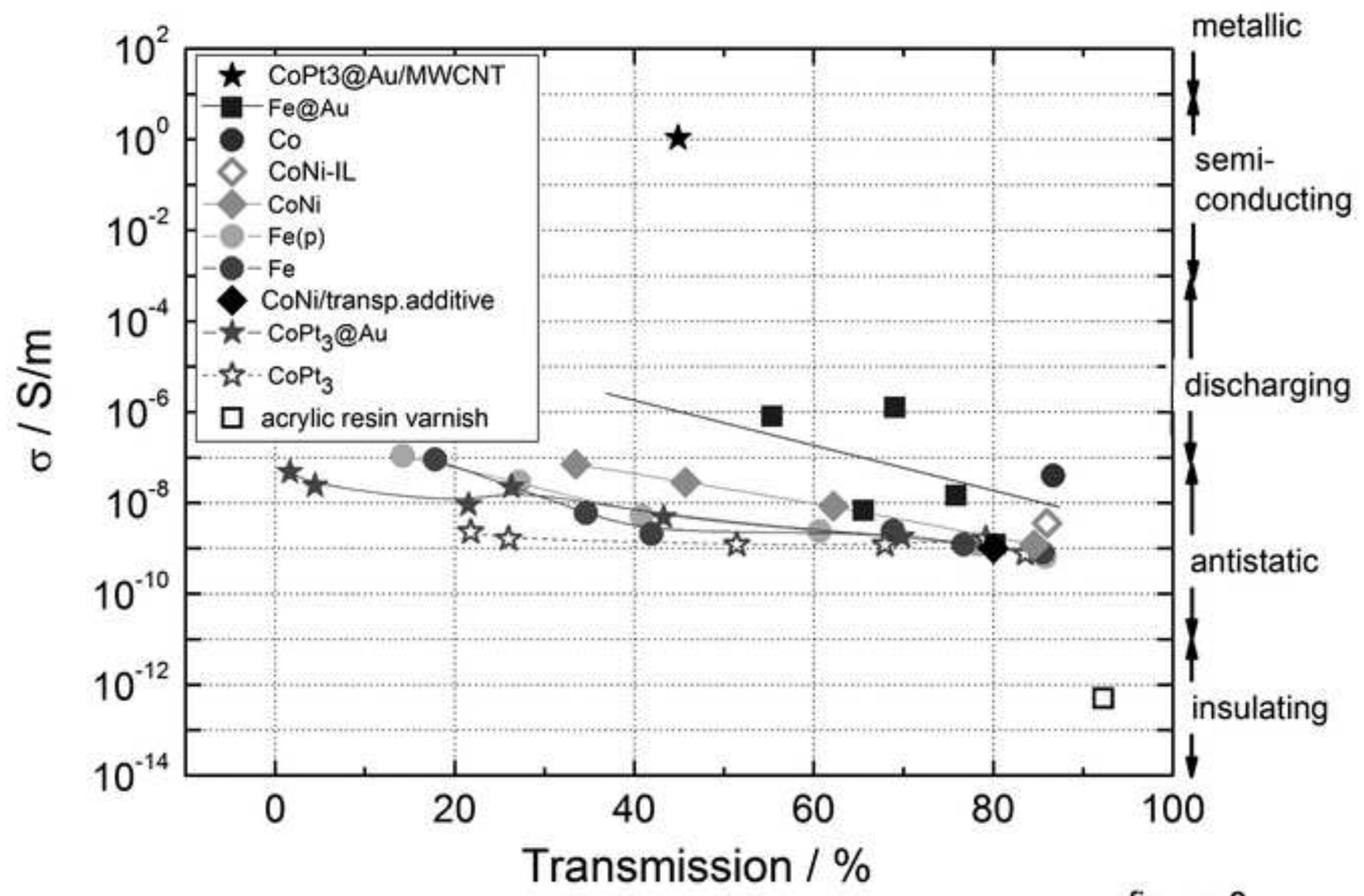

figure 8 


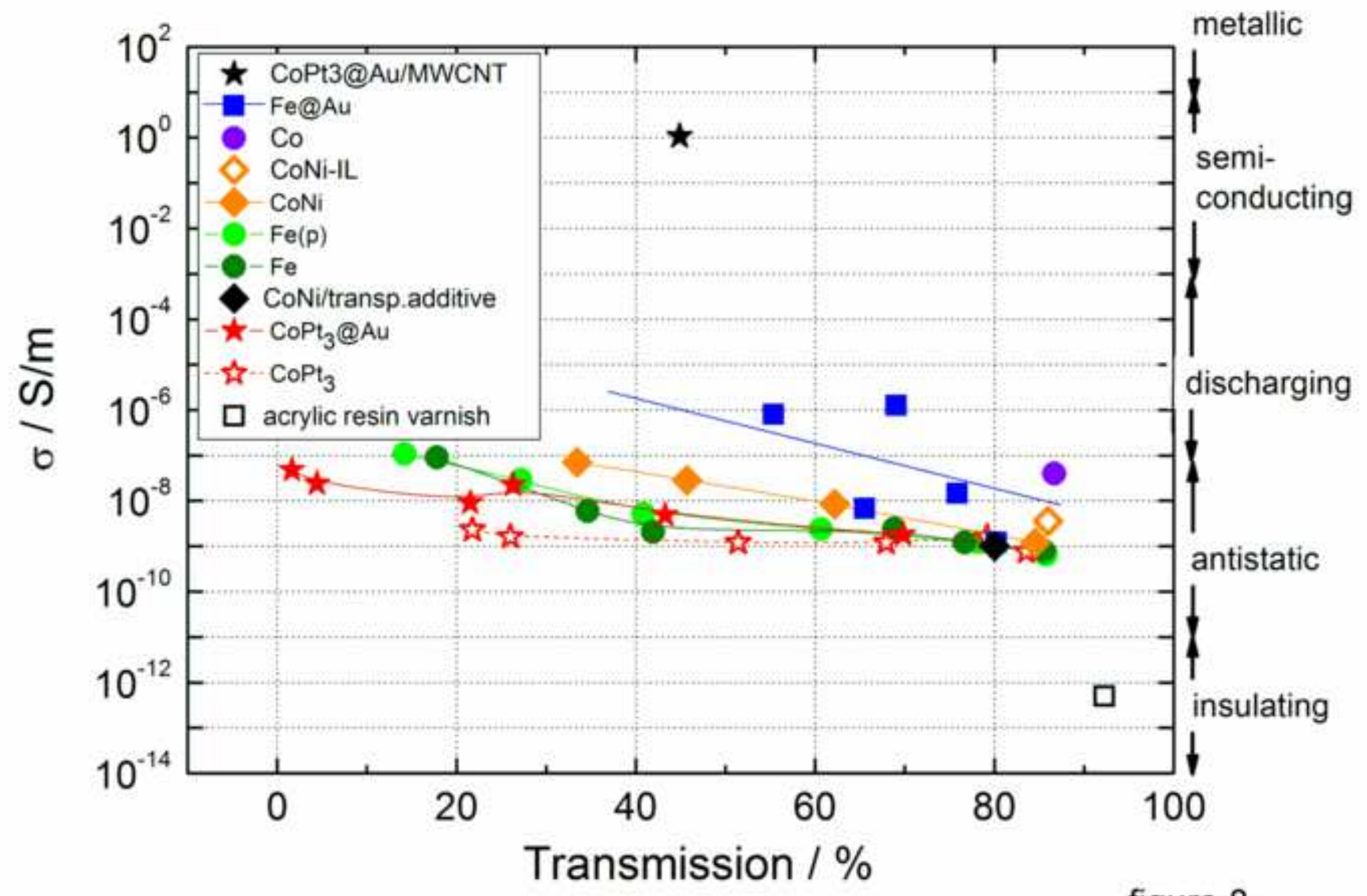

figure 8 
Click here to download high resolution image

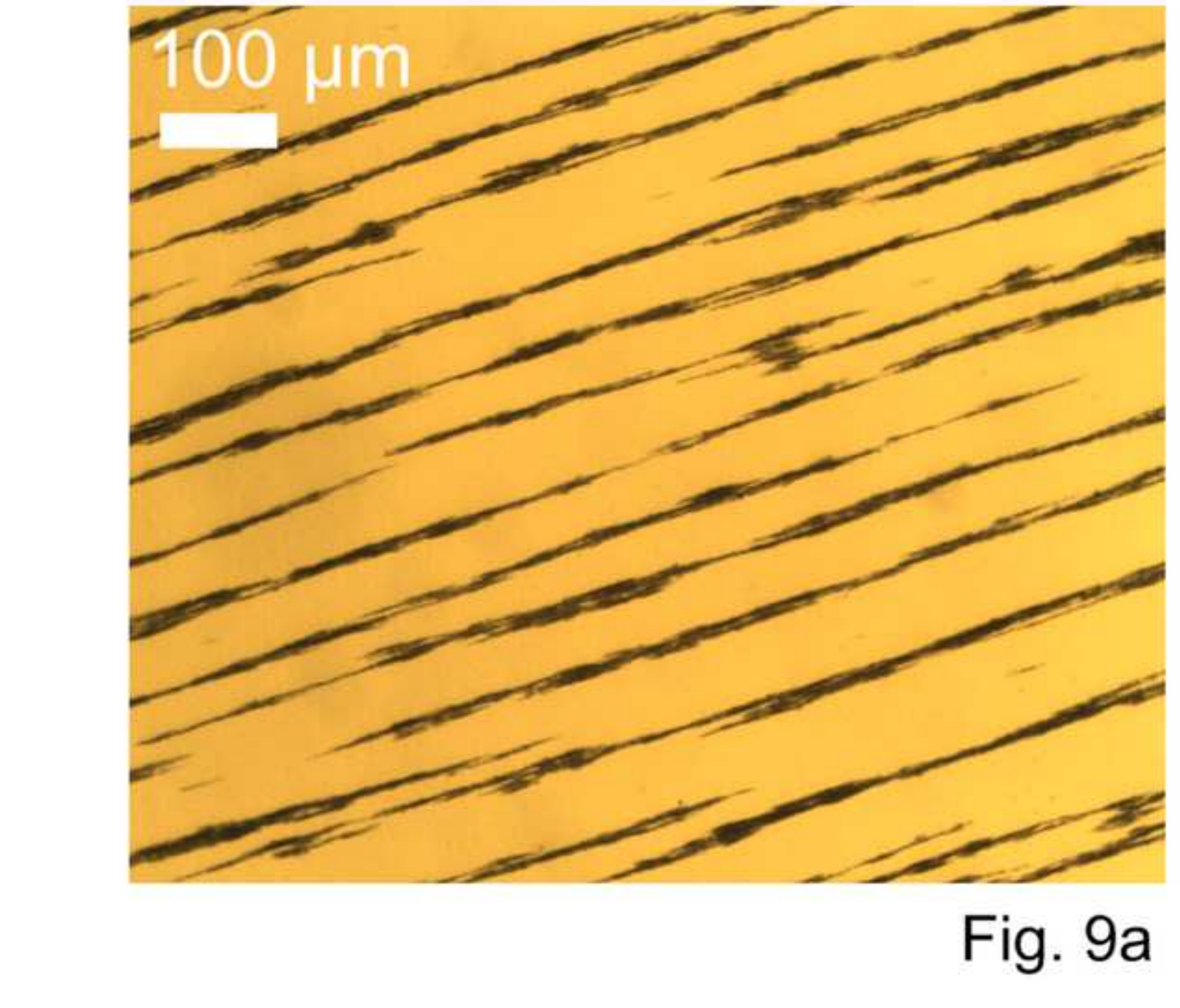

\section{Fig. 9a}


Click here to download high resolution image

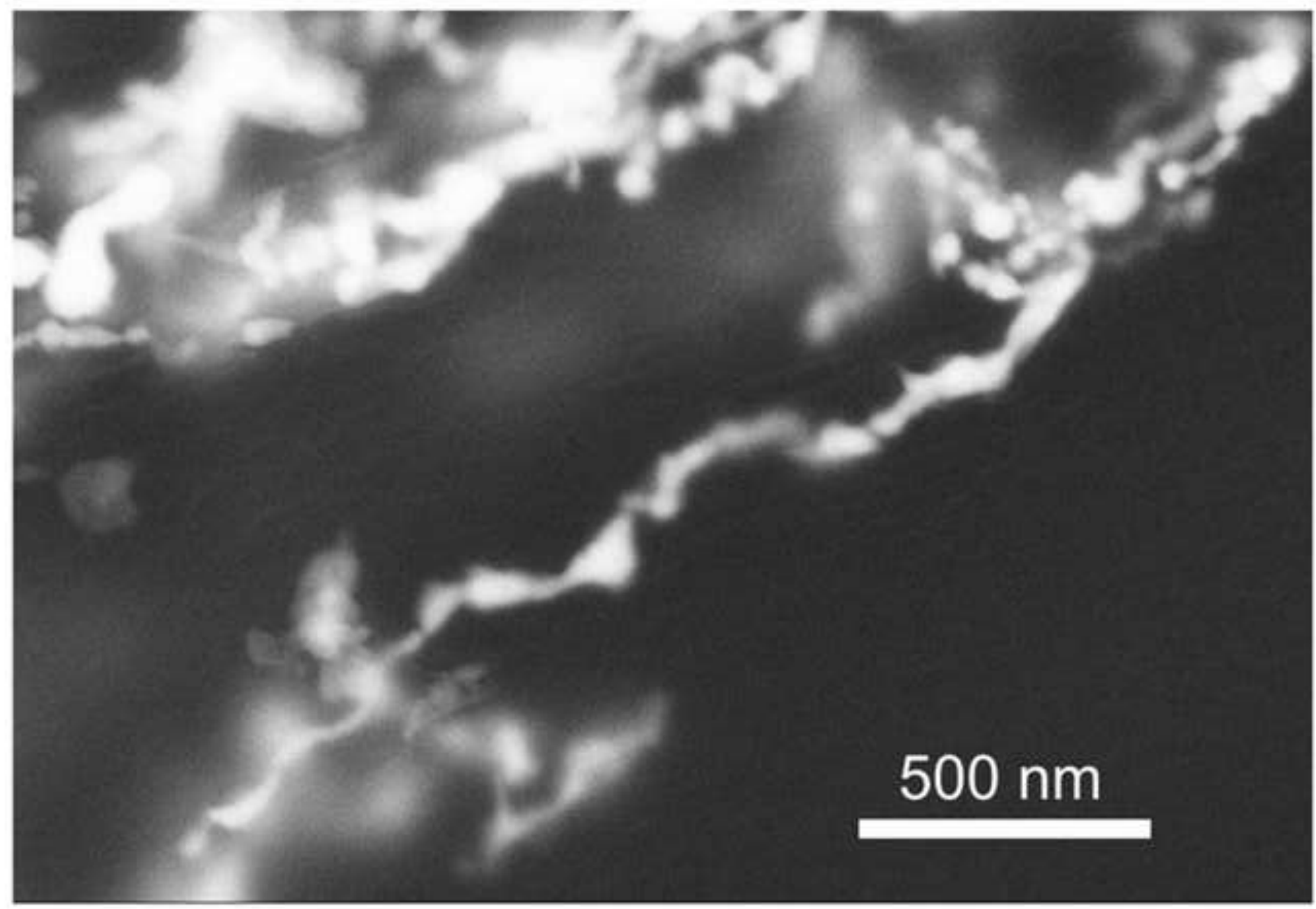

Figure 9b 
Figure10-colour
Click here to download high resolution image

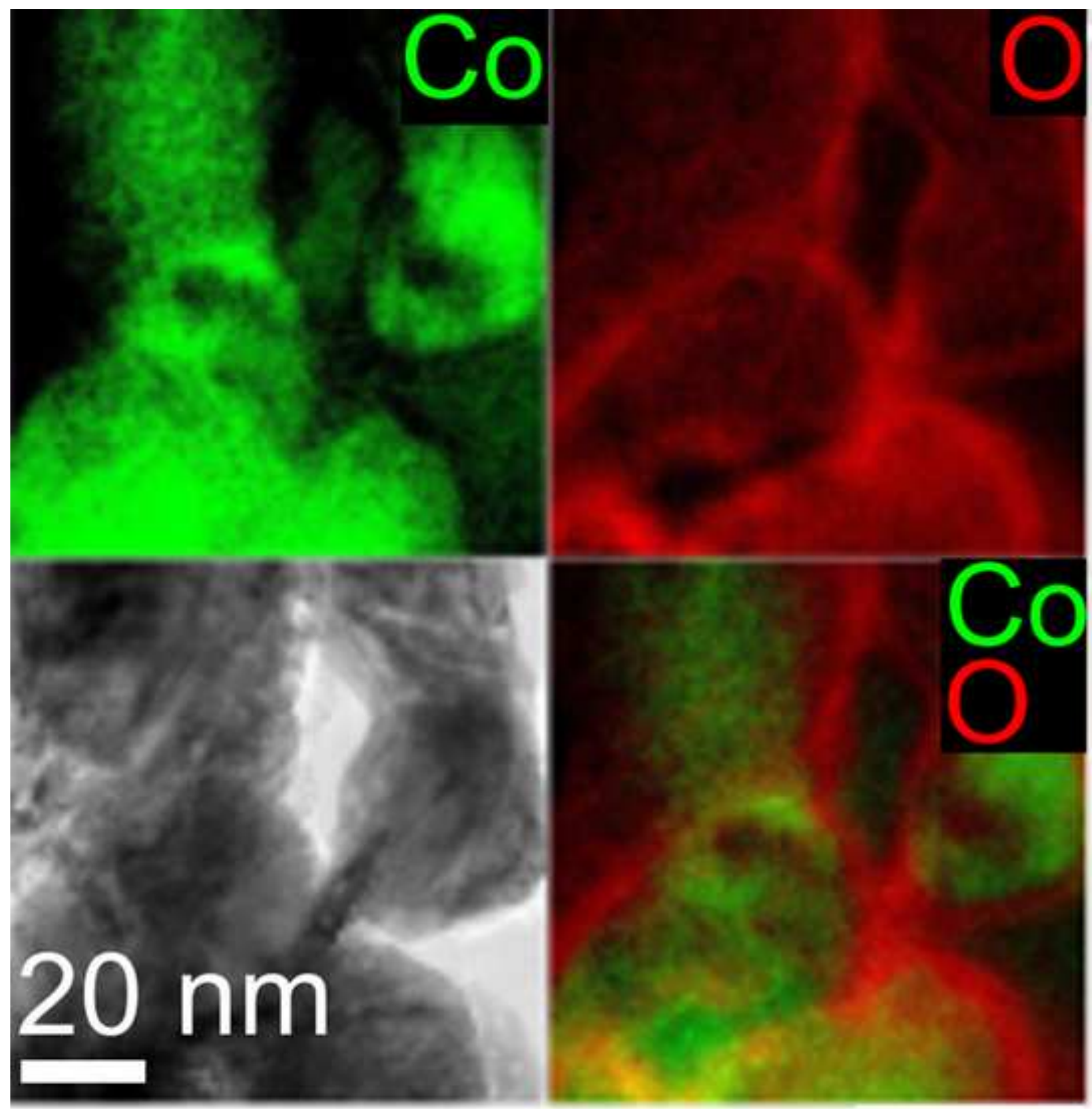

Figure 10 
Figure $10-$-bw
Click here to download high resolution image

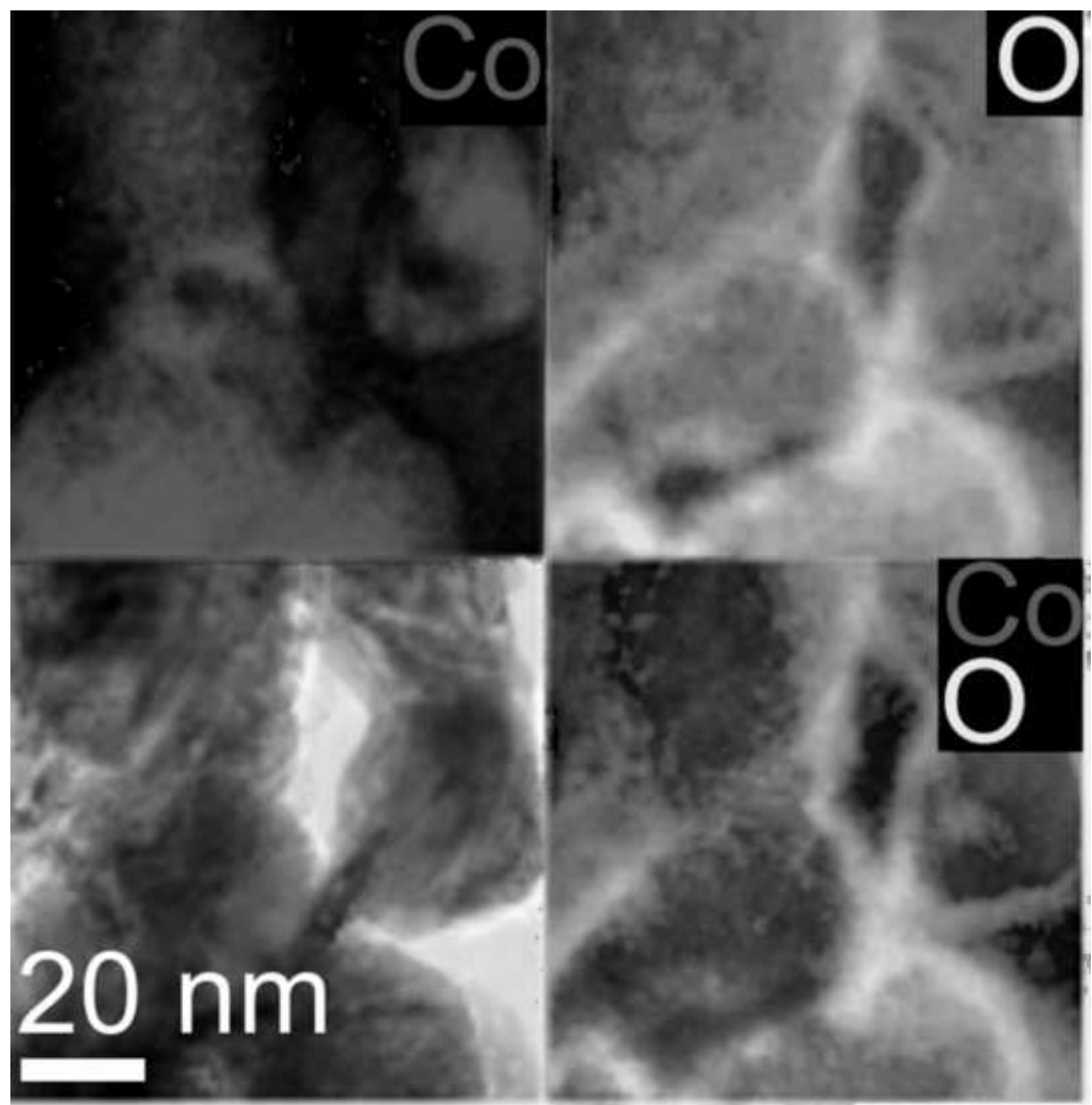

Figure 10 
Click here to download high resolution image

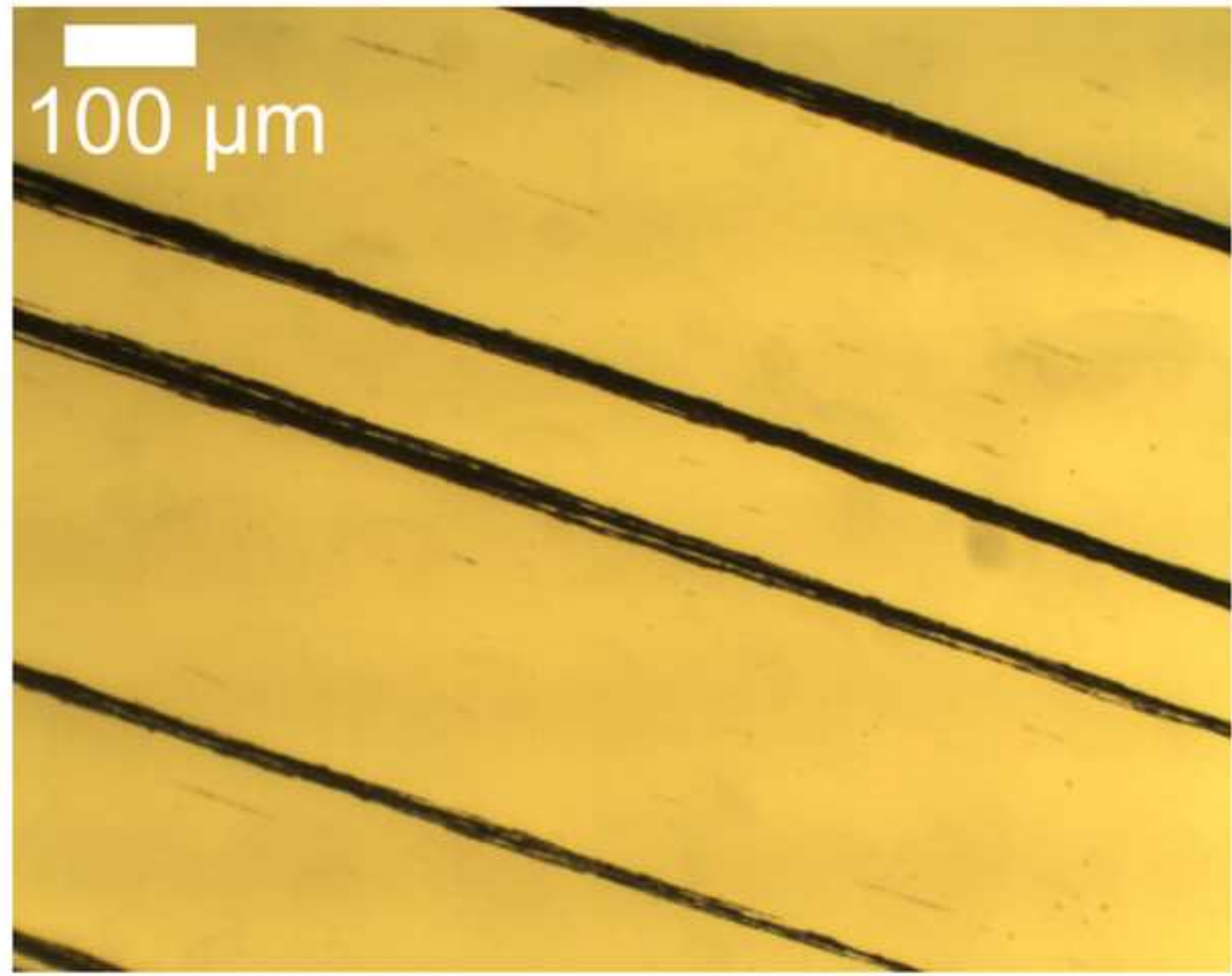

Fig. 11a 
Click here to download high resolution image

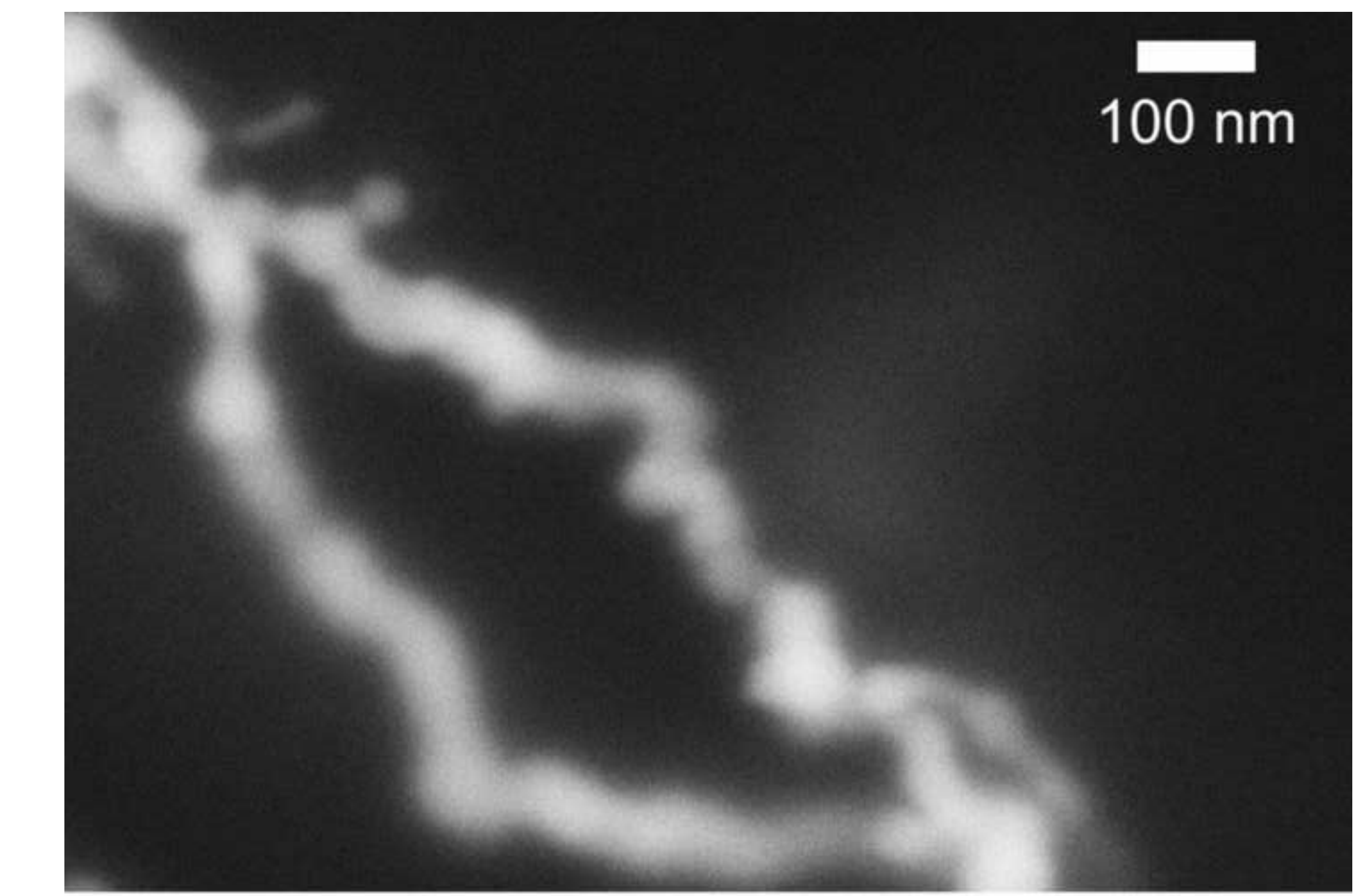

Figure $11 \mathrm{~b}$

Figure11b

$100 \mathrm{~nm}$

Figure 11 b




\section{Intensity / counts}

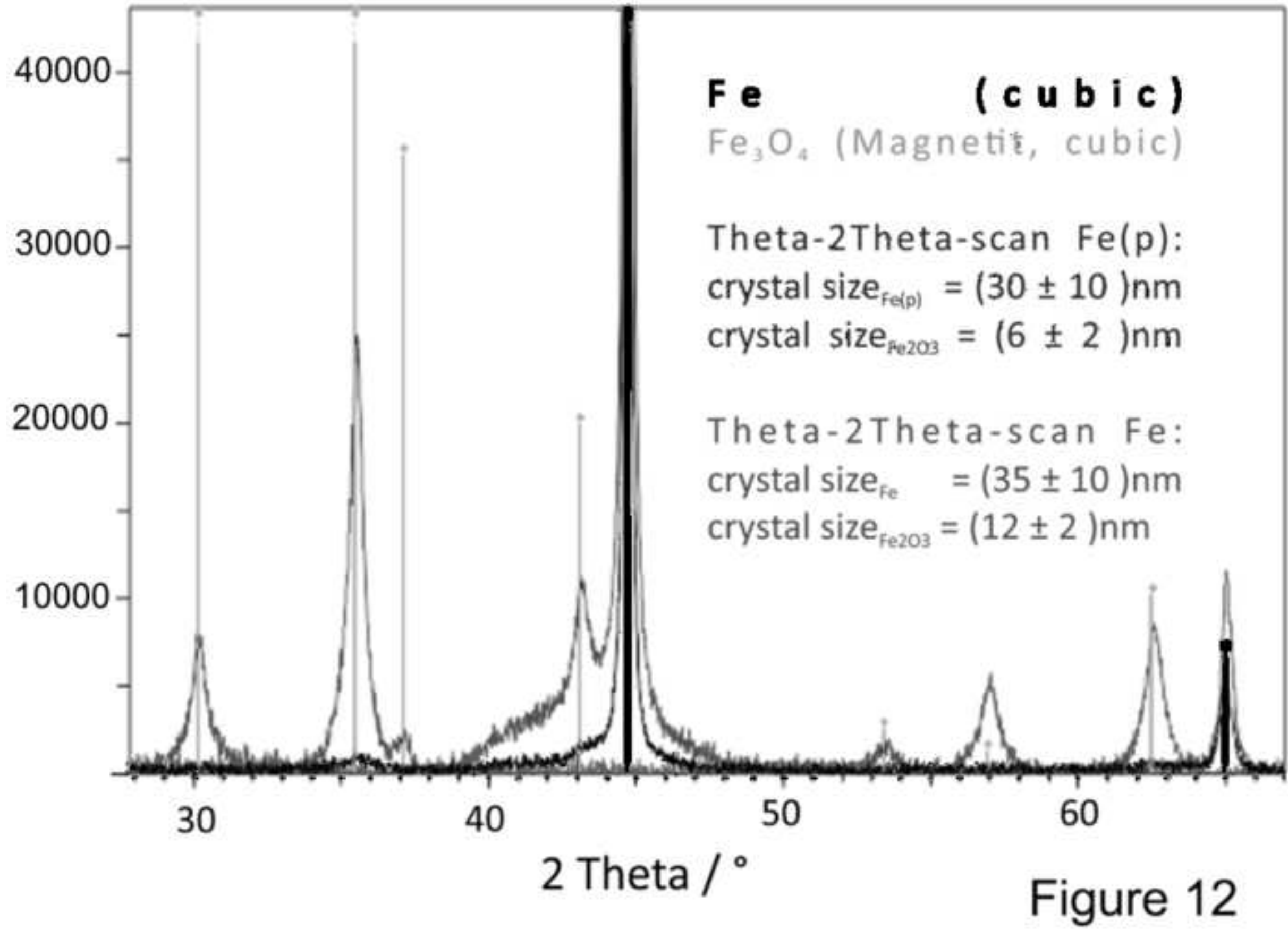




\section{Intensity / counts}

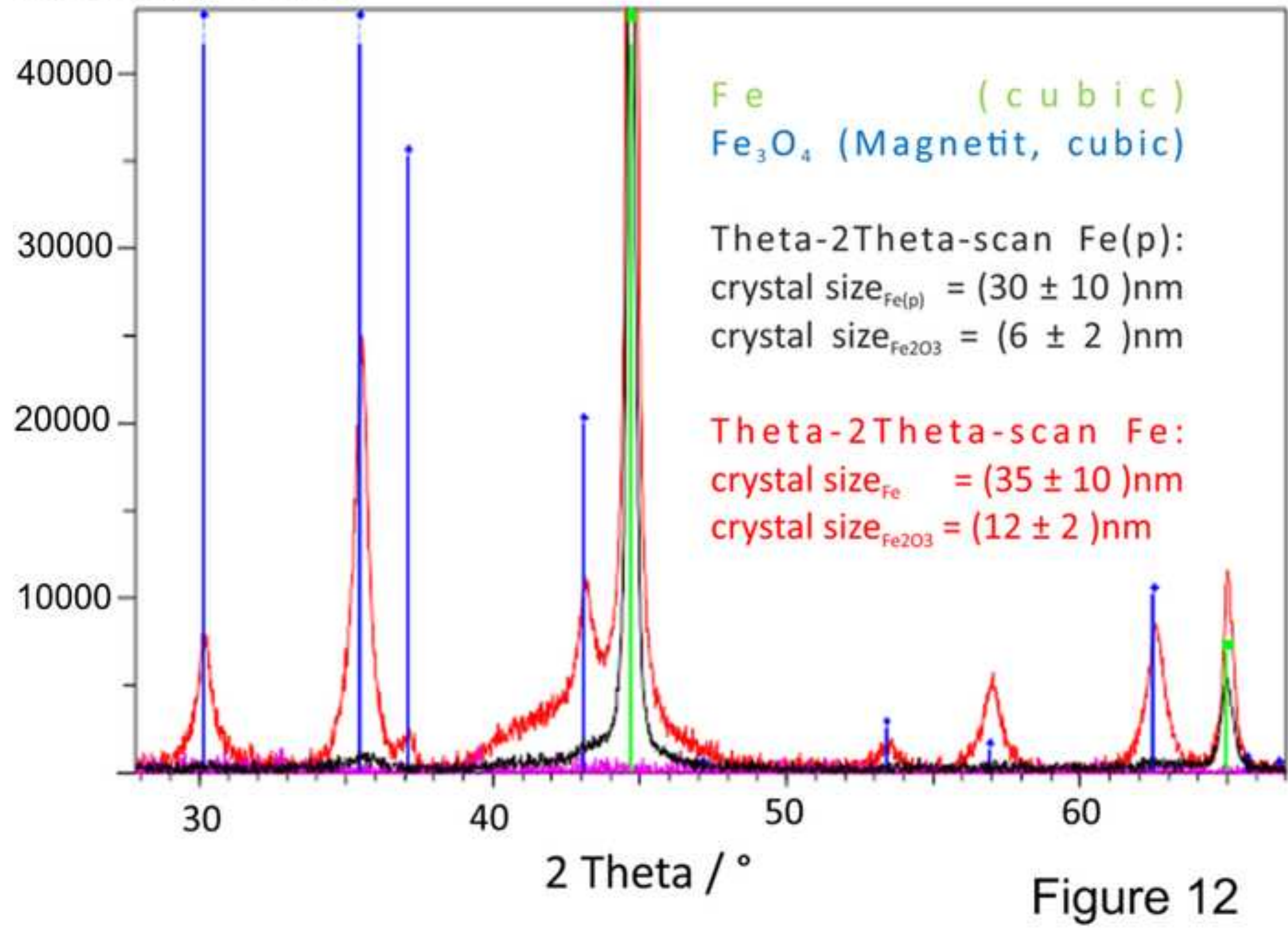


Click here to download high resolution image

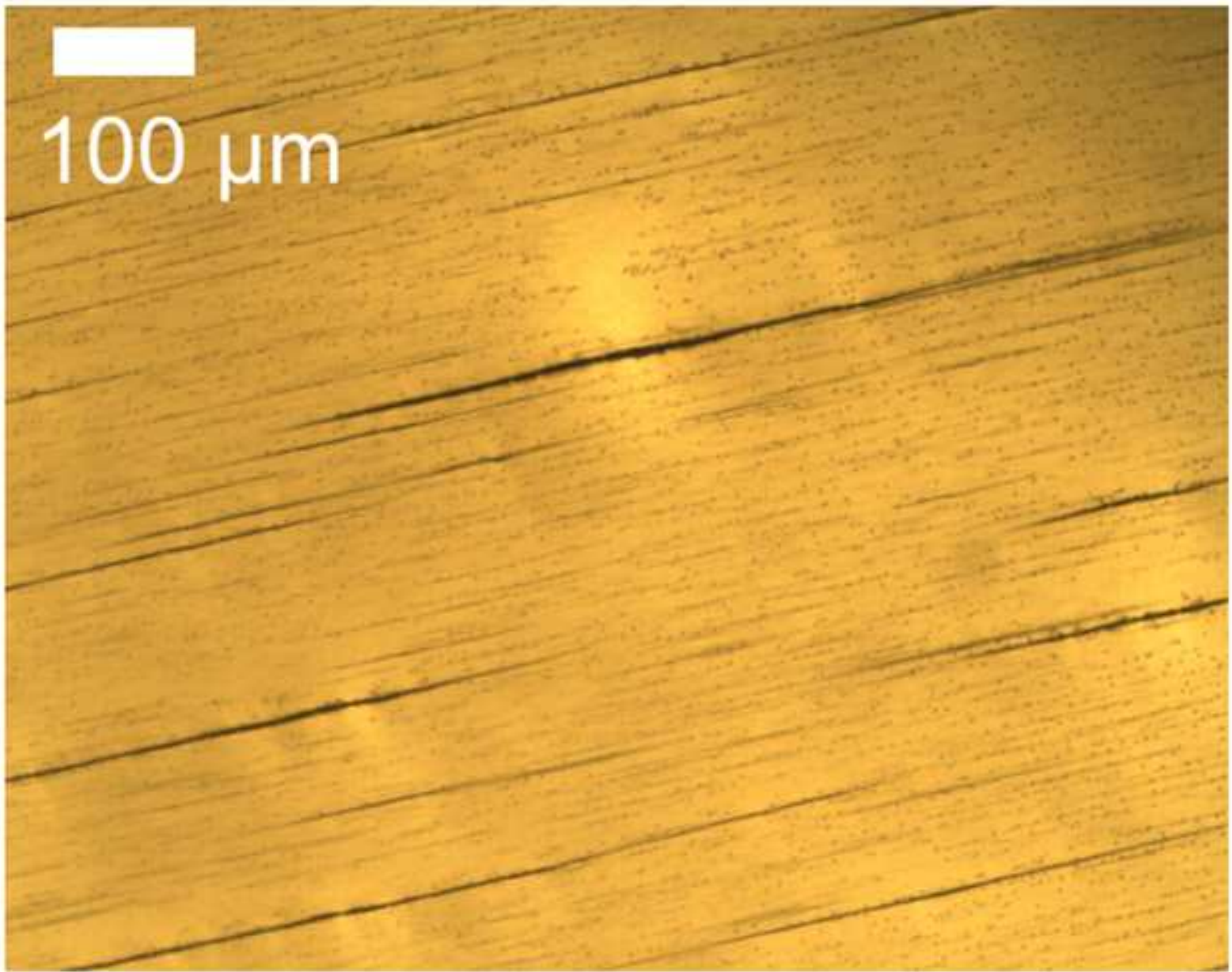

Fig. 13a 


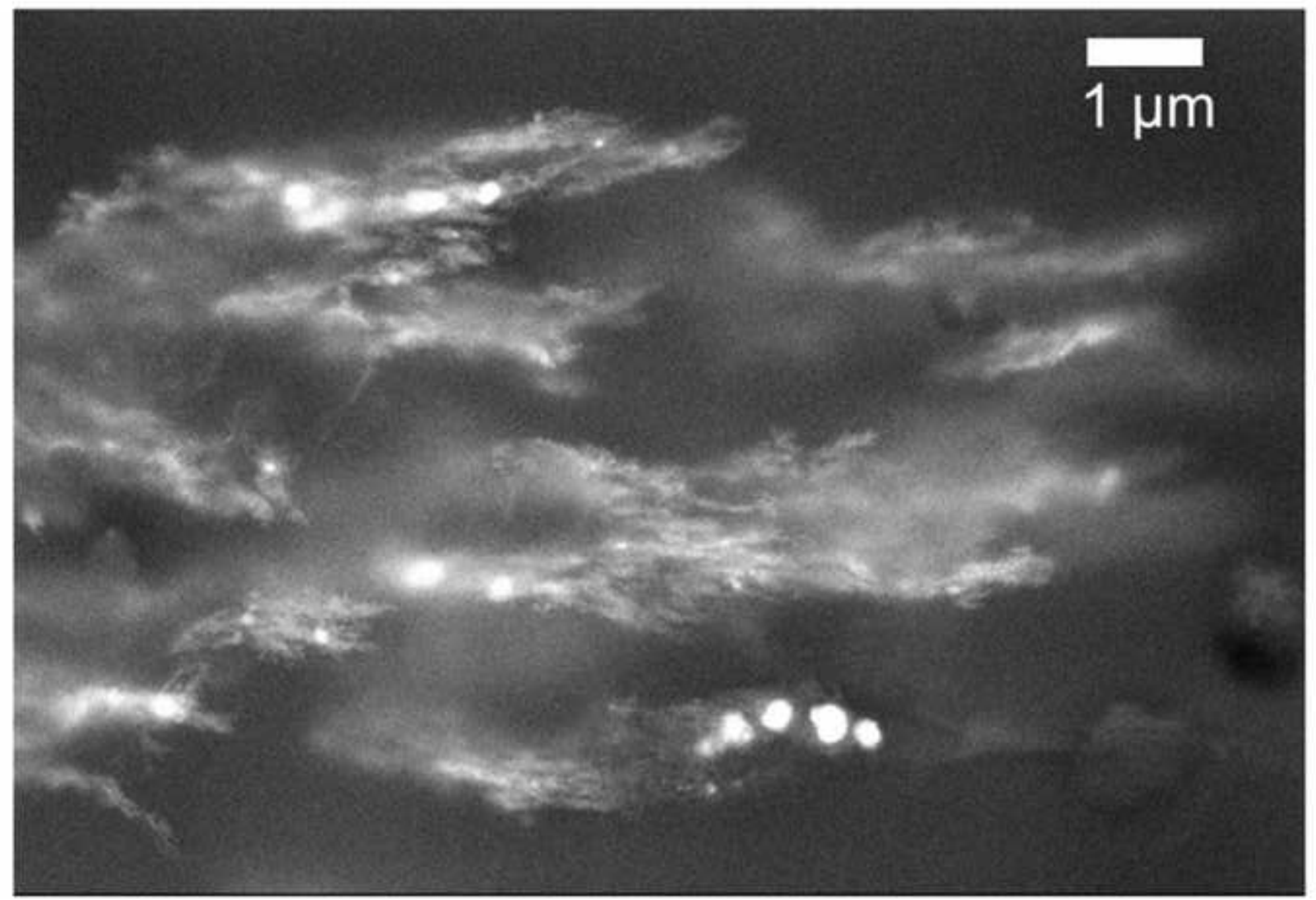

Figure 13b 
Click here to download high resolution image

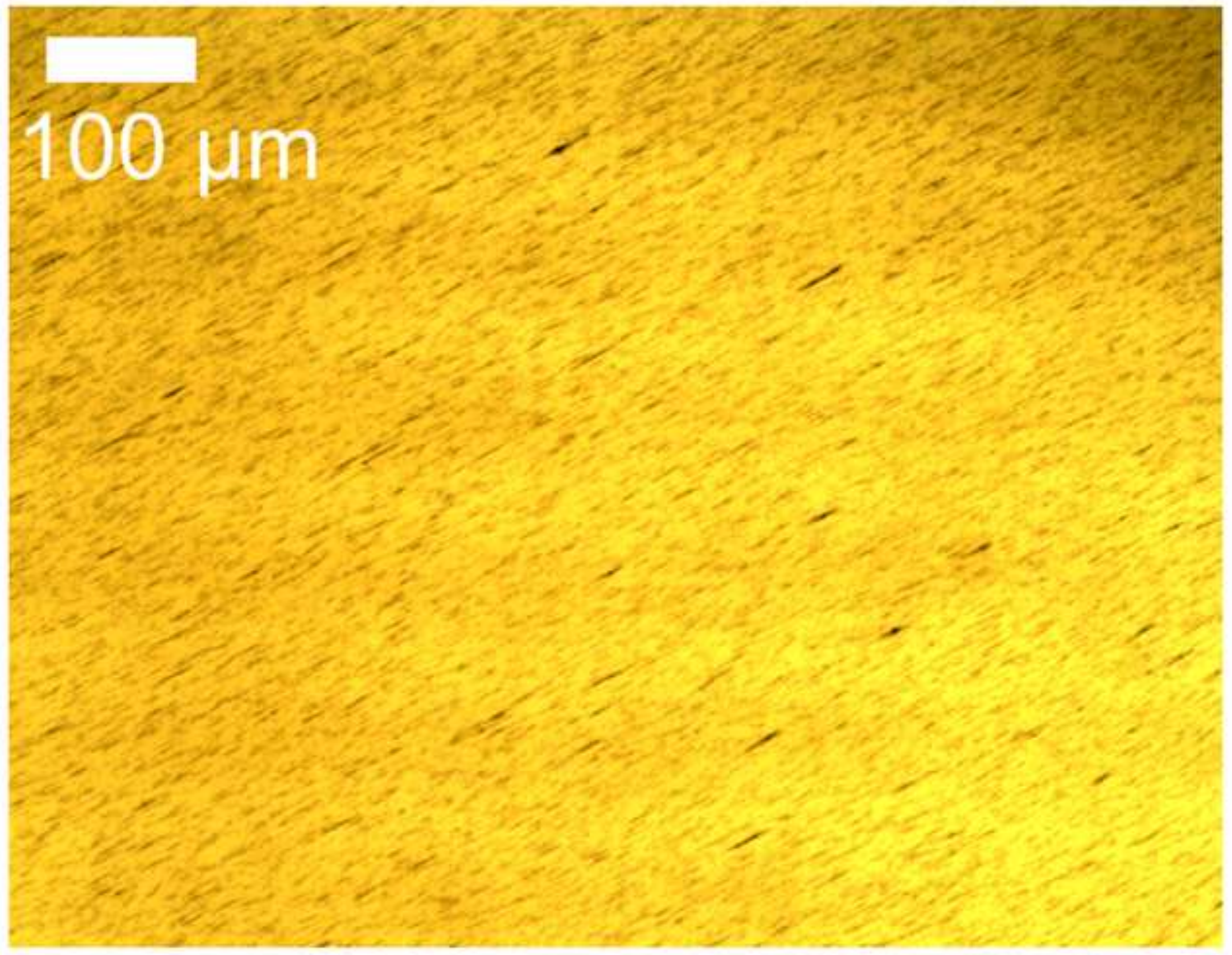

Fig. $14 a$ 


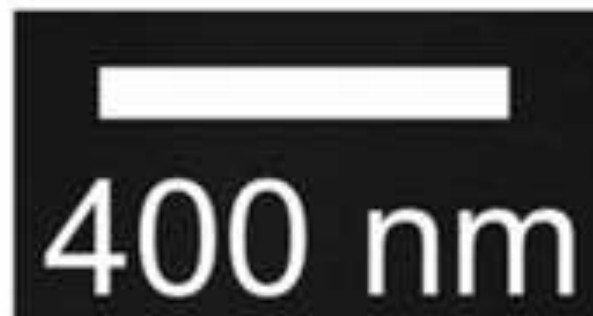

Figure 14b 
Click here to download high resolution image

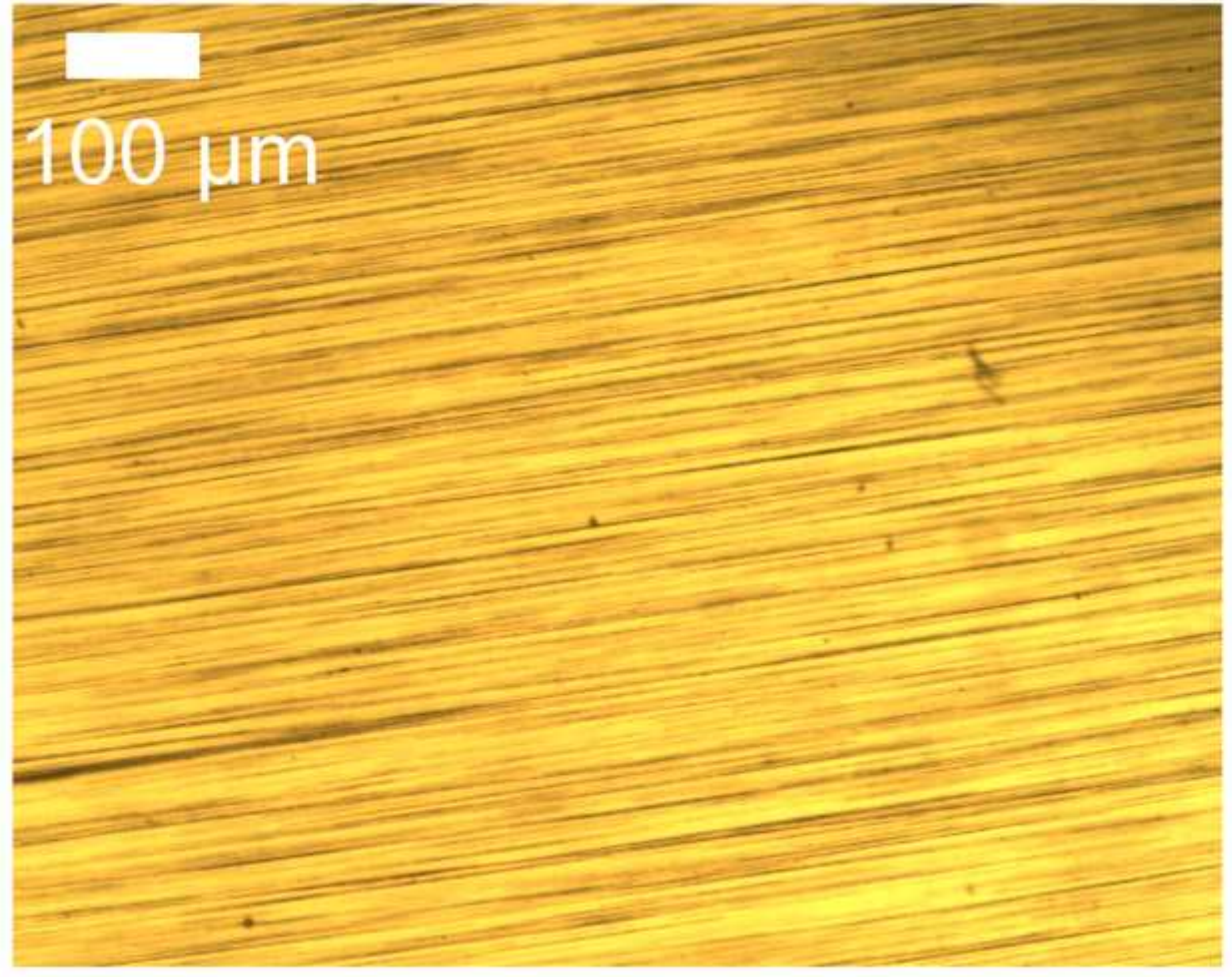

Fig. 15a 
Click here to download high resolution image

\section{$200 \mathrm{~nm}$}

Figure 15b

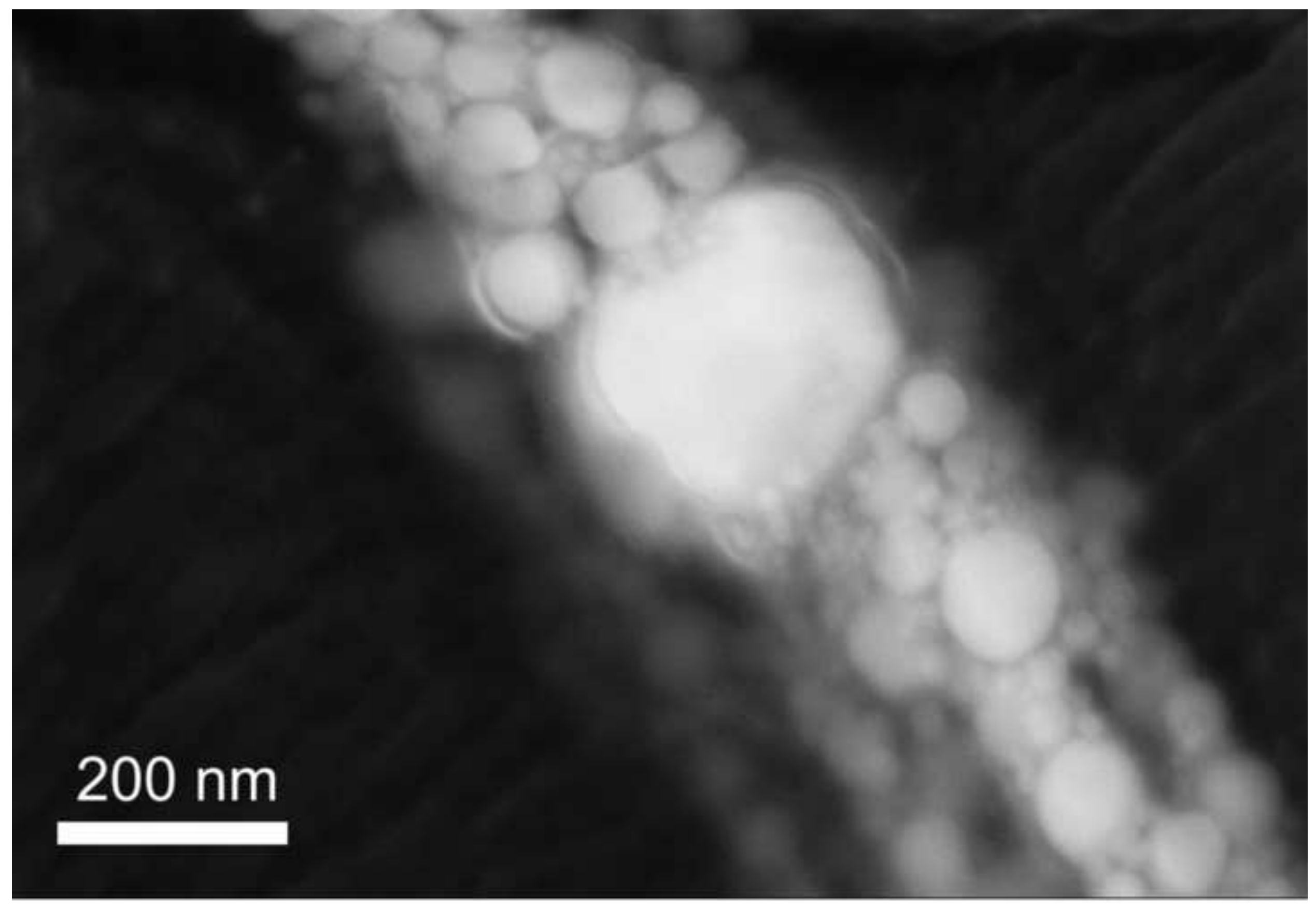



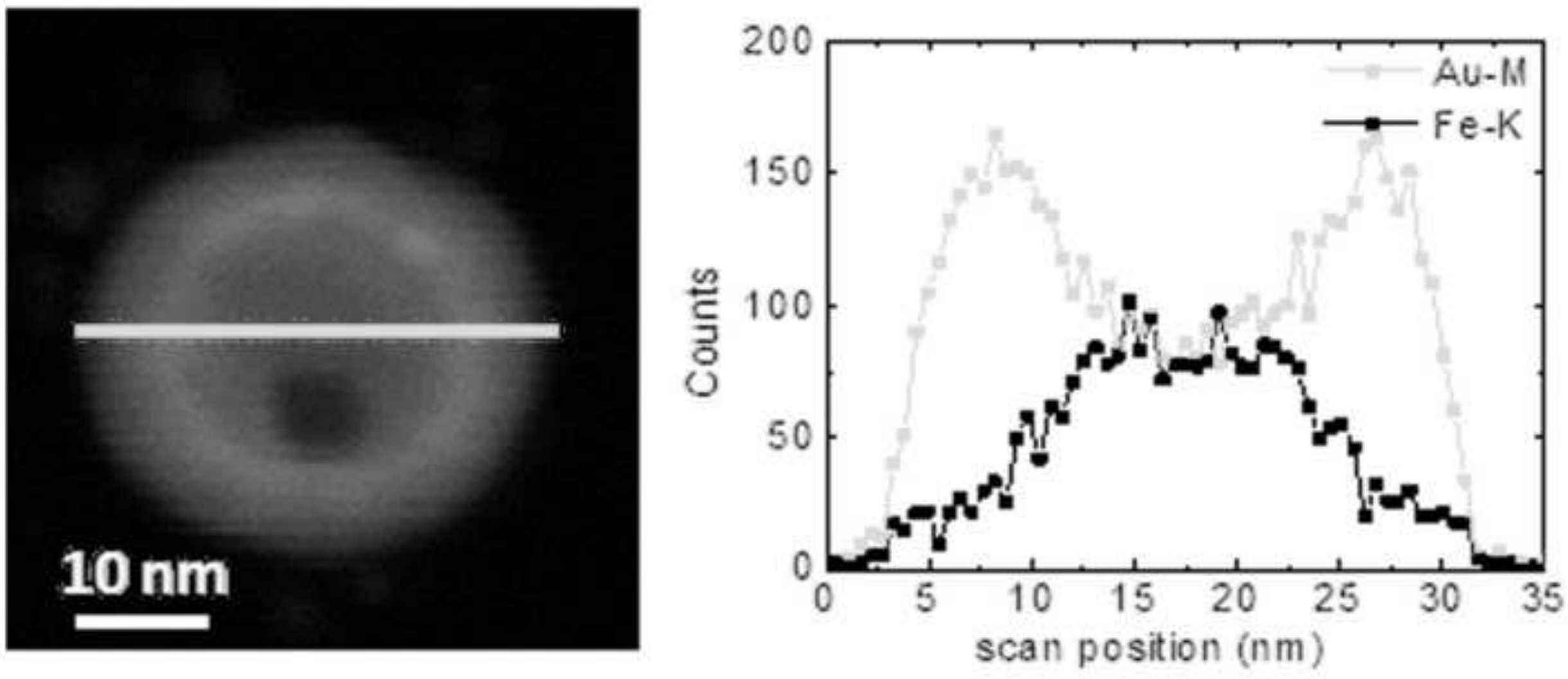

Figure 16a 

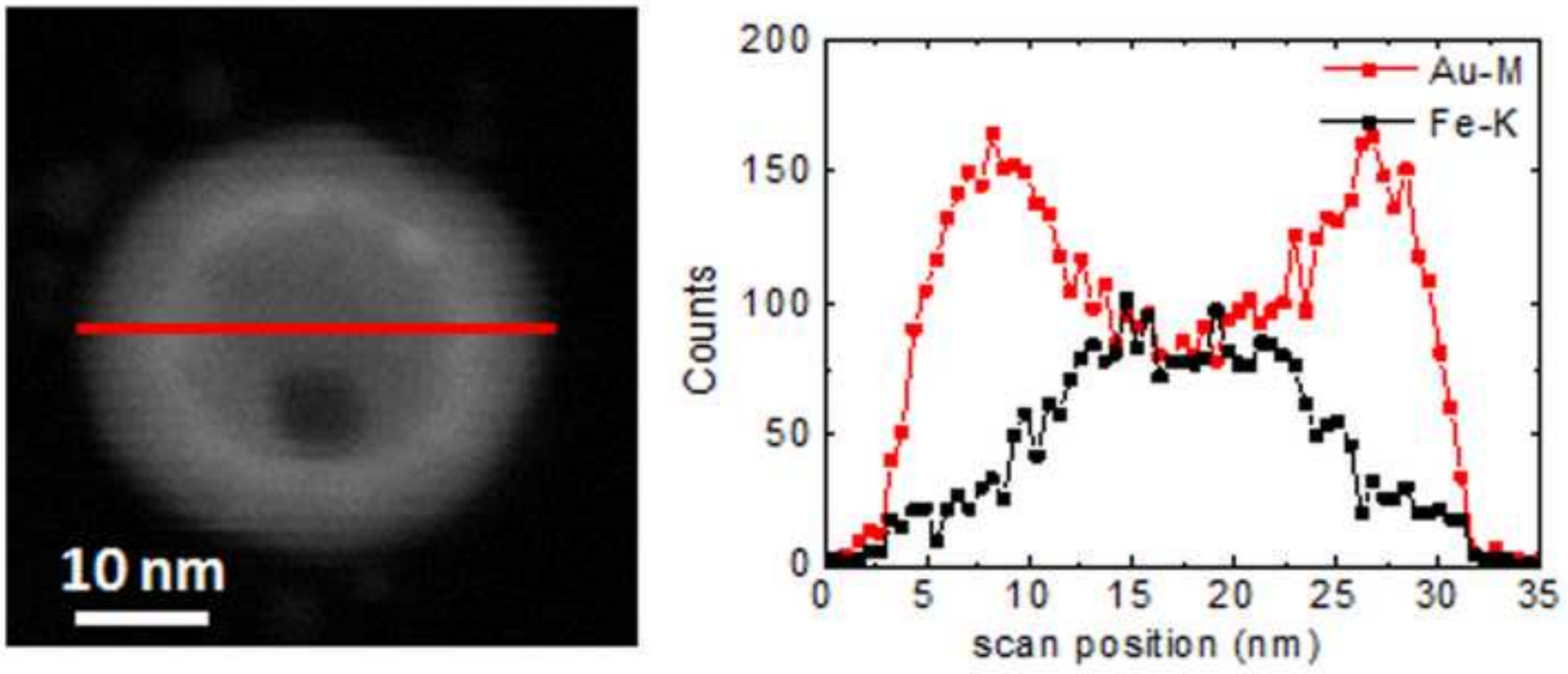

Figure 16a 

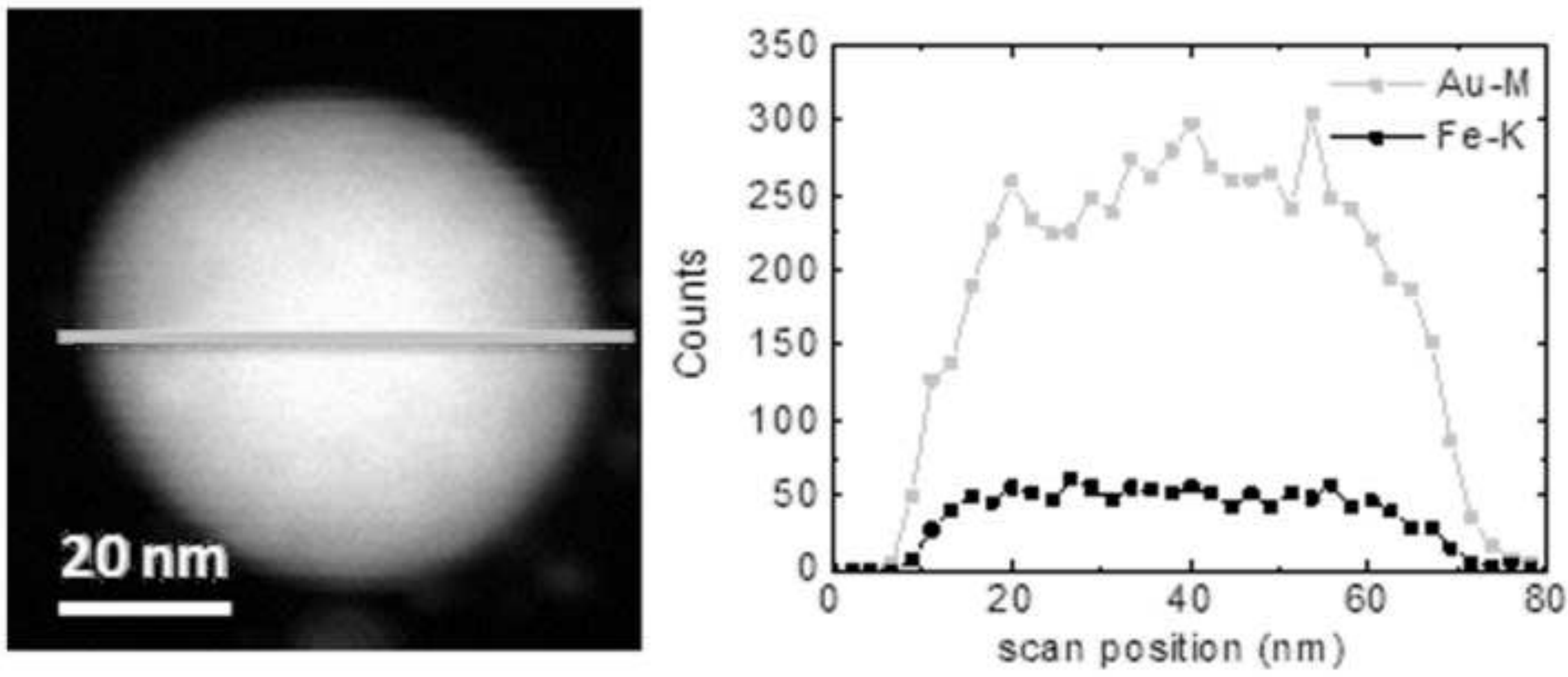

Figure 16b 

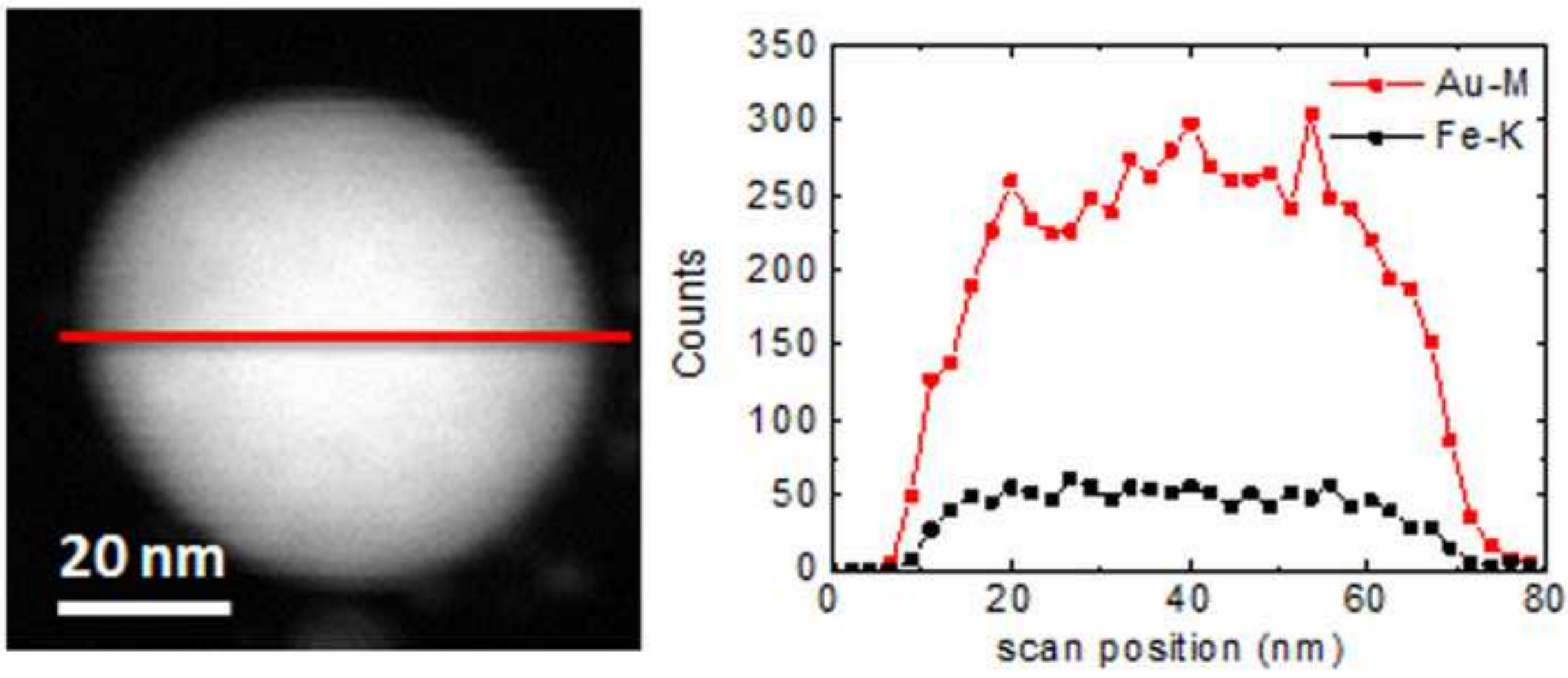

Figure 16b 

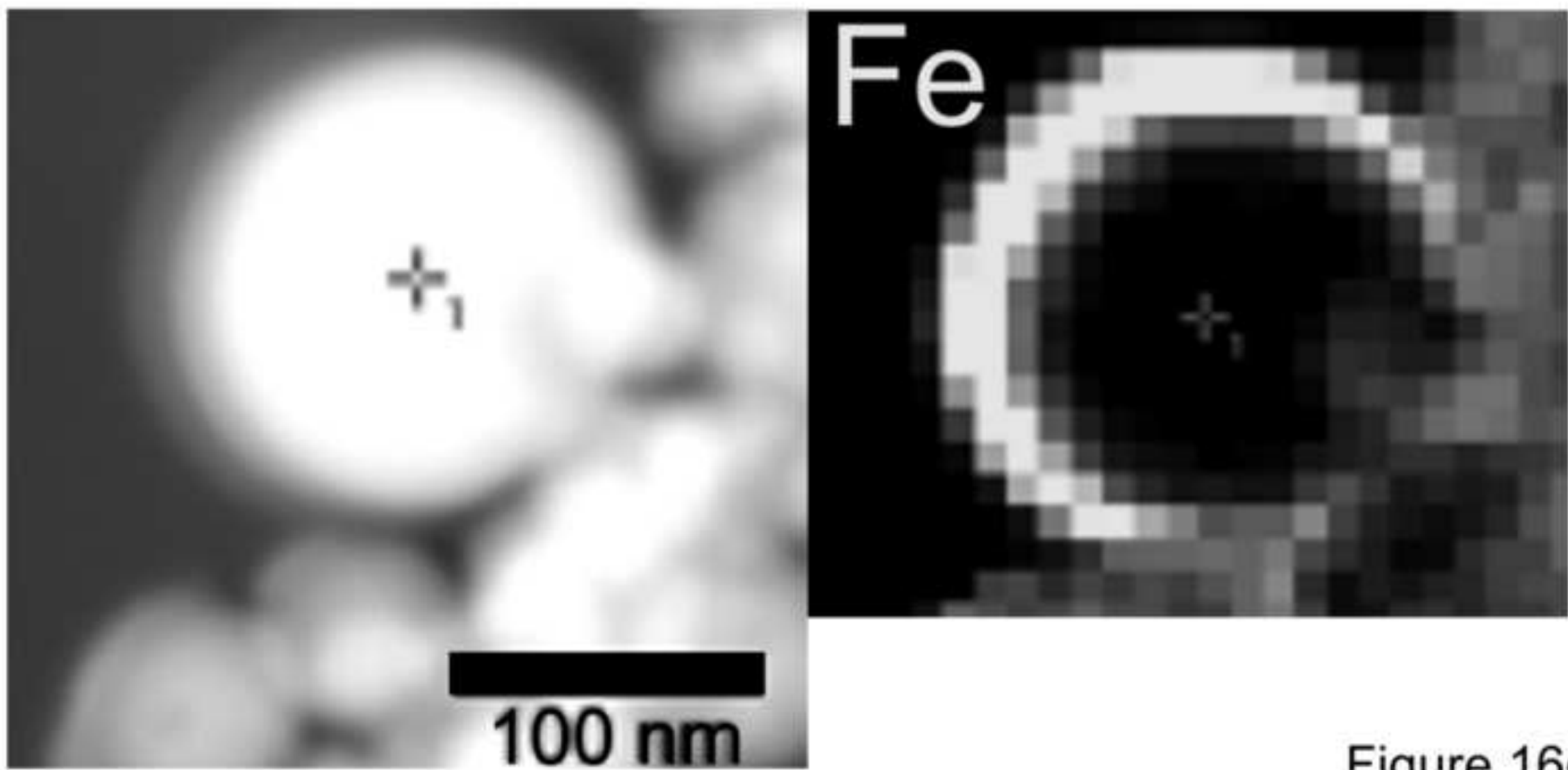

Figure 16c 

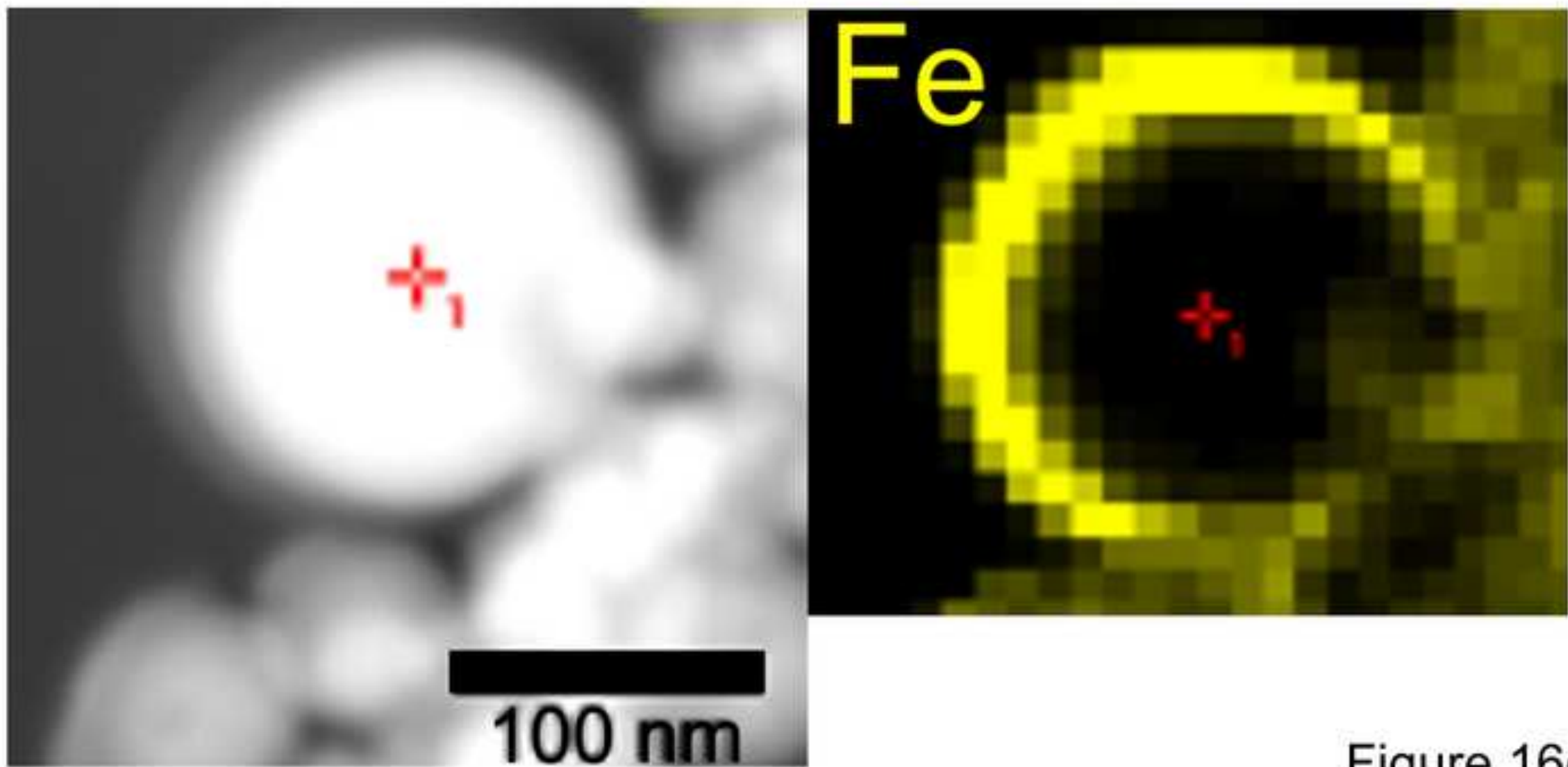

Figure 16c

$100 \mathrm{~nm}$ 


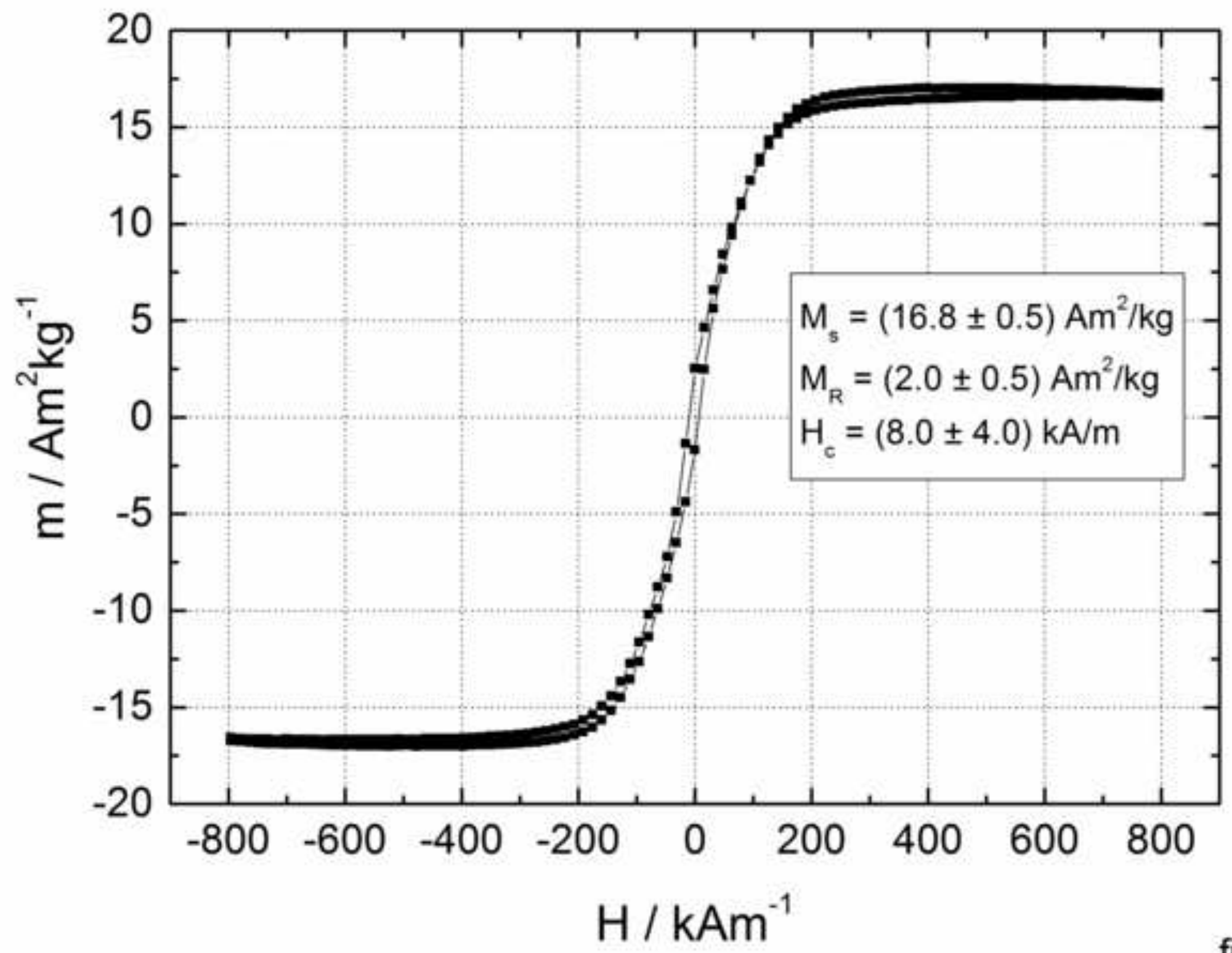

figure 17 